\title{
Advances in Magnetic Nanoparticles-Supported Palladium Complexes for Coupling Reactions
}

\author{
Mahmoud Nasrollahzadeh \\ Department of Chemistry, Faculty of Science, University of Qom, Qom 37185-359, Iran; \\ mahmoudnasr81@gmail.com; Tel.: +98-25-32850953; Fax: +98-25-32103595
}

Received: 28 August 2018; Accepted: 1 October 2018; Published: 4 October 2018

\begin{abstract}
Carbon-carbon (C-C) and carbon-heteroatom (C-X) bonds that form via transition-metalcatalyzed processes have been extensively used in the organic synthesis and preparation of natural products and important compounds such as heterocycles, biologically active molecules, and dendrimers. Among the most significant catalysts, magnetic nanoparticles-supported palladium complexes are very effective, versatile, and heterogeneous catalysts for a wide range of C-C and C-X coupling reactions due to their reusability, thermal stability, and excellent catalytic performance. In this review, recent advances to develop magnetic nanoparticles supported palladium complexes, including their preparation, characterization, catalytic application, and reusability in the formation of both C-C and C-X bonds, by authors such as Sonogashira, Heck, Suzuki-Miyaura, and Stille, and a few examples concerning $\mathrm{N}$-arylation, $\mathrm{S}$-arylation, and $\mathrm{C}_{\mathrm{sp} 2}-\mathrm{P}$ coupling reactions are discussed.
\end{abstract}

Keywords: magnetic nanoparticles; palladium complexes; coupling reactions

\section{Introduction}

Over the past 15 years, there has been growing interest in coupling reactions, one of the most powerful tools for $\mathrm{C}-\mathrm{C}$ and $\mathrm{C}-\mathrm{X}$ bond formation. $\mathrm{C}-\mathrm{C}$ and $\mathrm{C}-\mathrm{X}$ coupling reactions are widely utilized to assemble a vast range of important molecules in pharmaceutical, agricultural, natural products, non-linear optical materials, polymeric materials, molecular electronics, polyalkynylated molecules, and macrocycles with acetylene links [1-12]. There are a variety of studies on C-C and C-X coupling reactions with transition-metal-based catalysts.

During the past decade, there has been significant interest in improving experimental procedures for coupling reactions using various homogeneous metallic complexes. However, most of these catalysts are homogeneous and cannot be recovered from the reaction medium. Generally, heterogeneous catalysis is favored over homogeneous catalysis due to their ease of handling, reusability, and regenerability.

Among the catalysts or heterogeneous supports, metal or metal oxide nanoparticles (NPs) often showed high catalytic activity different from the corresponding bulk materials because of their different shapes and sizes and high surface-to-volume ratio, which gives rise to distinctive quantum properties. However, to avoid the agglomeration of the NPs or reusability of metallic complexes, the discovery of a safer, nontoxic, ecofriendly, and recyclable support is still in demand for coupling reactions in heterogeneous conditions.

In this regard, various solid supports have been introduced to prevent the agglomeration of NPs or reusability of metallic complexes and to facilitate catalyst separation and recycling. It is also well known that metallic nanocomposite-based magnetic supports are popular with scientists due to their chemical stability and high specific surface area [13-20]. Also, they do not swell in organic solvents and can be recovered from the reaction mixture with an external magnetic field and reused several times with considerable efficiency. Recently, magnetic materials have attracted increasing attention in the immobilization of palladium catalysts for coupling reactions. In general, carbon-carbon 
coupling reactions catalyzed by solid-supported Pd follow the usual reaction mechanism, as shown in Scheme 1 [1].

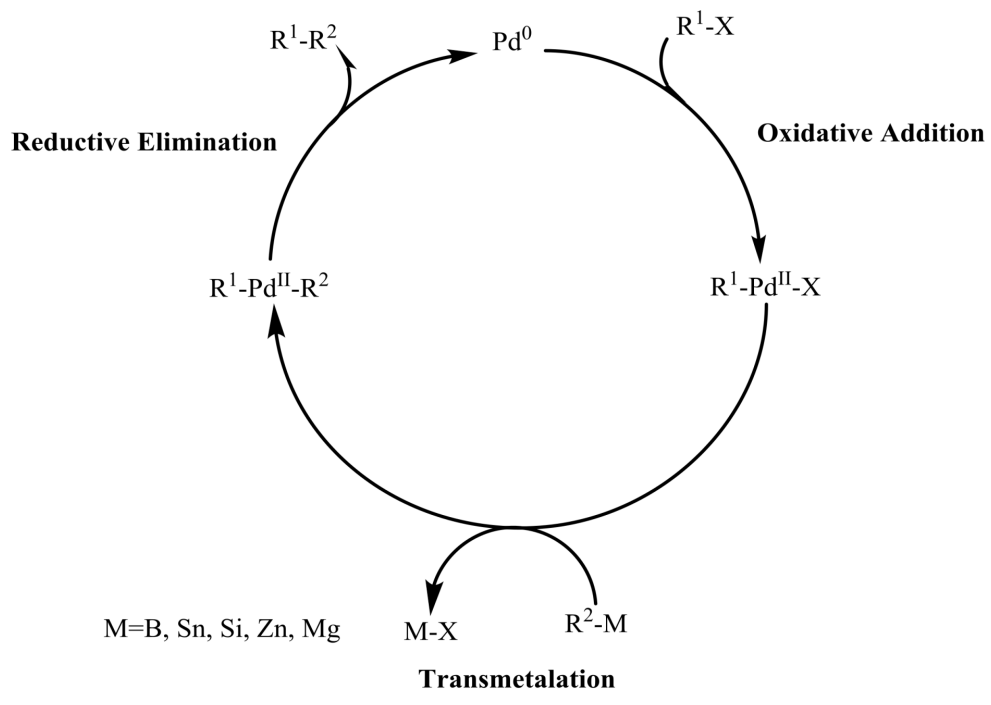

(a) Catalytic cycle found in coupling reactions

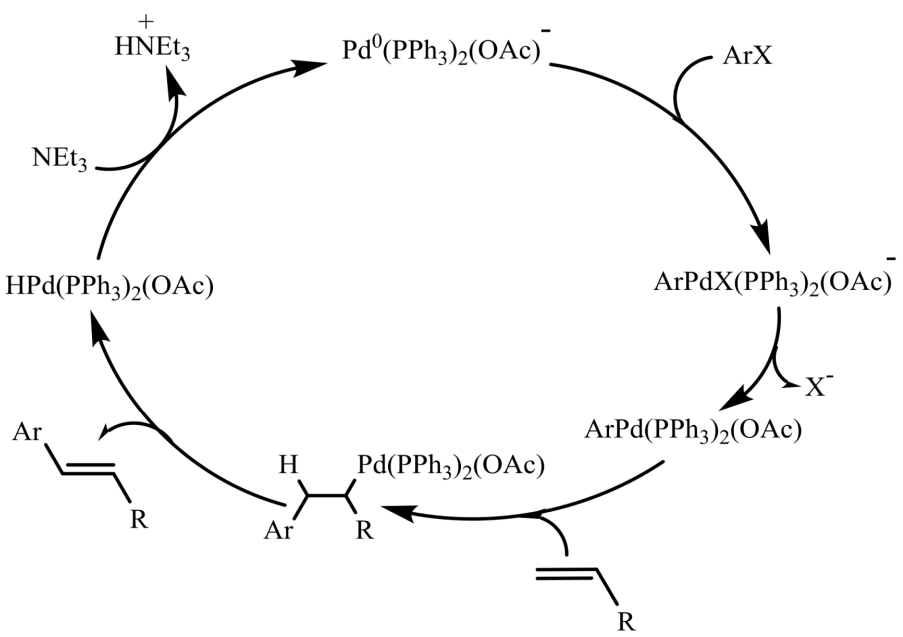

(b) Heck reaction cycle

Scheme 1. Major steps of Pd-catalyzed coupling reactions [1].

\section{Novel Types of Magnetic Nanoparticles-Supported Palladium Complexes for C-C and C-X Coupling Reactions}

There are many reports about the synthesis of magnetic nanoparticles-supported palladium complexes that used as effective catalysts for the formation $\mathrm{C}-\mathrm{C}$ and $\mathrm{C}-\mathrm{X}$ bonds via coupling reactions.

\subsection{Direct Immobilization on Magnetic Nanoparticles}

One of the simplest methods for the preparation of magnetically separable palladium catalysts is the direct immobilization of Pd NPs on the surfaces of magnetic materials; in this regard, Pd NPs are stabilized on un-functionalized $\mathrm{Fe}_{3} \mathrm{O}_{4}$ NPs. Indeed, this method has focused on combining high activity and selectivity of homogeneous species with ease of separation and recycling of heterogeneous catalysts. An example of this type of magnetically separable Pd-catalysts in C-C coupling reactions is a study by Plucinski and co-workers in 2009; they prepared a series of palladium-based catalysts supported on magnetic NPs and evaluated the catalytic activities of the resulting catalysts in C-C 
coupling, hydrogenation, and amination reactions [21]. The $\mathrm{Fe}_{3} \mathrm{O}_{4} \mathrm{NPs}$ was synthesized through co-precipitation of ferric and ferrous ions, adding tetramethylammonium hydroxide (TMAOH) to make a negative charge on the surface; following the addition of $\mathrm{Pd}$ salts, catalysts were prepared. The $\mathrm{Fe}_{3} \mathrm{O}_{4}-\mathrm{Pd}^{0}$ catalyst was synthesized by reduction of $\mathrm{H}_{2} \mathrm{PdCl}_{4}$ using $\mathrm{NaBH}_{4}$ and $\mathrm{Fe}_{3} \mathrm{O}_{4}-\mathrm{Pd}(\mathrm{OAc})_{2}$ and $\mathrm{Fe}_{3} \mathrm{O}_{4}-\mathrm{Pd}\left(\mathrm{PPh}_{3}\right)_{2}(\mathrm{OAc})_{2}$ catalysts were prepared from $\mathrm{Pd}(\mathrm{OAc})_{2}$ and $\mathrm{Pd}\left(\mathrm{PPh}_{3}\right)_{2}(\mathrm{OAc})_{2}$ salts, respectively (Scheme 2).

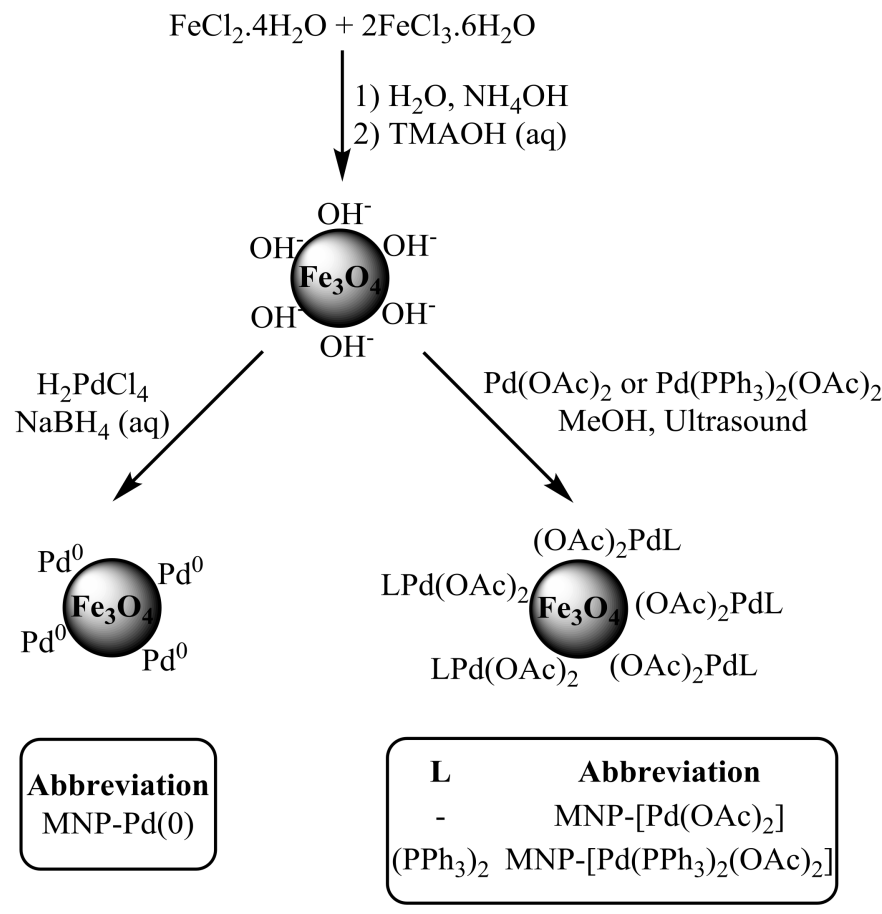

Scheme 2. The preparation of MNP-supported palladium catalysts. Reproduced with permission from [21].

The Suzuki-Miyaura coupling of phenylboronic acid with bromobenzene in $\mathrm{DMF}$ at $60{ }^{\circ} \mathrm{C}$ in the presence of $\mathrm{Fe}_{3} \mathrm{O}_{4}-\mathrm{Pd}(\mathrm{OAc})_{2}, \mathrm{Fe}_{3} \mathrm{O}_{4}-\mathrm{Pd}^{0}$ and $\mathrm{Fe}_{3} \mathrm{O}_{4}-\mathrm{Pd}\left(\mathrm{PPh}_{3}\right)_{2}(\mathrm{OAc})_{2}$ as the catalyst showed 85\%, 54\%, and $45 \%$ yield, respectively. Also, $\mathrm{Fe}_{3} \mathrm{O}_{4}-\mathrm{Pd}(\mathrm{OAc})_{2}$ was used in the Suzuki-Miyaura coupling reaction of various (hetero)aryl bromides with phenylboronic acid in DMF at $100{ }^{\circ} \mathrm{C}$. In addition, the application of all catalysts in a Heck coupling reaction in the presence of potassium acetate as a base in NMP at $130{ }^{\circ} \mathrm{C}$ was evaluated (Scheme 3). A recycling experiment for $\mathrm{Fe}_{3} \mathrm{O}_{4}-\mathrm{Pd}^{0}$ and $\mathrm{Fe}_{3} \mathrm{O}_{4}-\left[\mathrm{Pd}(\mathrm{OAc})_{2}\right]$ showed high activity; however, in the case of the $\mathrm{Fe}_{3} \mathrm{O}_{4}-\left[\mathrm{Pd}\left(\mathrm{PPh}_{3}\right)_{2}(\mathrm{OAc})_{2}\right]$ system, the conversion markedly decreases after the second run.

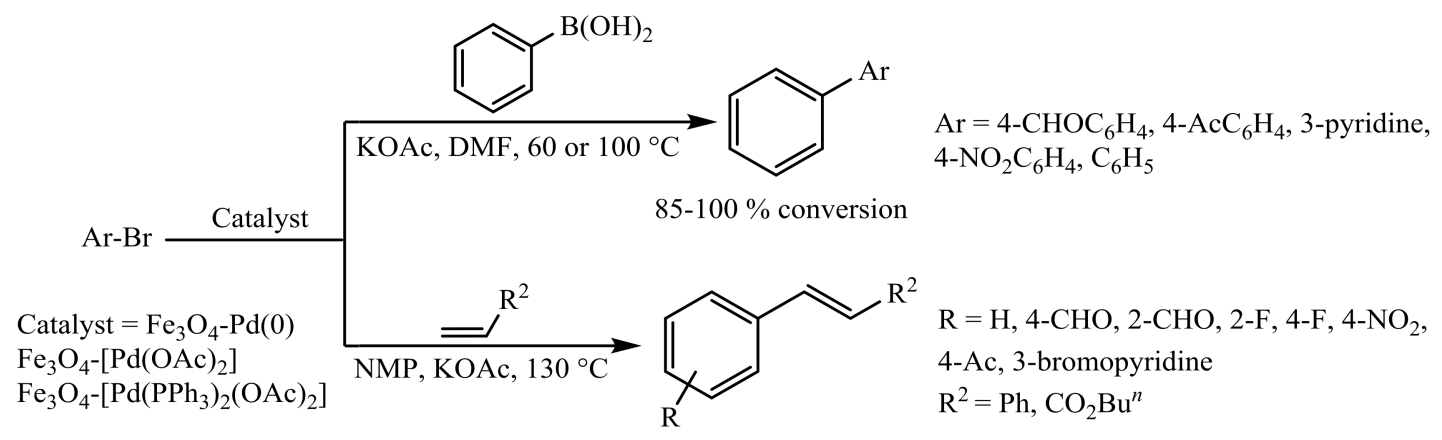

Scheme 3. Heck and Suzuki-Miyaura coupling reactions catalyzed by $\mathrm{Fe}_{3} \mathrm{O}_{4}-\mathrm{Pd}(\mathrm{OAc})_{2}, \mathrm{Fe}_{3} \mathrm{O}_{4}-\mathrm{Pd}^{0}$, and $\mathrm{Fe}_{3} \mathrm{O}_{4} \mathrm{Pd}\left(\mathrm{PPh}_{3}\right)_{2}(\mathrm{OAc})_{2}$ [21]. 


\subsection{Core-Shell Magnetic Nps with an Inorganic Shell}

One of the methods used to develop magnetically separable catalysts is encapsulation of magnetic NPs by inorganic materials such as metal oxides. Along this line, Sokolov and Karan have prepared a catalyst with a magnetite core and Mg-Al-layered double hydroxide shell functionalized with a palladium $(0)$ complex $\left(\mathrm{Pd}_{2}(\mathrm{dba})_{3}\right.$ in which $\mathrm{dba}=$ dibenzylideneacetone) [22]. Spherical particles with diameters about 10-40 nm were revealed in TEM images (Figure 1). Suzuki-Miyaura reaction of aryl halides with arylboronic acid in $\mathrm{H}_{2} \mathrm{O} / \mathrm{MeOH}$ at $70{ }^{\circ} \mathrm{C}$ was performed in the presence of Pd-LDH@M catalyst and gave product in good yield. Also, the catalyst showed high activity in the Heck coupling of aryl iodides (Scheme 4). The catalyst could be separated due to its ferromagnetic behavior from the reaction mixture by means of magnetic field. The activity of the reused catalyst in the next run decreased markedly. The authors believe that the interaction of Pd with hydroxide shell is not strong enough and leaching of $\mathrm{Pd}^{0}$ from this support is not unexpected, thus the catalyst has limited recyclability.

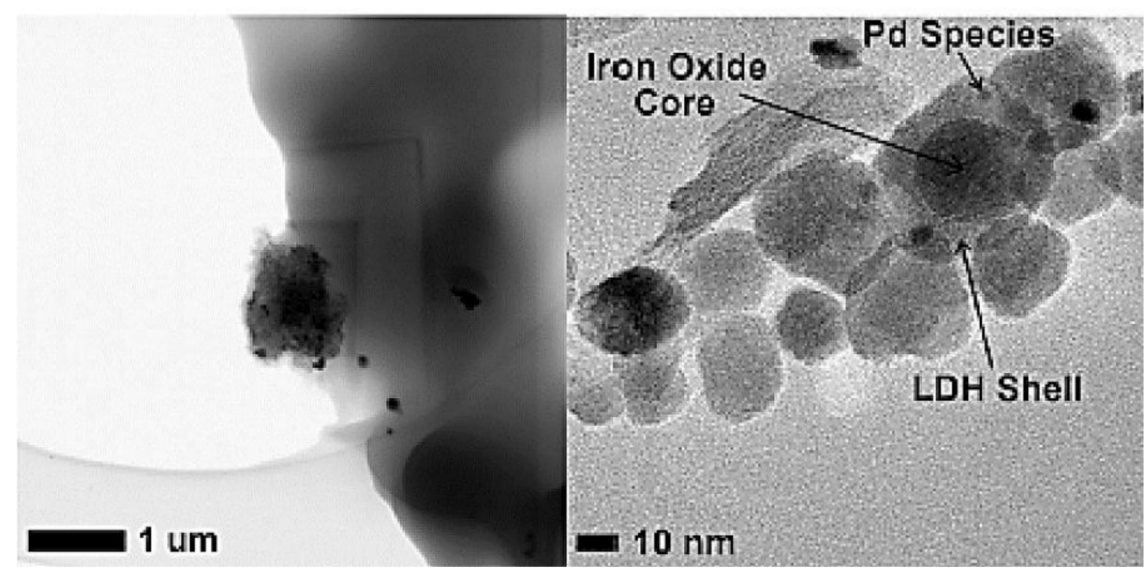

Figure 1. TEM images of the Pd-LDH@M catalyst. Reproduced with permission from [22].

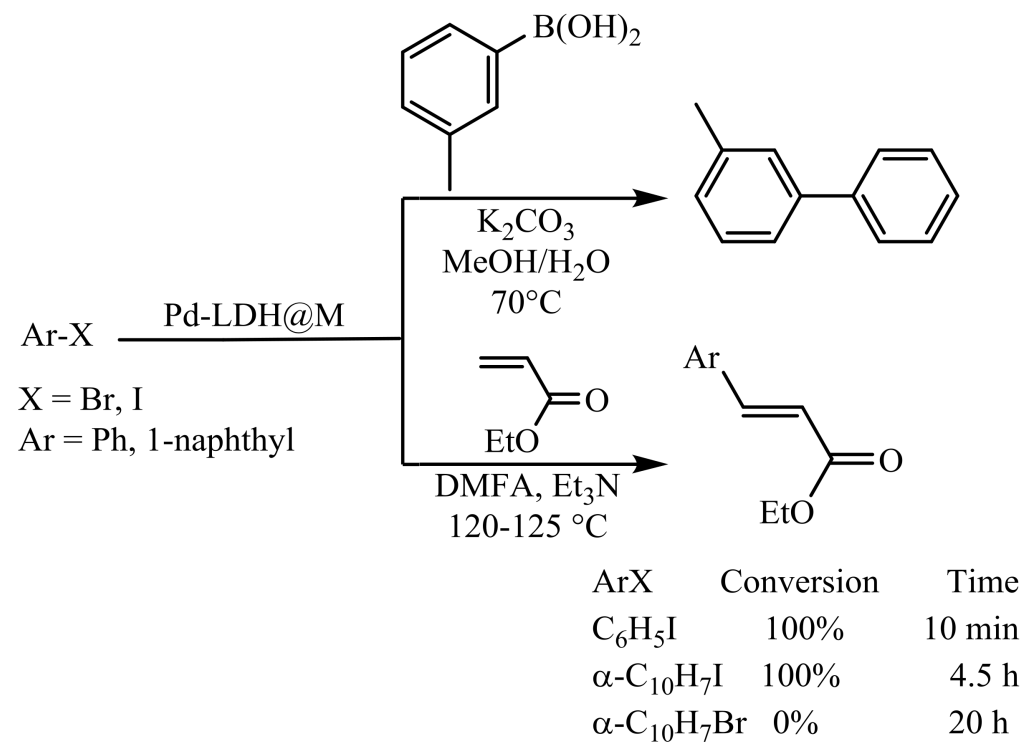

Scheme 4. Suzuki-Miyaura and Heck reaction of aryl halides catalyzed by Pd-LDH@M [22].

\subsection{Magnetic Polymer Nanocomposites}

Coating the surfaces of magnetic NPs with polymers provides another way to stabilize metal NPs on the surfaces of magnetic materials. In addition, since a decrease in activity and selectivity often appeared due to the low solubility of the supported catalysts in the reaction media, by using 
various hydrophobic and hydrophilic polymeric coatings, the solubility of the catalyst in both organic and aqueous solvents is markedly enhanced. In this regard, Co-based magnetic NPs functionalized with a polymeric phosphine ligand were synthesized by Reiser and Hanson [23]. The grafting of this polymeric ligand onto carbon-coated cobalt magnetic NPs was based on a "click" reaction, followed by ring-opening metathesis polymerization (ROMP). Treating $\mathrm{PPh}_{3}$-functionalized $\mathrm{Co} / \mathrm{C}$ magnetic NPs with $\mathrm{Pd}(\mathrm{OAc})_{2}$ results in the generation of a recyclable Pd catalyst (Scheme 5).

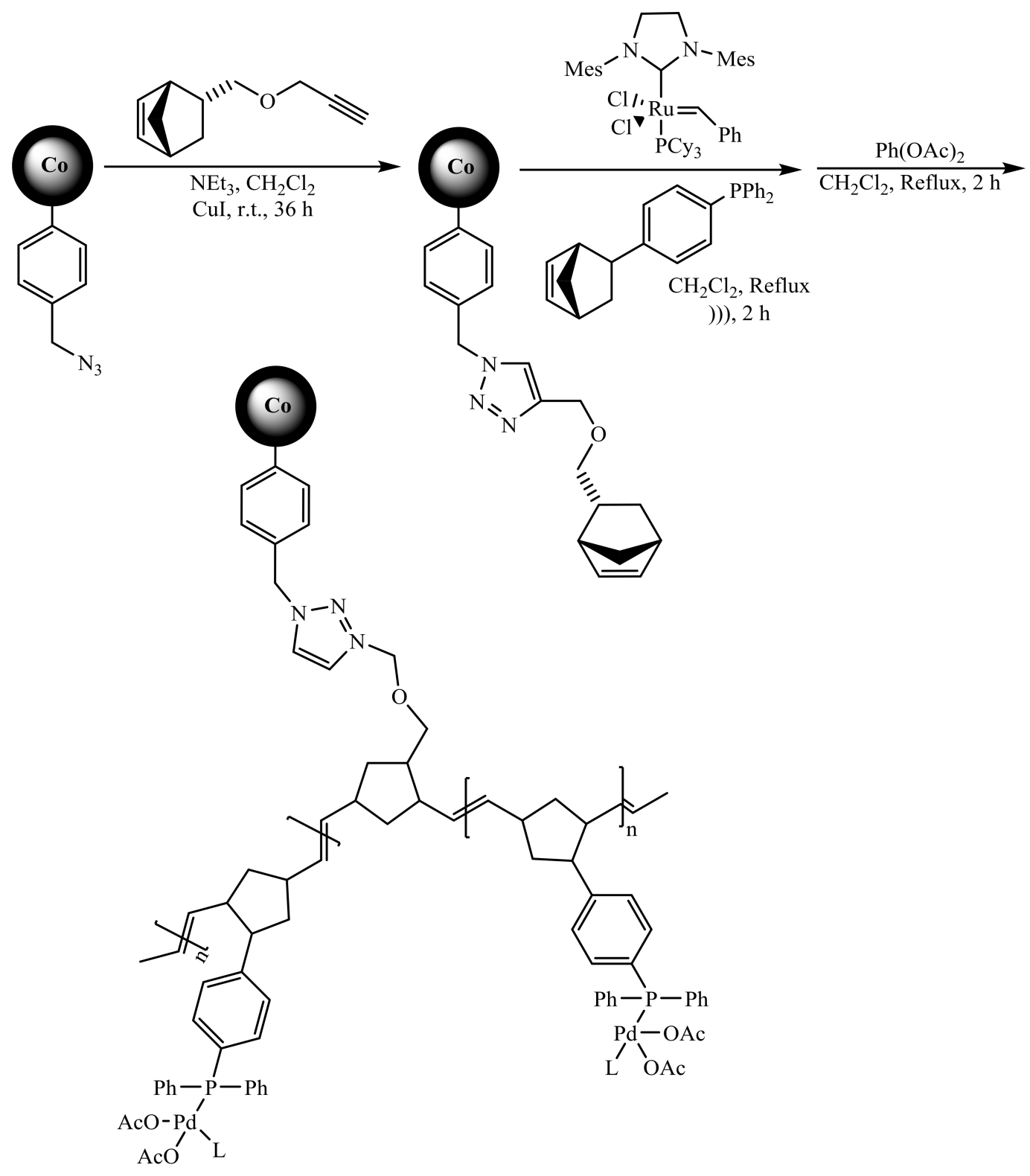

Scheme 5. Formation of a heterogeneous palladium complex on $\mathrm{PPh}_{3}$-functionalized Co/C-ROMPgel. Reproduced with permission from [23].

The efficiency of the hybrid material was estimated from the Suzuki-Miyaura cross-coupling reactions between iodobenzene, bromobenzene, and chlorobenzene with phenylboronic acid. Coupling reactions were conducted in THF $/ \mathrm{H}_{2} \mathrm{O}$ at $65^{\circ} \mathrm{C}$ by using $\mathrm{Na}_{2} \mathrm{CO}_{3}$ as the base (Scheme 6). Due to the ferromagnetic behavior of metal core NPs, an external magnetic field can be utilized to recycle the catalyst after each run, and the effectiveness of the catalyst is retained even after seven runs, which is due to high loading in ROMP technology. 


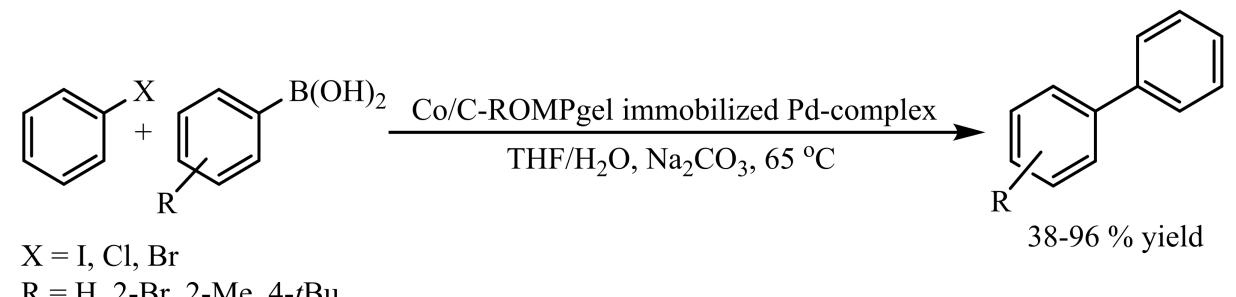

Scheme 6. Suzuki-Miyaura cross-coupling reactions catalyzed by recyclable Co/C-ROMPgel immobilized Pd complex [23].

In 2011, Stark and co-workers reported a self-separating phase switching catalyst system with grafting of palladium(II) onto amphiphilic $N$-isopropylacrylamide (PNIPAM) polymer-functionalized graphene-coated cobalt NPs (Scheme 7) [24].

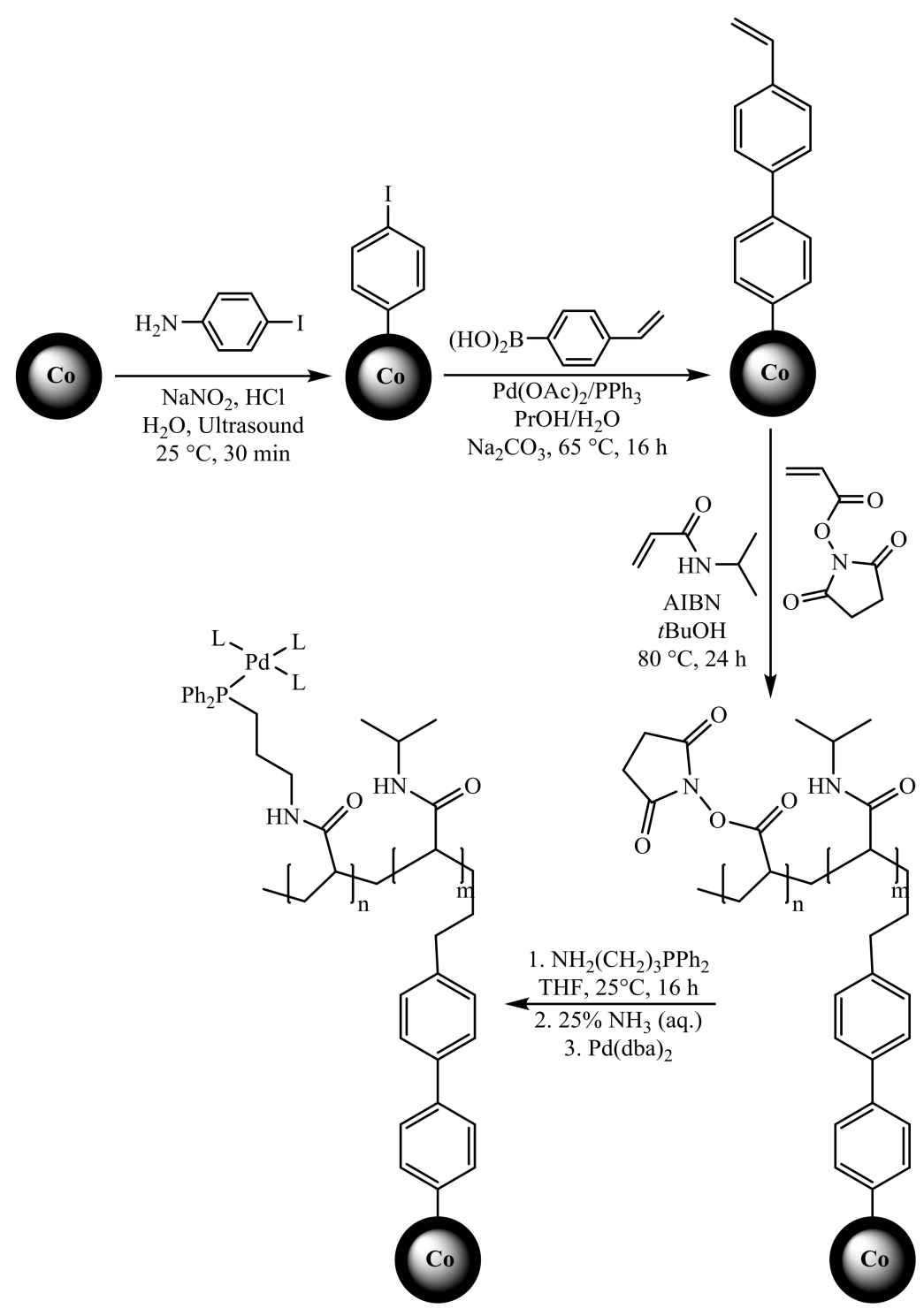

Scheme 7. Preparation of recyclable C/Co@PNIPAM immobilized Pd complex. Reproduced with permission from [24].

The obtained catalyst was used successfully in Suzuki-Miyaura cross-coupling reactions in the presence of $\mathrm{K}_{2} \mathrm{CO}_{3}$ as a base (Scheme 8). In this catalyst system, collapse of the polymer chains makes 
the material more hydrophobic; on the other hand, the cobalt core makes the catalyst magnetically separable. Due to the temperature-responsive nature of PNIPAM, adding toluene to a dispersed catalyst in water and increasing the temperature to $85^{\circ} \mathrm{C}$ moved the particles into the organic phase and caused coupling of the aryl halide and boronic acid in a biphasic water/toluene mixture. Finally, after completion of the reaction and cooling the reaction mixture, defolding the polymeric chain results in transfer of the particles into the aqueous phase. The organic layer, including the product, is separated and the particles are removed from the aqueous phase by magnetic separation and can be reused 10 times or more.

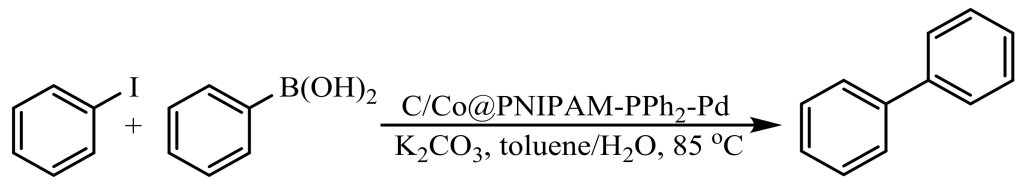

$99 \%$ conversion

Scheme 8. Suzuki-Miyaura cross-coupling reactions catalyzed by recyclable C/Co@PNIPAM immobilized Pd complex. Reproduced with permission from [24].

A catalyst with palladium NPs supported on $\mathrm{Fe}_{3} \mathrm{O}_{4} @ \mathrm{SiO}_{2} @ \mathrm{mSiO}_{2}-\mathrm{HPG}-\mathrm{COOH}$ microspheres was synthesized and evaluated in a Suzuki-Miyaura cross-coupling reaction by Li and co-workers [25]. Grafting hyperbranch polyglycerol (HPG) onto the surface of $\mathrm{Fe}_{3} \mathrm{O}_{4} @ \mathrm{SiO}_{2} @ \mathrm{mSiO}_{2}$ microspheres, followed by a reaction of the mesopore wall of this material with isopropanol aluminum and epoxide opening with amino groups, gave $\mathrm{Fe}_{3} \mathrm{O}_{4} @ \mathrm{SiO}_{2} @ \mathrm{mSiO}_{2}-\mathrm{HPG}$. Subsequently, treating this material with succinic anhydride resulted in the transformation of terminal hydroxyl groups of HPG into carboxyl groups. Finally, a $\mathrm{Fe}_{3} \mathrm{O}_{4} @ \mathrm{SiO}_{2} @ \mathrm{mSiO}_{2}-\mathrm{HPG}-\mathrm{COOH}-\mathrm{Pd}(0)$-supported catalyst was obtained through complexation of $\mathrm{Pd}^{2+}$ ions and carboxyl groups (Scheme 9).

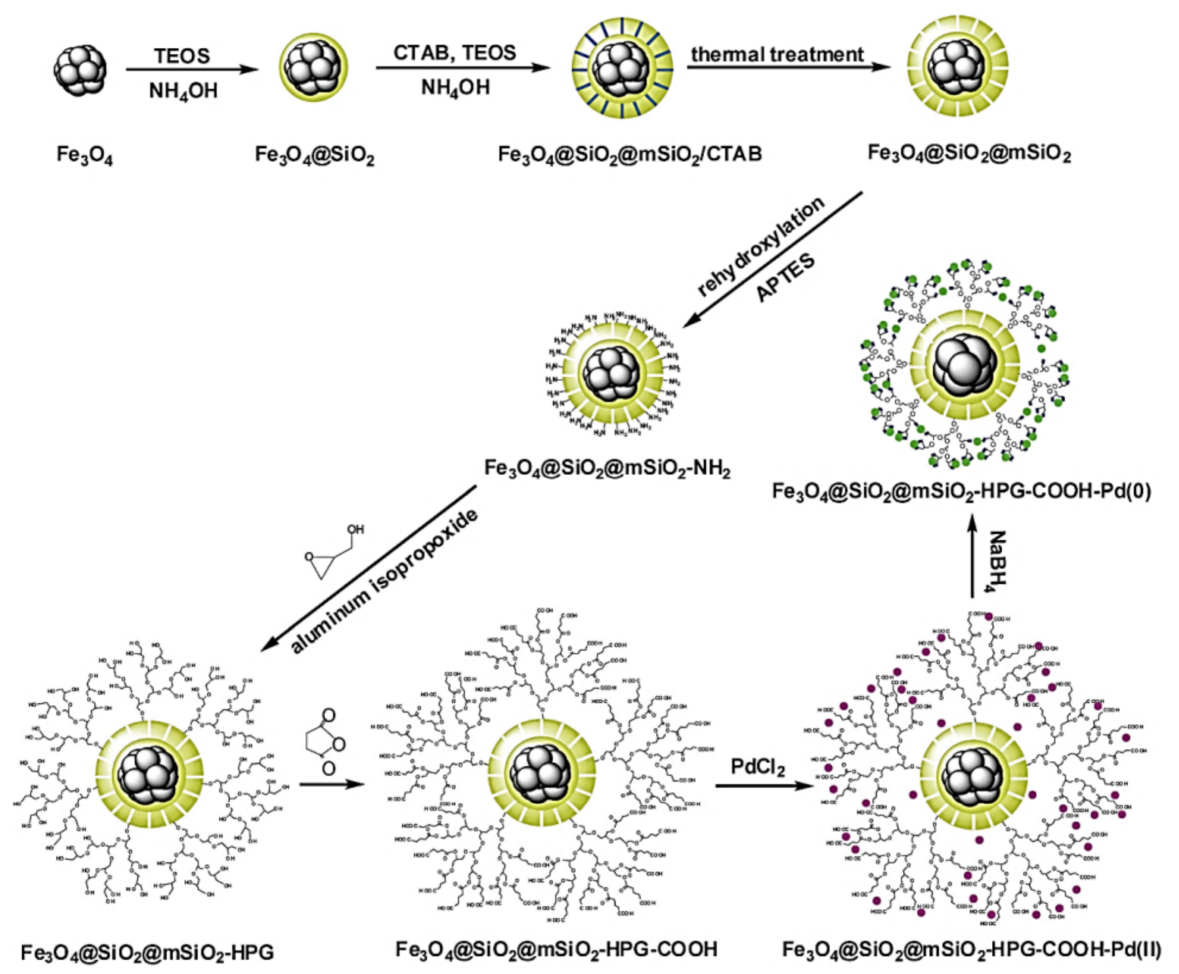

Scheme 9. Preparation process of $\mathrm{Fe}_{3} \mathrm{O}_{4} @ \mathrm{SiO}_{2} @ \mathrm{mSiO} 2-\mathrm{HPG}-\mathrm{COOH}-\mathrm{Pd}(0)$. Reproduced with permission from [25]. 
The heterogenized catalyst showed remarkable catalytic activity in the Suzuki-Miyaura cross-coupling reaction of aryl halides and phenylboronic acid (Scheme 10). The high catalytic performance and stability of this magnetic catalyst are due to numerous terminal carboxyl groups on the surface of the magnetic $\mathrm{Fe}_{3} \mathrm{O}_{4} @ \mathrm{SiO}_{2} @ \mathrm{mSiO}_{2}$ microspheres that can provide plenty of binding sites for Pd NPs. The supported catalyst can be reused at least eight times without evident loss of activity [25].

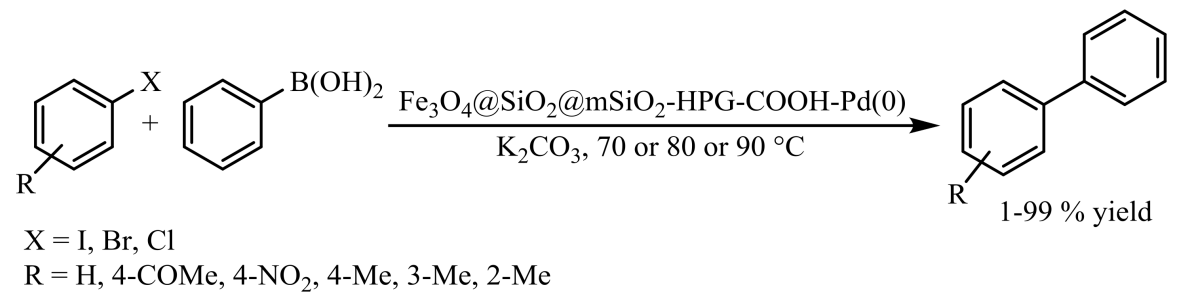

Scheme 10. Suzuki-Miyaura coupling reactions catalyzed by $\mathrm{Fe}_{3} \mathrm{O}_{4} @ \mathrm{SiO}_{2} @ \mathrm{mSiO}_{2}-\mathrm{HPG}-\mathrm{COOH}-\mathrm{Pd}(0)$ under different conditions [25].

Zhang et al. have prepared Pd NPs supported on branched/linear polyethylenimine-grafted magnetic $\mathrm{Fe}_{3} \mathrm{O}_{4} / \mathrm{SiO}_{2} / \mathrm{P}(\mathrm{GMA}-\mathrm{co}-\mathrm{EGDMA})$ composite [26]. The procedure and utilized steps for the preparation of catalyst are shown in Scheme 11. Hydrolyzing tetraethyl orthosilicate (TEOS) in the presence of $\mathrm{Fe}_{3} \mathrm{O}_{4} \mathrm{NPs}$, followed by surface-grafted copolymerization, gave a magnetic $\mathrm{Fe}_{3} \mathrm{O}_{4} / \mathrm{SiO}_{2} / \mathrm{P}$ (GMA-co-EGDMA) nanocomposite. Complexation between $\mathrm{Pd}^{2+}$ ions and imidogen groups or tertiary amine groups after grafting of the branched/linear polyethylenimine by a chemical method gave $\mathrm{Fe}_{3} \mathrm{O}_{4} / \mathrm{SiO}_{2} / \mathrm{P}(\mathrm{GMA}$-co-EGDMA)-PEI-Pd(0) catalyst.

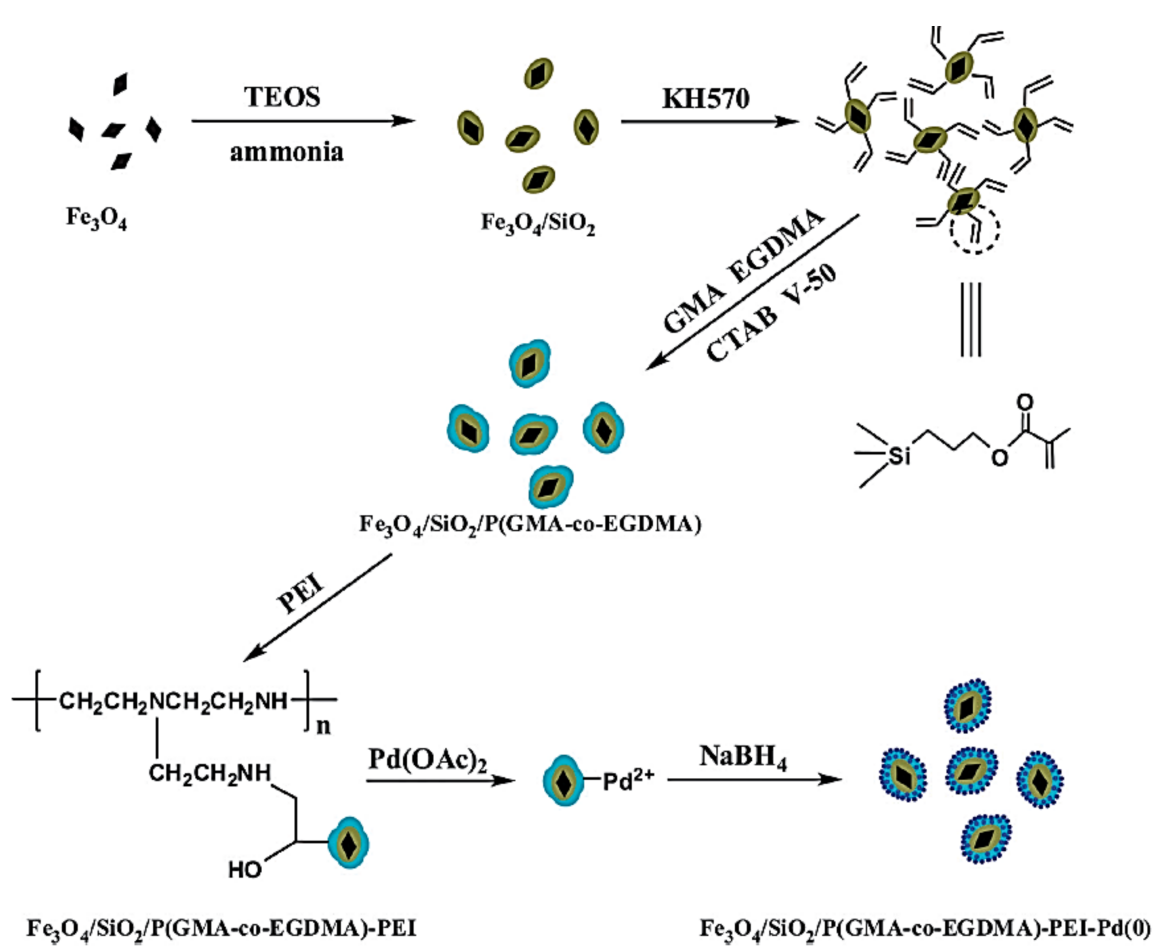

Scheme 11. Preparation process of the $\mathrm{Fe}_{3} \mathrm{O}_{4} / \mathrm{SiO}_{2} / \mathrm{P}(\mathrm{GMA}-\mathrm{co}-\mathrm{EGDMA})-\mathrm{PEI}-\mathrm{Pd}(0)$ catalyst. Reproduced with permission from [26]. GMA: glycidyl methacrylate, EGDMA: ethyleneglycol dimethacrylate, CTAB: hexadecyltrimethylammonium bromide, V-50: 2,20-azobis-(2-methylpropionamide) dihydrochloride, PEI: polyethyleneimine.

The obtained material act as effective catalyst for coupling reactions of aryl halides and arylacetylenes (Sonogashira cross-coupling reaction) (Scheme 12). Gratifyingly, this catalyst can be reused 
at least eight times without significant loss of catalytic activity, which is conducive to its application. The yield of iodobenzene with phenylacetylene, 3-aminophenylacetylene, and 4-(ethynyl)phthalic anhydride is approximately $85 \%, 84 \%$, and $100 \%$, respectively. Recycling studies of the nanocatalyst were investigated for the Sonogashira cross-coupling reaction between iodobenzene and phenylacetylene, 3-aminophenylacetylene and 4-(ethynyl)phthalic anhydride, which indicated around 79\%, 78\%, and 95\%, respectively, after eight times of reusing.

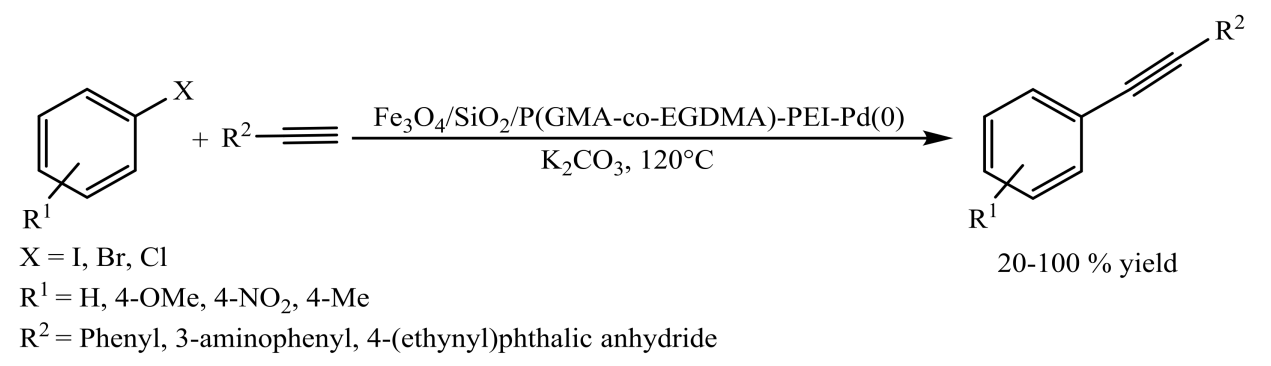

Scheme 12. Sonogashira coupling reactions catalyzed by $\mathrm{Fe}_{3} \mathrm{O}_{4} / \mathrm{SiO}_{2} / \mathrm{P}(\mathrm{GMA}-\mathrm{co}-\mathrm{EGDMA})-\mathrm{PEI}-$ $\operatorname{Pd}(0)[26]$.

Zhao and Lu designed a highly water-dispersible and magnetically separable palladium catalyst based on functionalized PEG-supported iminophosphine [27]. The magnetic NPs were prepared by reacting a palladium complex containing (diphenylphosphino) benzaldehyde as a ligand with amino-functionalized PEG-coated iron oxide NPs (Scheme 13). TEM images of the obtained catalyst showed mostly spherical particles with an average diameter of about 15-20 nm (Figure 2a).

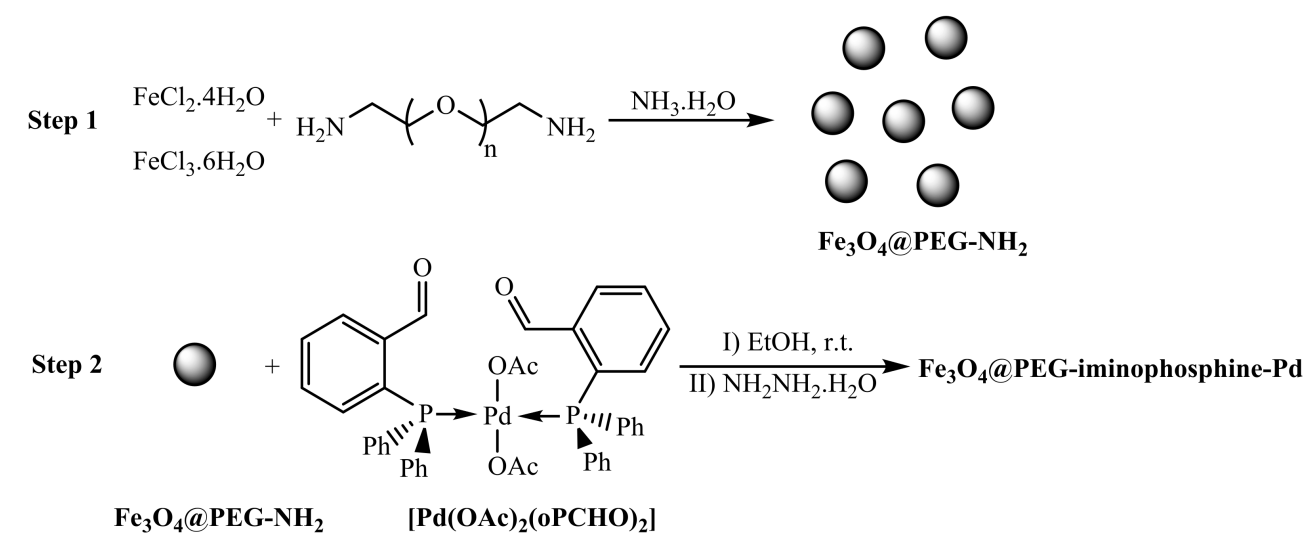

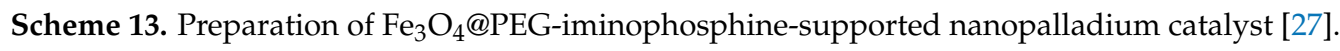
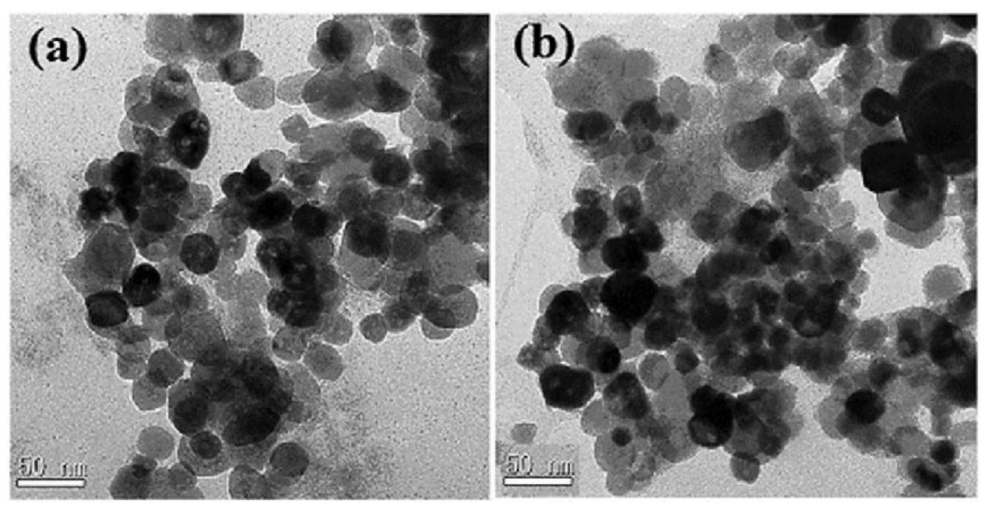

Figure 2. TEM images: (a) fresh $\mathrm{Fe}_{3} \mathrm{O}_{4} @$ PEG-iminophosphine-supported palladium complex; (b) catalyst after being used five times. Reproduced with permission from [27]. 
Suzuki-Miyaura reaction of aryl halides with arylboronic acids based on functionalized PEG-supported iminophosphine in neat water were investigated. The heterogeneous palladium catalyst presented good activity in the transportation and all of the coupling products were obtained in good to excellent yields (Scheme 14). Furthermore, a magnetically separable catalyst can be recovered from the reaction mixture using an external magnet and reused for five consecutive runs without a significant decrease in its activity. The TEM image of the recovered catalyst after the fifth reaction run also indicated that the $\mathrm{Fe}_{3} \mathrm{O}_{4} @$ PEG-iminophosphine-supported palladium catalyst maintained its core-shell structure after five consecutive Suzuki-Miyaura reactions (Figure 2b) [27].

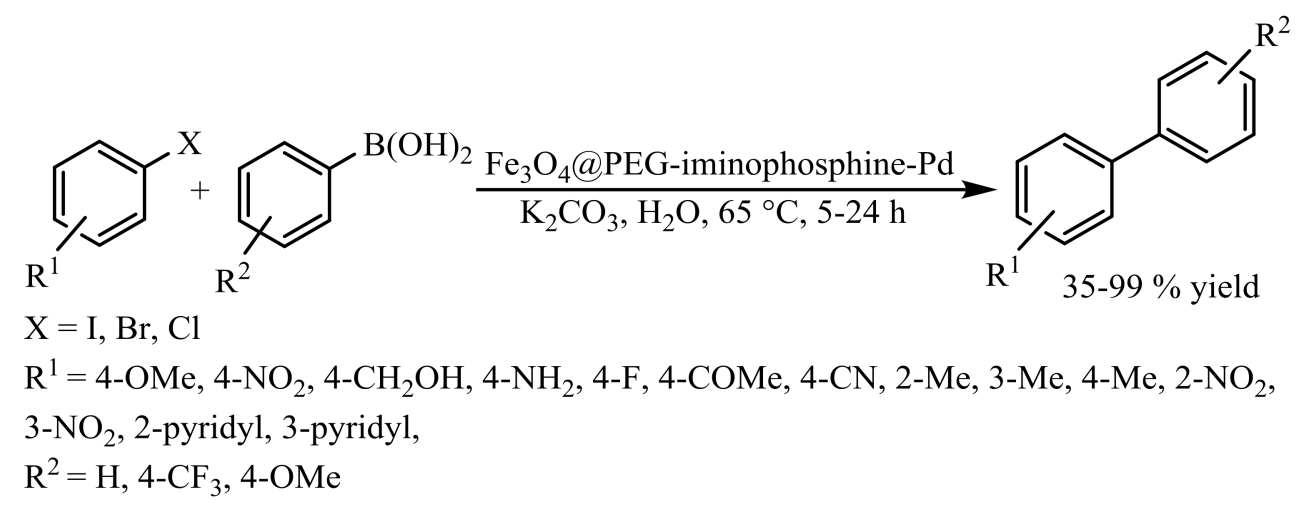

Scheme 14. Suzuki-Miyaura reaction of aryl halides with arylboronic acids catalyzed by $\mathrm{Fe}_{3} \mathrm{O}_{4} @$ PEG-iminophosphine-Pd complex [27].

Yuan and co-workers reported a soap-free emulsion polymerization technique for the formation of superparamagnetic polymer composite microspheres as the support for immobilization of Schiff base palladium catalyst for Suzuki-Miyaura coupling reactions (Scheme 15) [28]. HRTEM TEM of $\mathrm{Fe}_{3} \mathrm{O}_{4} / \mathrm{P}(\mathrm{GMA}-\mathrm{AA}-\mathrm{MMA})$-Schiff base Pd showed Pd NPs with an average size of about 5-10 nm on the surface of the support materials (Figure 3 ).

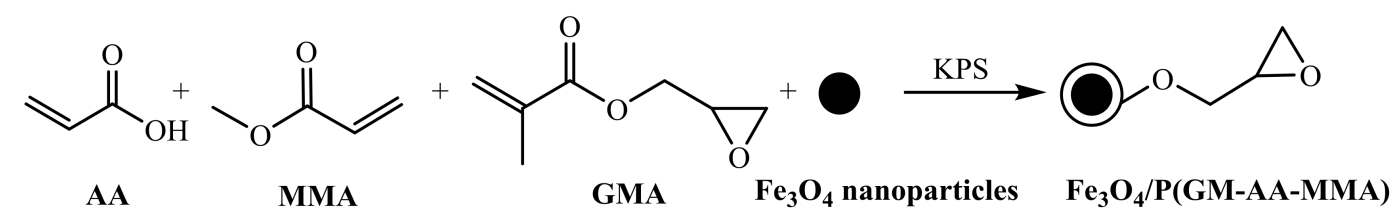

AA

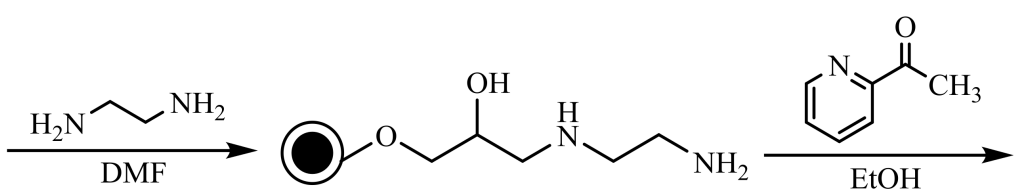

$\mathrm{Fe}_{3} \mathrm{O}_{4} / \mathbf{P}(\mathrm{GM}-\mathrm{AA}-\mathrm{MMA})-\mathrm{NH}_{2}$

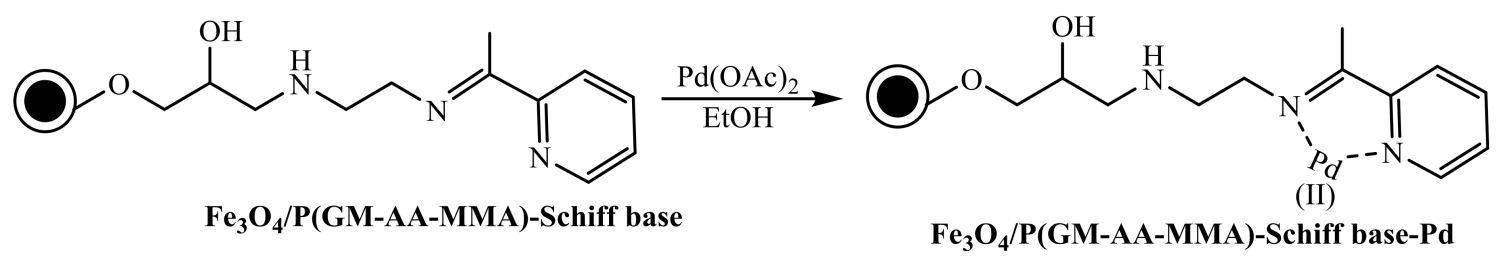

Scheme 15. Synthesis of $\mathrm{Fe}_{3} \mathrm{O}_{4} / \mathrm{P}(\mathrm{GMA}-\mathrm{AA}-\mathrm{MMA})$-Schiff base Pd [28]. 

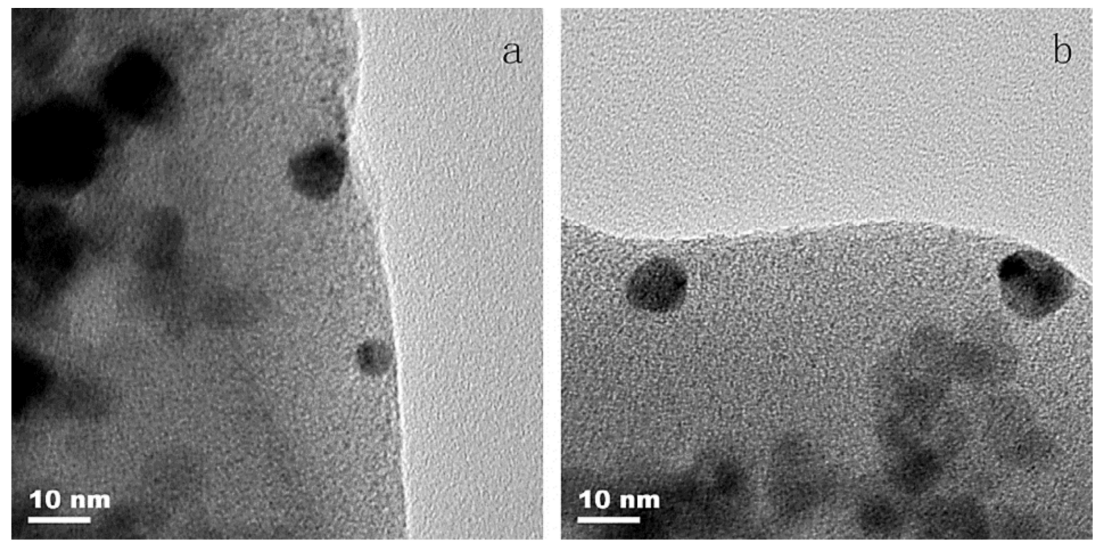

Figure 3. HRTEM images of $\mathrm{Fe}_{3} \mathrm{O}_{4} / \mathrm{P}(\mathrm{GMA}-\mathrm{AA}-\mathrm{MMA})$-Schiff base-Pd before (a) and after (b) Suzuki-Miyaura reaction. Reproduced with permission from [28].

This magnetic catalyst demonstrated excellent reactivity in the Suzuki-Miyaura coupling reactions of aryl halides bearing both electron-withdrawing and electron-donating groups with phenylboronic acids (Scheme 16) and could be reused at least seven times without any loss of catalytic activity or Pd leaching. As shown in Figure 3, the HRTEM image of the catalyst after seven times of its frequent using revealed no change in Pd size and also ICP-AES results showed insignificant Pd leaching of the supported magnetic catalyst.

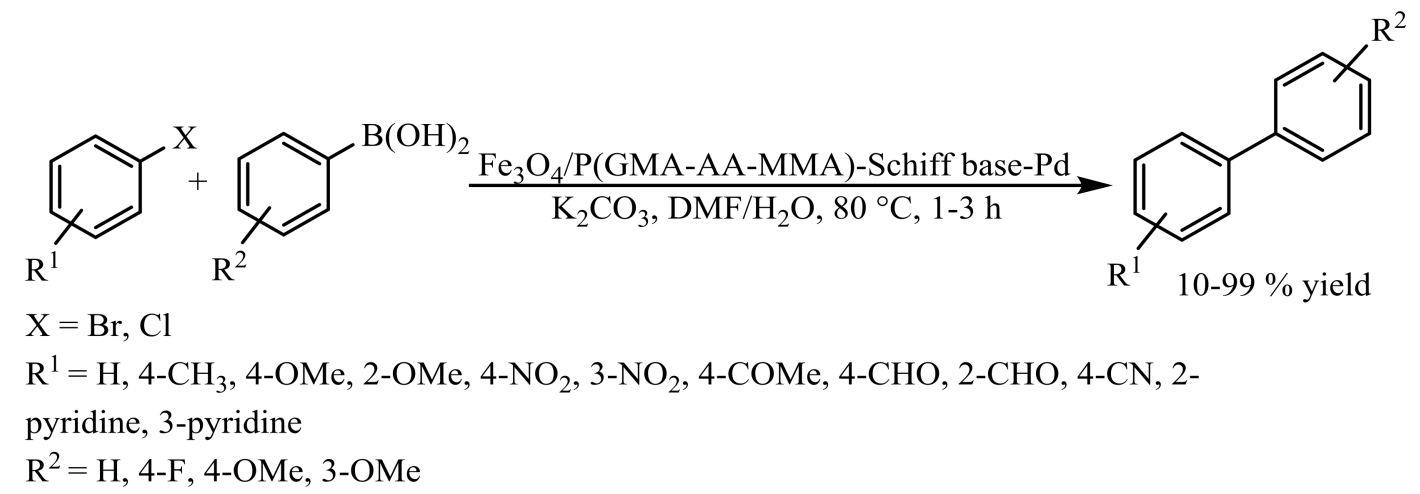

Scheme 16. Suzuki-Miyaura reactions between aryl halides and aryl boronic acids catalyzed by $\mathrm{Fe}_{3} \mathrm{O}_{4} / \mathrm{P}(\mathrm{GMA}-\mathrm{AA}-\mathrm{MMA})-$ Schiff base Pd [28].

Tabatabaei Rezaei and co-workers reported a novel magnetically retrievable palladium catalyst for the C-C cross-coupling of aryl halides with olefin compounds. The catalyst was prepared by immobilizing palladium NPs on amphiphilic and hyperbranched polymer-functionalized magnetic NPs. In this catalyst, hyperbranched poly (ethylene glycol)-block poly (citric acid)-functionalized $\mathrm{Fe}_{3} \mathrm{O}_{4}$ magnetic NPs $\left(\mathrm{Fe}_{3} \mathrm{O}_{4} @ \mathrm{PCA}-b\right.$-PEG) with the presence of a large number of carboxyl groups as anchoring sites are capable to effectively immobilize and stabilize Pd NPs (Scheme 17) [29]. The TEM image indicates the dispersion of Pd NPs into the hyperbranched polymers on the surface of $\mathrm{Fe}_{3} \mathrm{O}_{4}$ and also size distribution diagram indicates a uniform distribution of the particles with an average diameter of about $49.5 \mathrm{~nm}$ (Figure 4). 

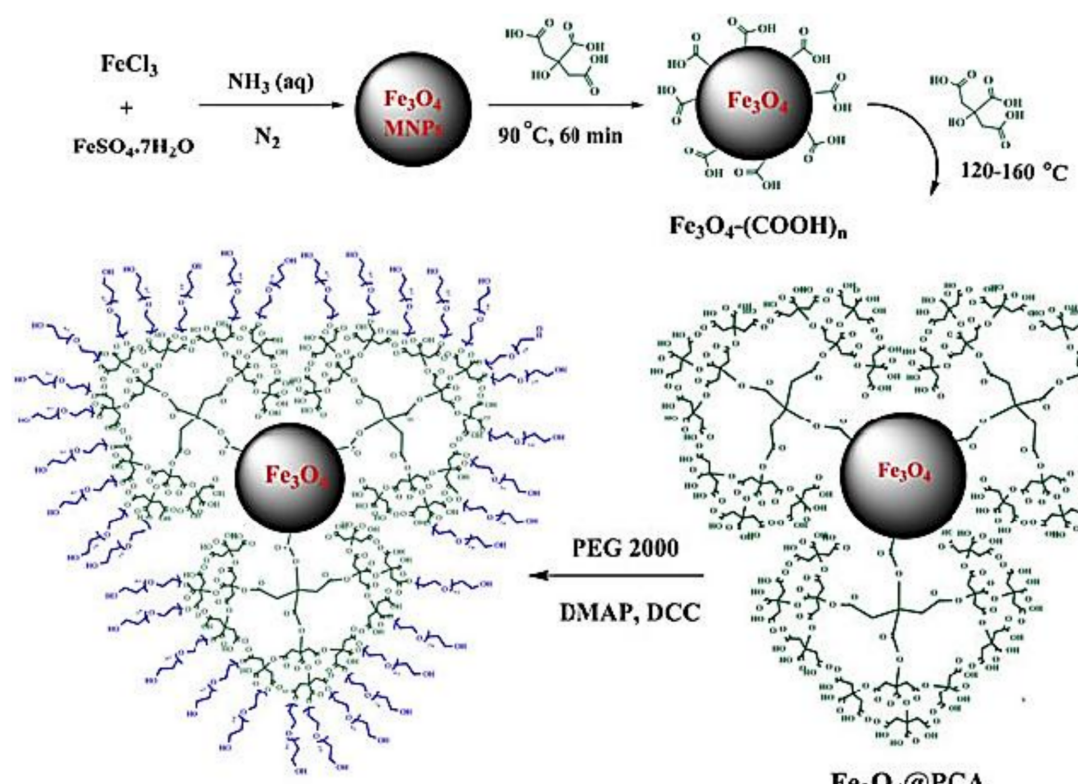

$\mathrm{Fe}_{3} \mathrm{O}_{4} @ \mathrm{PCA}-b$-PEG

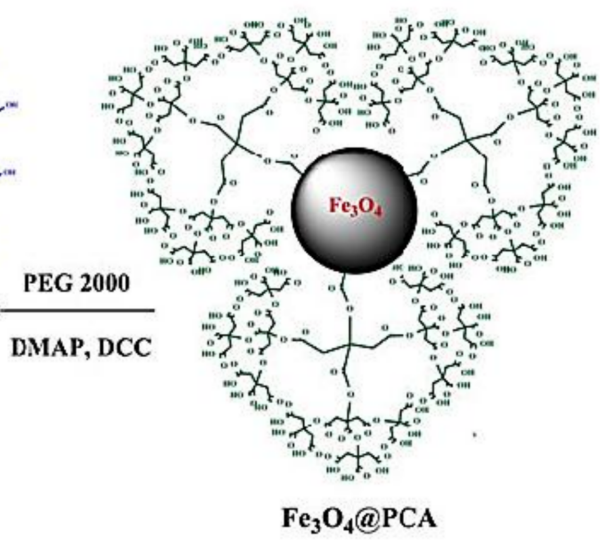

Scheme 17. Synthetic route employed for preparation of $\mathrm{Fe}_{3} \mathrm{O}_{4} @$ PCA-b-PEG magnetic NPs. Reproduced with permission from [29].
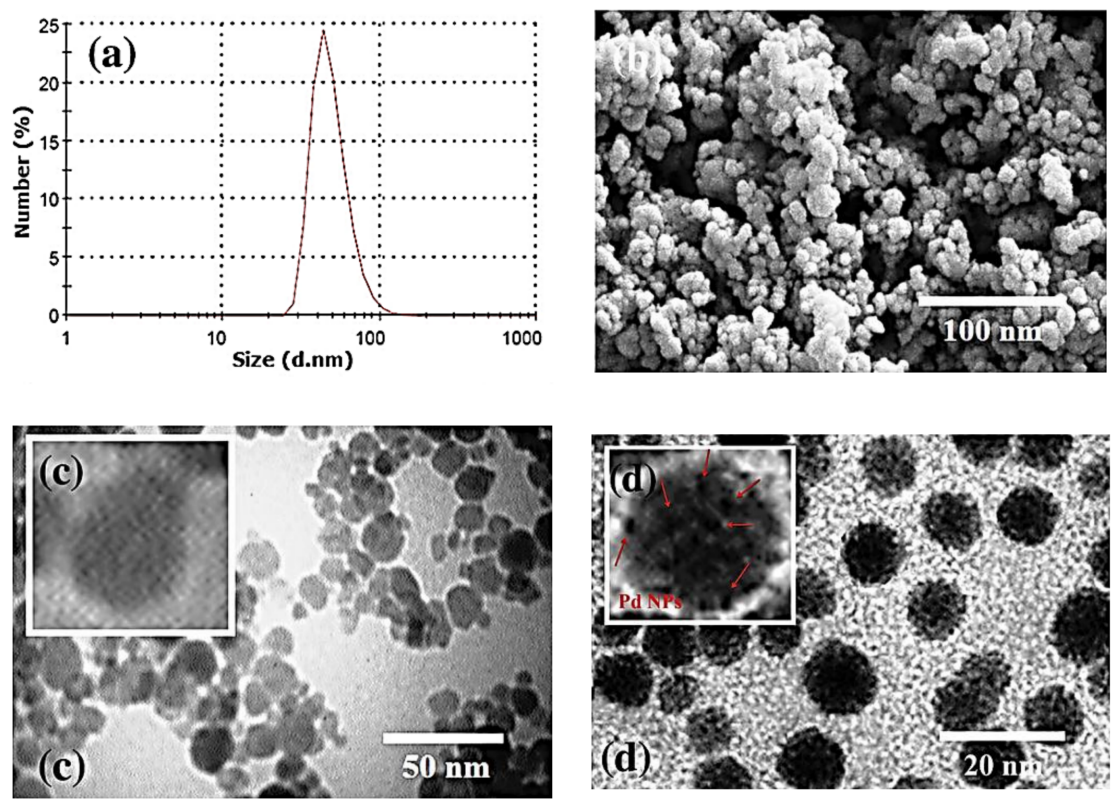

Figure 4. (a) DLS plot of $\mathrm{Fe}_{3} \mathrm{O}_{4} @ P C A / P d(0)-b$-PEG in water. (b) SEM image of $\mathrm{Fe}_{3} \mathrm{O}_{4} @ P C A-b$-PEG. TEM images of (c) $\mathrm{Fe}_{3} \mathrm{O}_{4} @ \mathrm{PCA}-b$-PEG and (d) $\mathrm{Fe}_{3} \mathrm{O}_{4} @ \mathrm{PCA} / \mathrm{Pd}(0)-b$-PEG at different magnifications. Reproduced with permission from [29].

The heterogenized catalyst was used in the palladium-catalyzed Heck coupling reaction of aryl halides with olefin compounds in the presence of water as a green solvent and $\mathrm{K}_{2} \mathrm{CO}_{3}$ as base (Scheme 18). In addition, the catalyst could be simply separated from the reaction mixture by applying an external magnetic field and reused for more than 10 consecutive cycles without much loss in its activity. 


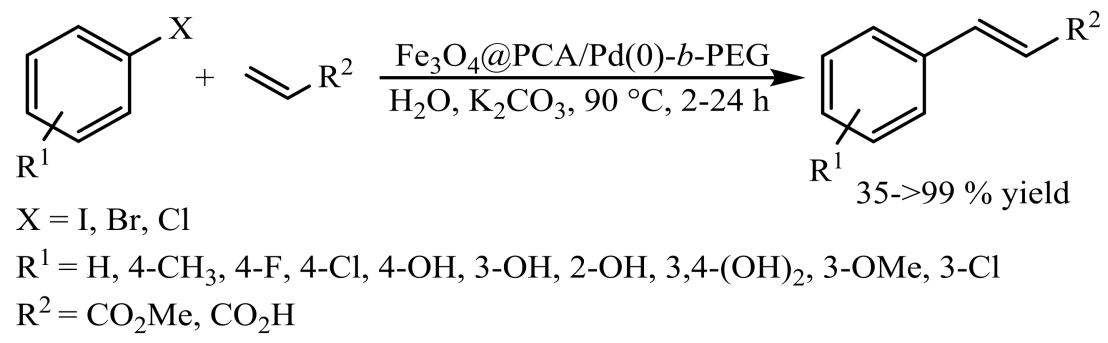

Scheme 18. Heck reaction of acrylic acid and methyl acrylate with various aryl halides in the presence of $\mathrm{Fe}_{3} \mathrm{O}_{4} @$ PCA- $b$-PEG magnetic NPs [29].

\subsection{Ligand-Functionalized Magnetic Nanoparticles}

Generally, a popular approach for the effective and stable immobilization of a metal catalyst on the surfaces of magnetic NPs is using a suitable organic ligand as a linker between an inorganic support and a metal catalyst core. Therefore, nature of magnetic NPs combines with a highly stable metal complex to arrive at recyclable catalysts. In this regard, Gao and co-workers, by click chemistry, immobilized dipyridyl palladium complex onto magnetite core/shell particles and prepared a catalyst for the Suzuki-Miyaura cross-coupling reaction [30]. For preparation of catalyst, silica-capped magnetite nanoparticles functionalized by 3-azido-1-triethoxysilylpropane followed by copper-catalyzed triazole formation using an alkyne-functionalized dipyridyl precursor obtained covalently fixed ligand for coordination with palladium(II) (Scheme 19).

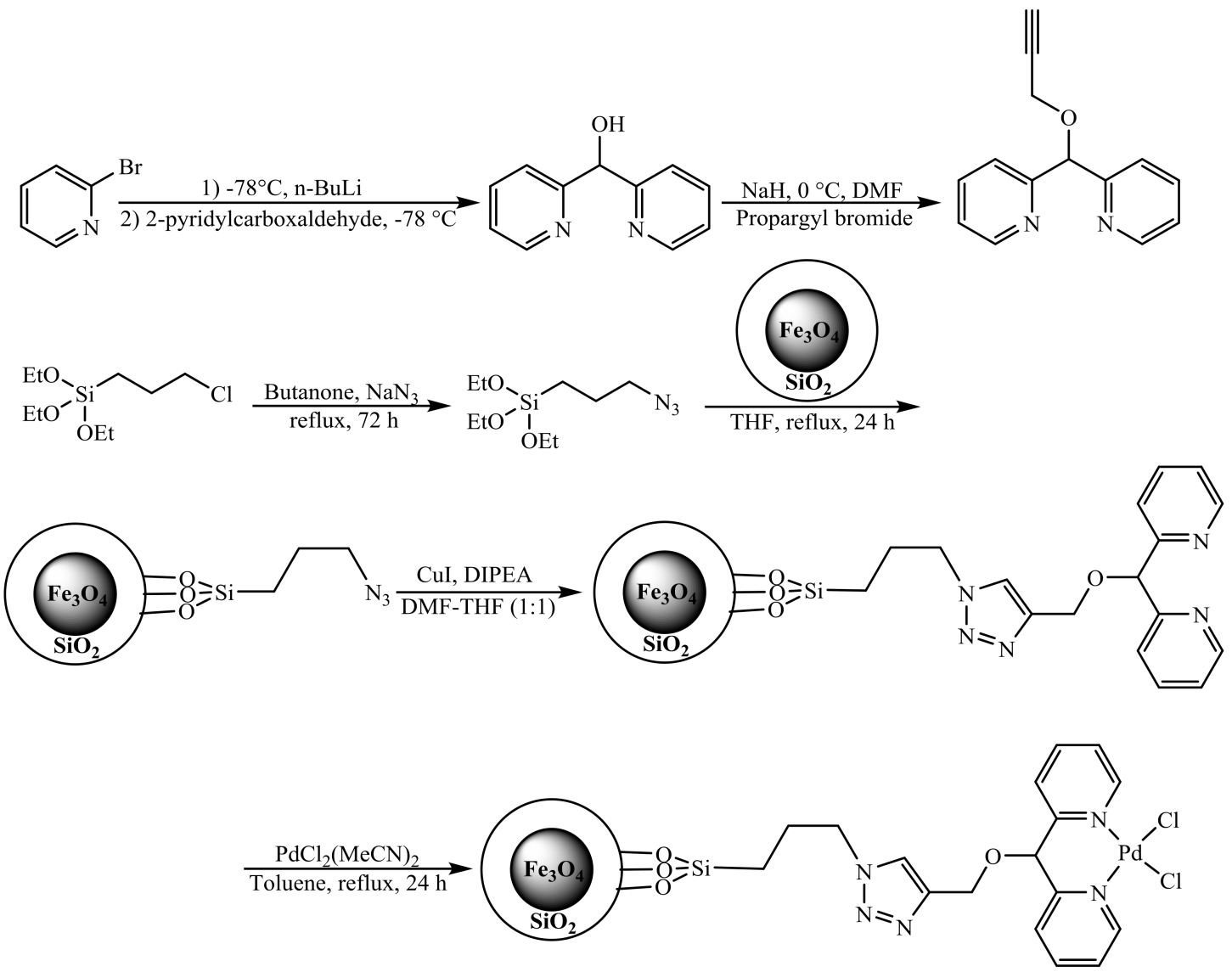

Scheme 19. Preparation of MNP-supported di(2-pyridyl)methanol-Pd complex. Reproduced with permission from [30]. 
The activity of resulting DPP-Pd@ $\mathrm{Fe}_{3} \mathrm{O}_{4}$ catalyst was evaluated in the Suzuki-Miyaura cross-coupling of different aryl halides with arylboronic acids by using $\mathrm{K}_{2} \mathrm{CO}_{3}$ as the base in DMF, which showed very good to excellent yields (Scheme 20). Moreover, the recyclable catalyst could be reused for five consecutive runs without a significant loss in activity.

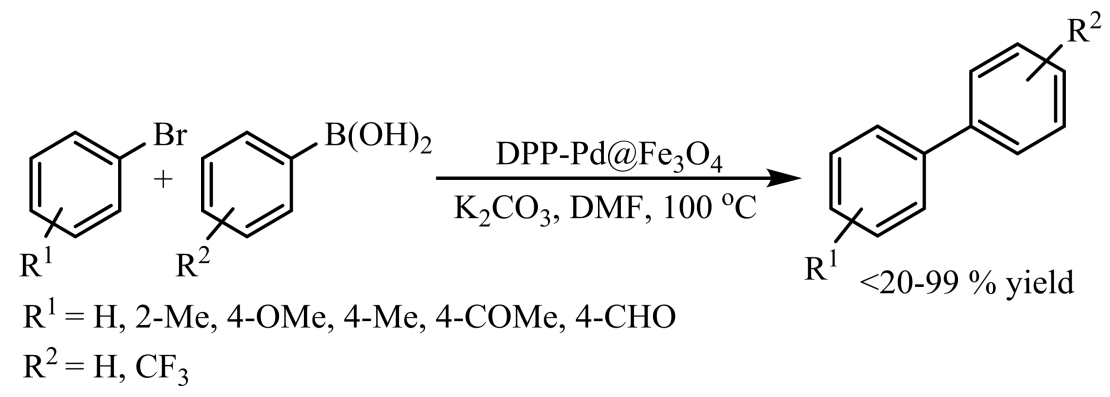

Scheme 20. DPP-Pd@ $\mathrm{Fe}_{3} \mathrm{O}_{4}$ catalyst in Suzuki-Miyaura coupling of aryl halides and aryl boronic acids [30].

Phan and co-workers reported palladium complex immobilized on pyridinylimine-functionalized cobalt ferrite NPs and investigated its catalytic activity in Sonogashira reaction of aryl halides and phenylacetylene [31]. Superparamagnetic NPs were obtained through microemulsion method; functionalization of this material with Schiff base groups gave immobilized bidentate ligands. Adding palladium acetate result in complexation of palladium with immobilized ligand and affording the superparamagnetic NPs-supported phosphine-free palladium catalyst (Scheme 21).
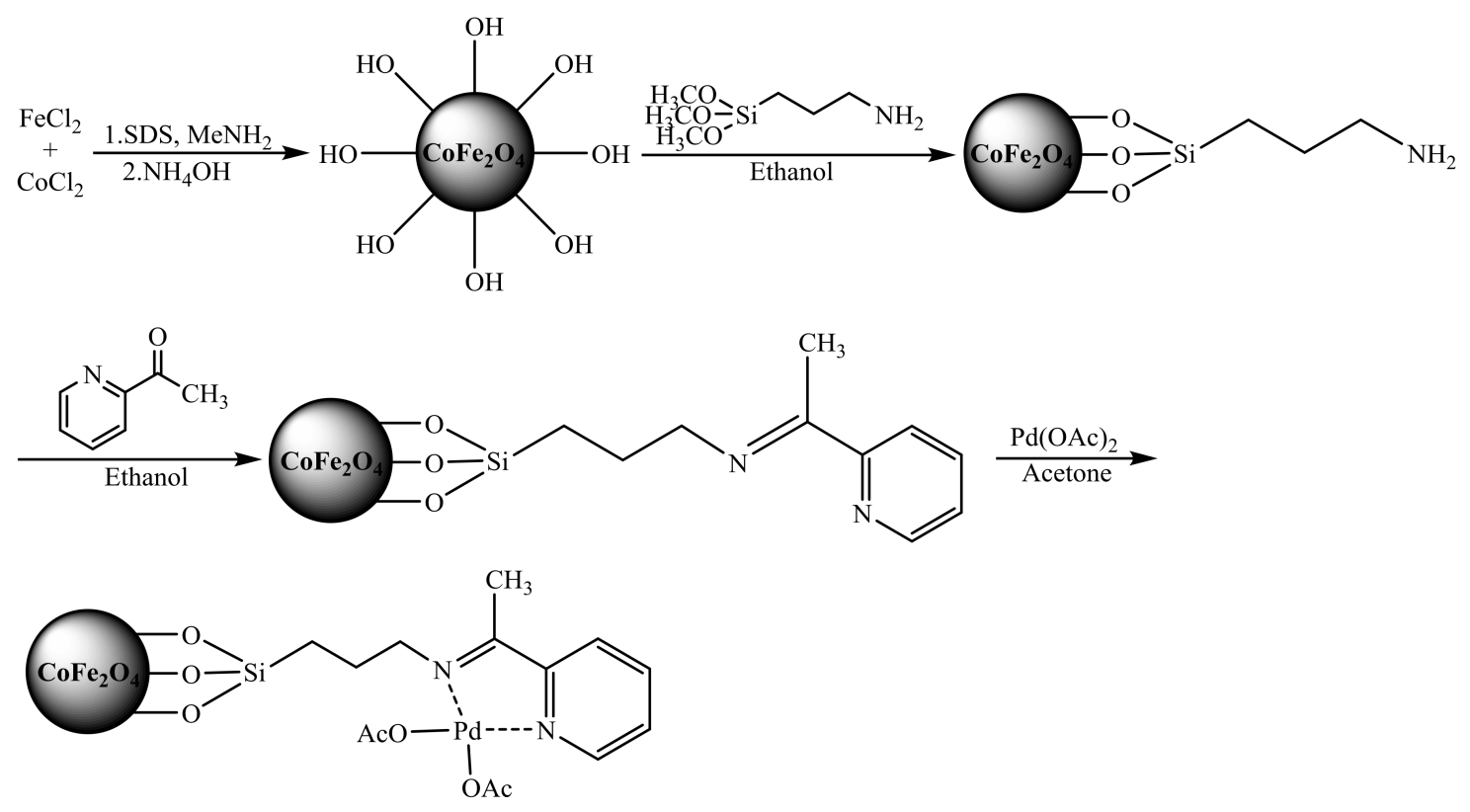

Scheme 21. Synthesis of the palladium catalyst immobilized on superparamagnetic NPs [31].

The Sonogashira reaction takes place in the presence of $\mathrm{K}_{3} \mathrm{PO}_{4}$ as a base without adding phosphine ligands and a corresponding diphenylacetylene product; in the case of electron-withdrawing groups on the benzene ring, it was obtained in favored yields, whereas electron-donating groups slowed down the cross-coupling process (Scheme 22). Superparamagnetic NPs could be recovered and reused more than 10 times with no significant decrease in their catalytic activity. 


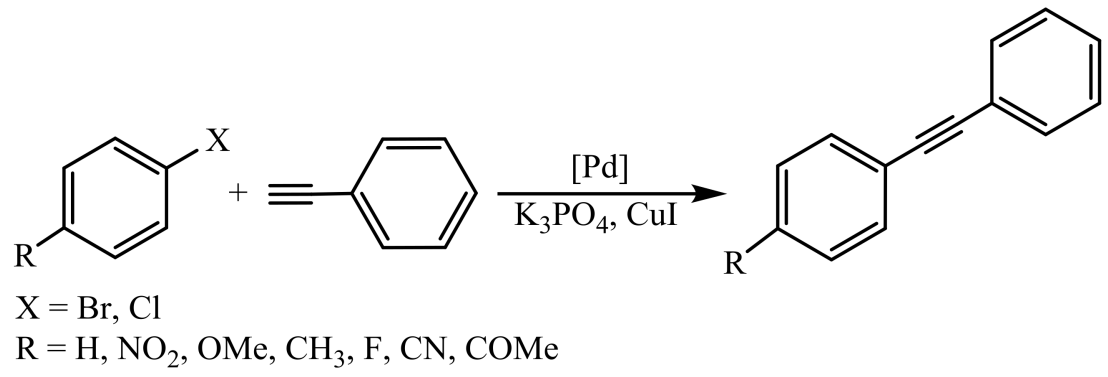

Scheme 22. The Sonogashira reaction of aryl halides and phenylacetylene using the palladium complex catalyst immobilized on the superparamagnetic NPs [31].

Zheng and co-workers reported the preparation of a palladium pincer complex immobilized on magnetic NPs and investigated its catalytic activity in the reductive homocoupling of aryl halides [32]. The $\mathrm{Fe}_{3} \mathrm{O}_{4}$ NPs were synthesized through thermal decomposition of $\mathrm{Fe}(\mathrm{Acac})_{3}$ in triethylene glycol, modification of these materials with 3-aminopropyltrimethoxysilane followed by grafting 4-\{3,5-bis[(1H-pyrazol-1-yl)methyl]phenylamino\}-4-oxobutanoic acid onto the surface of amine-functionalized $\mathrm{Fe}_{3} \mathrm{O}_{4}$ magnetic NPs resulted NCN pincer ligand for the formation of complex with palladium (Scheme 23). The formed MNPs were composed of relatively uniform particles with an average size of about $6 \pm 1 \mathrm{~nm}$ (Figure 5).

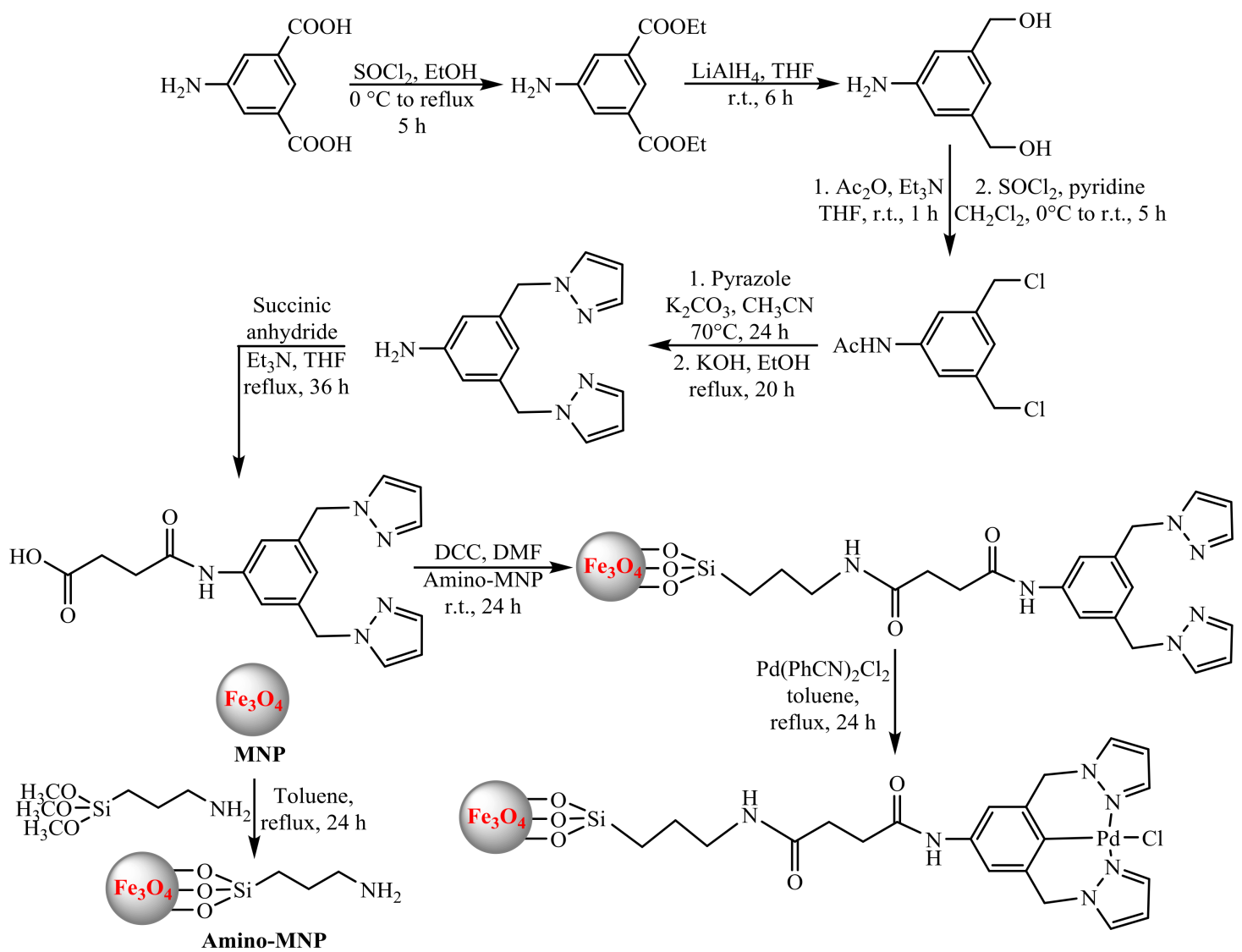

Scheme 23. Synthesis of magnetic nanoparticle (MNP)-grafted NCN pincer Pd catalyst [32]. 


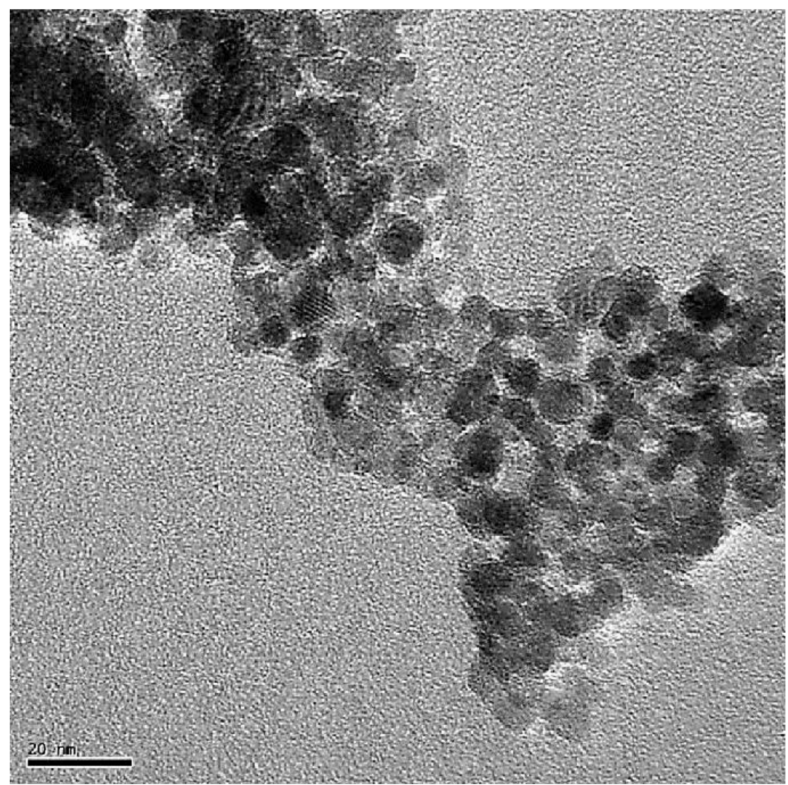

Figure 5. Transmission electron microscopy (TEM) image of magnetic nanoparticle (MNP)-grafted NCN pincer Pd catalyst. Reproduced with permission from [32].

This catalyst with magnetic nanoparticle support acts as the reducing agent and catalyzes the reductive homocoupling of various aryl halides in the absence of additional reducing agents. A homocoupling reaction in DMF at $110^{\circ} \mathrm{C}$ by using $\mathrm{K}_{2} \mathrm{CO}_{3}$ as the base demonstrated symmetrical biaryls in quantitative yields (Scheme 24). Furthermore, the catalyst can be recycled using a magnetic bar and reused in five consecutive runs. With the application of the catalyst for more than five runes, homocoupling yield was decreased, indicating the diminutive reducing capability of the MNPs. To confirm the possibility of the $\mathrm{Fe}_{3} \mathrm{O}_{4}$ magnetic core acting as a reducing agent, the XRD pattern of the recovered catalyst was analyzed. It indicated oxidation of $\mathrm{Fe}_{3} \mathrm{O}_{4}$ to $\mathrm{Fe}_{2} \mathrm{O}_{3}$ after five cycles and proved the synergetic role of $\mathrm{Fe}_{3} \mathrm{O}_{4}$ as a reducing agent in this process.

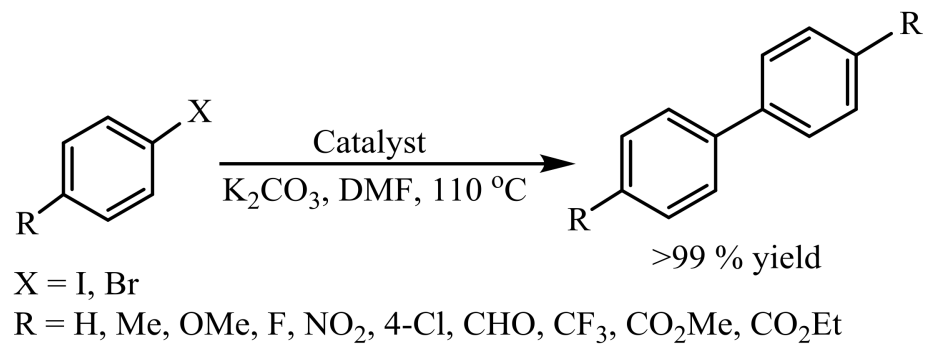

Scheme 24. Homocoupling reaction of aryl halides in the present of magnetic nanoparticle (MNP)-grafted NCN pincer Pd catalyst [32].

Esmaeilpour and co-workers prepared a Schiff base complex of $\mathrm{Pd}(\mathrm{II})$ immobilized on super-paramagnetic $\mathrm{Fe}_{3} \mathrm{O}_{4}$ NPs. The Schiff base complex was prepared by the condensation of 3-aminopropyl (triethoxy) silane with salicylaldehyde in ethanol followed by treatment with palladium acetates. Refluxing the Schiff base complex and silica-coated $\mathrm{Fe}_{3} \mathrm{O}_{4}$ in ethanol yielded the Schiff base complex of $\mathrm{Pd}(\mathrm{II})$ functionalized $\mathrm{Fe}_{3} \mathrm{O}_{4} @ \mathrm{SiO}_{2} \mathrm{NPs}$ (Scheme 25) [33]. 


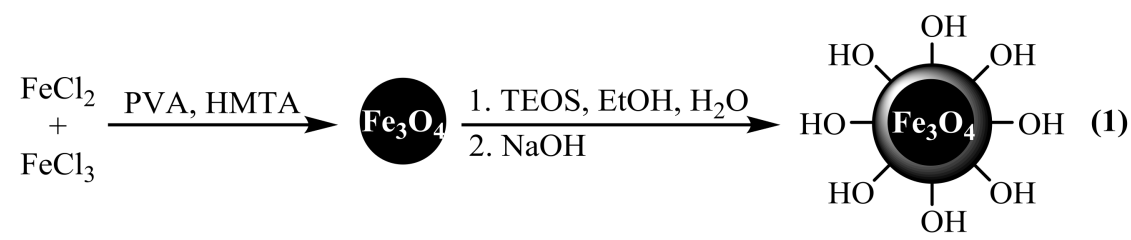<smiles></smiles>

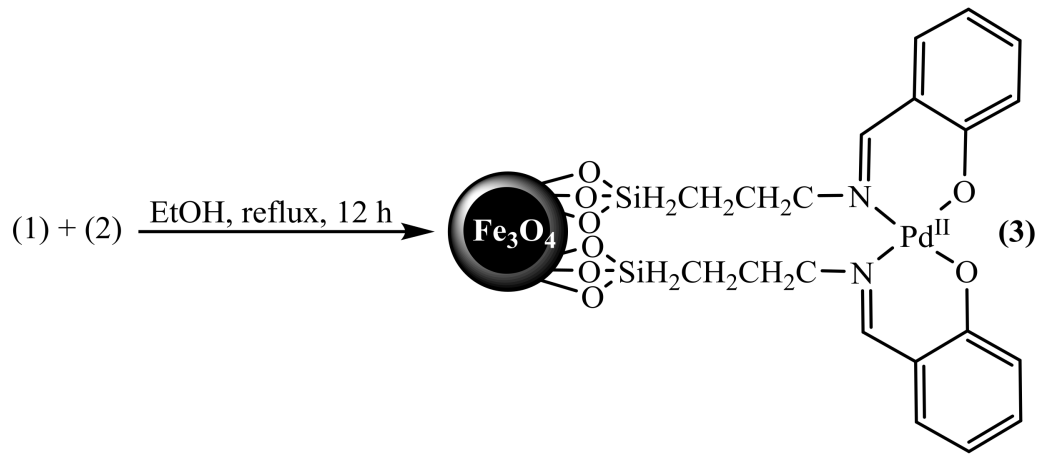

Scheme 25. Preparation process of Schiff base complex of $\mathrm{Pd}(\mathrm{II})$ functionalized $\mathrm{Fe}_{3} \mathrm{O}_{4} @ \mathrm{SiO}_{2} \mathrm{NPs}$. Reproduced with permission from [33].

The heterogenized catalyst was used for copper- and phosphine-free Sonogashira reaction of various substituted aryl halides and phenylacetylene. High yields of diphenyl acetylene as the principal product were obtained in the presence of $\mathrm{NEt}_{3}$ as a base in DMF (Scheme 26). Simplicity of operation, excellent yields, short reaction times, heterogeneous nature, easy magnetic work-up, and recyclability are some notable advantages of this catalyst. Recycling studies showed that the catalyst can be reused at least six times without any noticeable loss of catalytic activity.

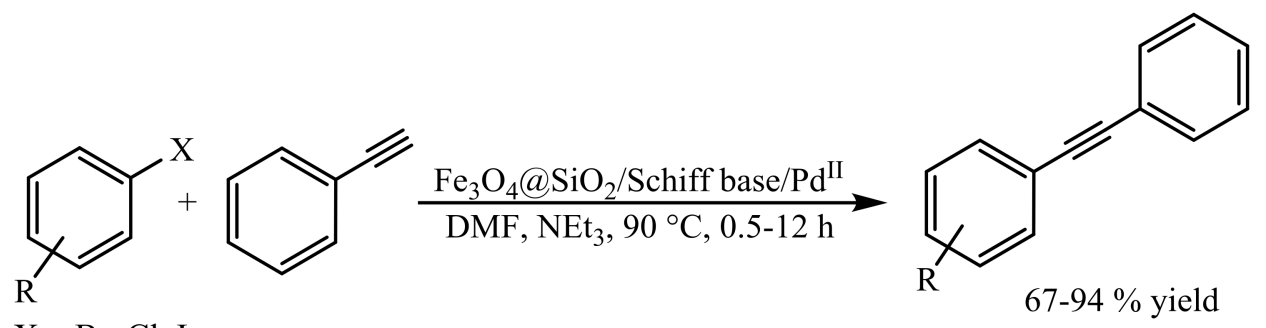

$\mathrm{X}=\mathrm{Br}, \mathrm{Cl}, \mathrm{I}$

$\mathrm{R}=\mathrm{H}, 4-\mathrm{OMe}, 4-\mathrm{NO}_{2}, 4-\mathrm{Me}, 2-\mathrm{Me}, 4-\mathrm{COMe}, 4-\mathrm{CN}$

Scheme 26. Sonogashira-Hagihara coupling reaction in the presence of $\mathrm{Fe}_{3} \mathrm{O}_{4} @ \mathrm{SiO}_{2} / \mathrm{Schiff}$ base/Pd ${ }^{\mathrm{II}}$ [33].

Sobhani and co-workers published a study of a palladium-DABCO complex supported on $\gamma-\mathrm{Fe}_{2} \mathrm{O}_{3}$ magnetic NPs [34]. Surface modification of $\gamma-\mathrm{Fe}_{2} \mathrm{O}_{3}$ magnetite NPs with 3-chloropropyltrimethoxysilane, 
followed by covalent connection with DABCO, led to a fixed ligand system that was coordinated to palladium(II) (Scheme 27).
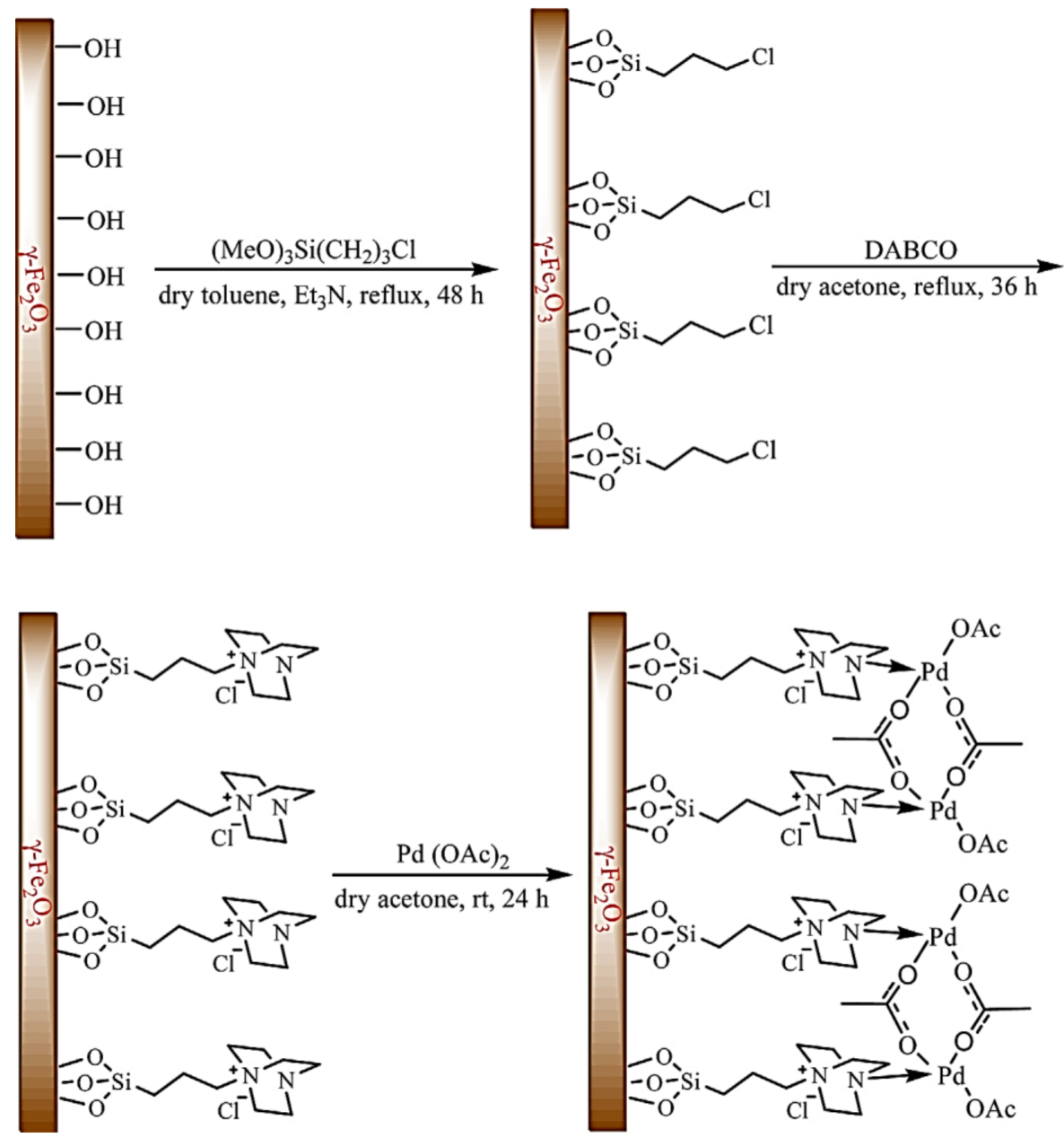

Scheme 27. Synthesis of Pd-DABCO- $\gamma-\mathrm{Fe}_{2} \mathrm{O}_{3}$. Reproduced with permission from [34].

The catalyst Pd-DABCO- $\gamma-\mathrm{Fe}_{2} \mathrm{O}_{3}$ showed high conversions in Heck cross-coupling reaction of aryl halides with alkyl acrylates and styrene. Under optimized reaction conditions, triethylamine $\left(\mathrm{Et}_{3} \mathrm{~N}\right)$ was used as the base at $100^{\circ} \mathrm{C}$, and excellent yields were obtained in solvent-free conditions (Scheme 28). This catalyst system could be reused for at least five runs with little loss of activity; the average isolated yield for five consecutive runs was $90 \%$.

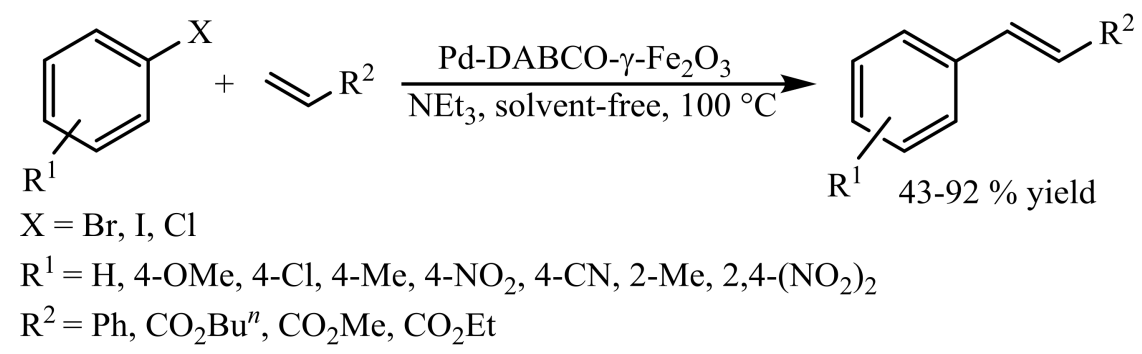

Scheme 28. Heck cross-coupling reaction in the presence of Pd-DABCO- $\gamma-\mathrm{Fe}_{2} \mathrm{O}_{3}$ catalyst [34].

Javidi and co-workers synthesized a series of magnetically separable catalysts for Sonogashira-Hagihara coupling reactions based on $\mathrm{M}(\mathrm{II})$ Schiff base complexes ( $\mathrm{M}=\mathrm{Zn}, \mathrm{Mn}, \mathrm{Cd}, \mathrm{Co}$, $\mathrm{Cu}, \mathrm{Ni}, \mathrm{Fe}$, and $\mathrm{Pd}$ ). $\mathrm{Fe}_{3} \mathrm{O}_{4} \mathrm{NPs}$ were synthesized by a co-precipitation method using polystyrene as the 
surfactant and aqueous $\mathrm{NH}_{3}$ as the precipitant. Modification of $\mathrm{Fe}_{3} \mathrm{O}_{4} \mathrm{NPs}$ via the Stober method using tetraethylorthosilicate (TEOS) resulted in preparation of $\mathrm{Fe}_{3} \mathrm{O}_{4} @ \mathrm{SiO}_{2} \mathrm{NPs}$. Surface functionalization of obtained NPs with Schiff base complexes of various transition metals gave $\mathrm{Fe}_{3} \mathrm{O}_{4} @ \mathrm{SiO}_{2} / \mathrm{Schiff}$ base/M(II) microspheres (Scheme 29) [35].
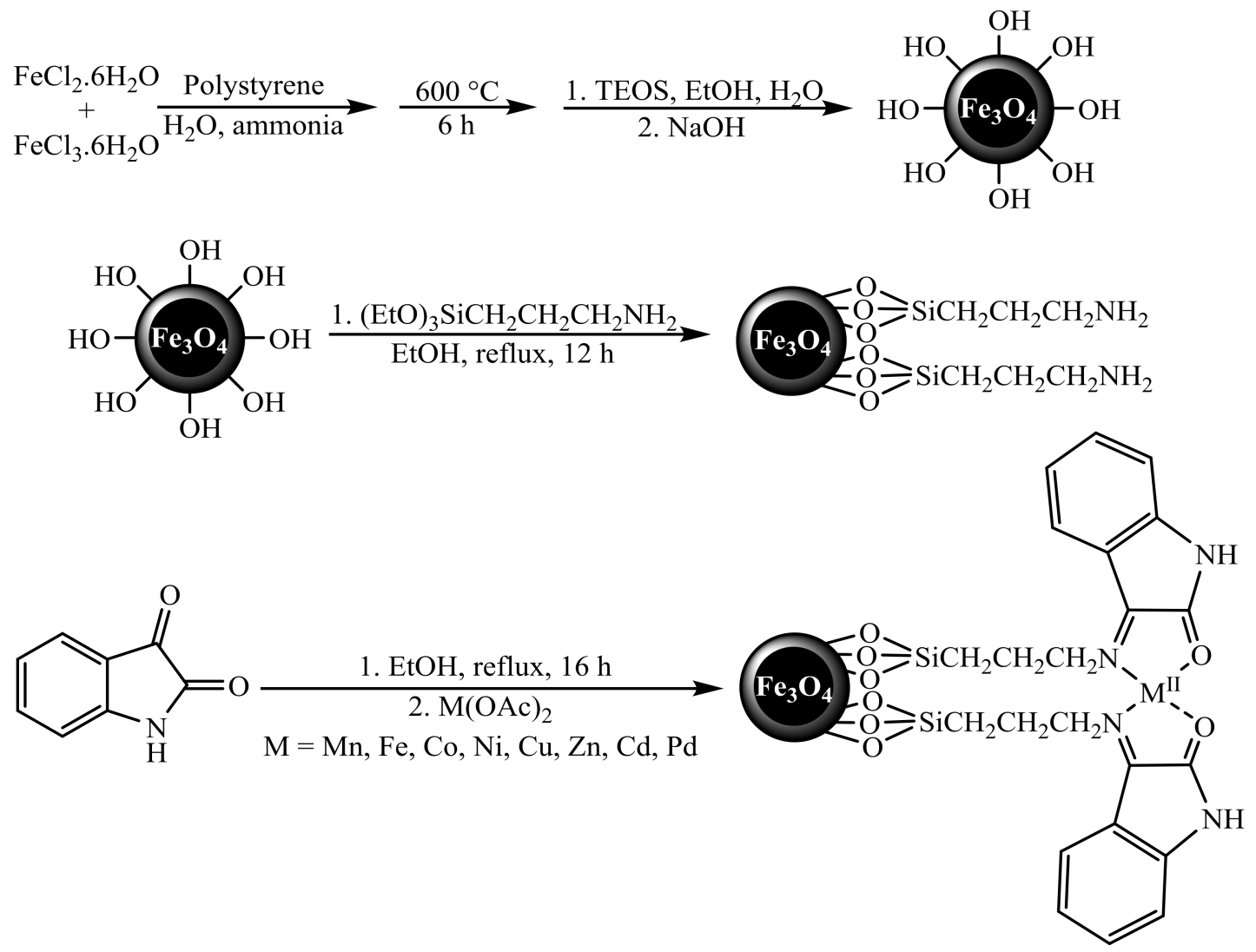

Scheme 29. Preparation process of Schiff base complexes functionalized $\mathrm{Fe}_{3} \mathrm{O}_{4} @ \mathrm{SiO}_{2} \mathrm{NPs}$. Reproduced with permission from [35].

The obtained catalyst was applied in the copper- and phosphine-free Sonogashira coupling reaction of aryl halides with phenylacetylene in the presence of $\mathrm{K}_{2} \mathrm{CO}_{3}$ in DMF at $90{ }^{\circ} \mathrm{C}$ (Scheme 30). Due to the high saturation magnetization of complexes, the catalyst was recovered by a magnetic bar and could be reused six times without significant loss in catalytic activity.

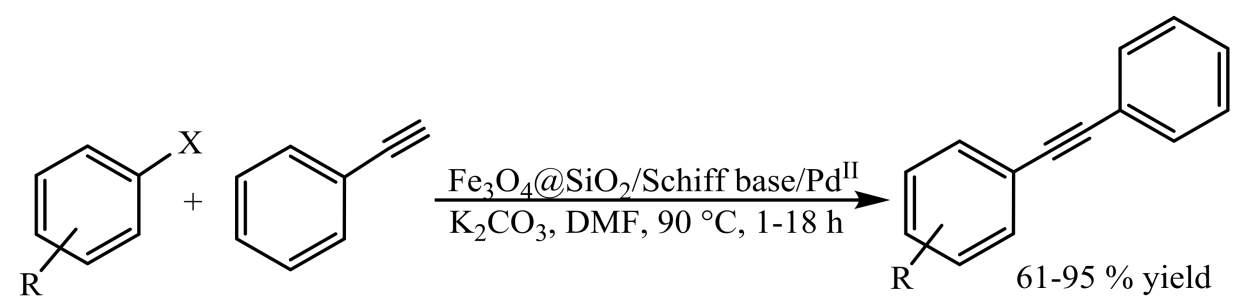

$\mathrm{X}=\mathrm{Br}, \mathrm{Cl}, \mathrm{I}$

$\mathrm{R}=\mathrm{H}$, 4-Me, 2-Me, 4-OMe, 4-CN, 4- $\mathrm{NH}_{2}$, 2-Me-4- $\mathrm{NO}_{2}$, 4-COMe, 4-NO 2 , 1-naphthyl, 3-thienyl, 5-pyrimidinyl

Scheme 30. Sonogashira-Hagihara coupling in the presence of $\mathrm{Fe}_{3} \mathrm{O}_{4} @ \mathrm{SiO}_{2} / \mathrm{Schiff}$ base/Pd(II) [35].

In a separate study, the activity of $\mathrm{Fe}_{3} \mathrm{O}_{4} @ \mathrm{SiO}_{2} / \mathrm{Schiff}$ base/Pd(II) as catalyst for coupling reactions of aryl halides with alkenes (Heck reaction) and phenylboronic acids (Suzuki-Miyaura reaction) was 
investigated. The use of this catalyst in the reaction has notable advantages, including heterogeneous nature of the catalyst, excellent yields, short reaction times, easy preparation, simplicity of operation, and cleaner reaction profiles. Also, recycling studies of the catalyst in Heck and Suzuki-Miyaura reactions revealed that the magnetic catalyst can be reused for eight runs with a slight decline in its catalytic activity (Scheme 31) [36].

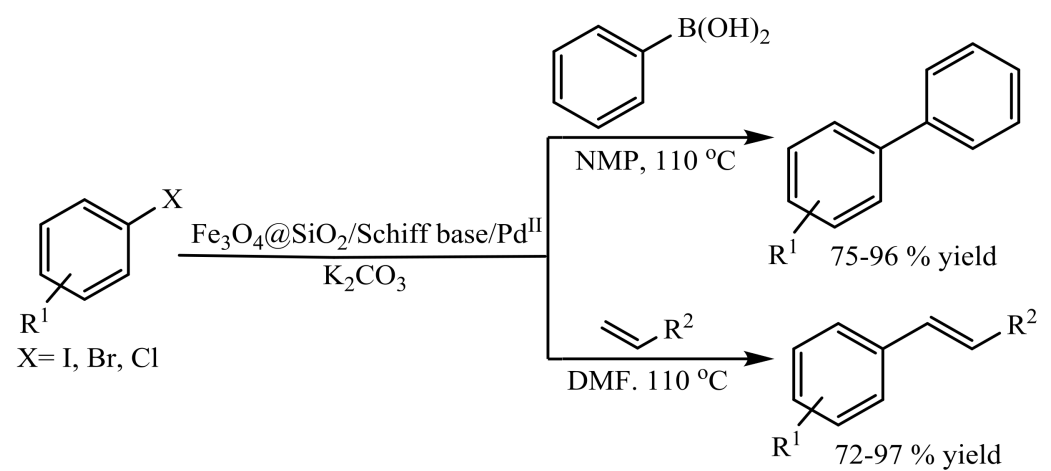

$\mathrm{R}^{1}=\mathrm{H}, 4-\mathrm{Me}, 4-\mathrm{OMe}$, 4-NO $\mathrm{NO}_{2}$, 4-F, 2-Me-4-NO ${ }_{2}$, 1-naphthyl, 2-Me, 3-Me, 4-COMe, 4-CN, 4-Cl, 4-OH, 2,4-Br 2 , 3-thienyl, 5pyrimidinyl, 6-Br-pyrimidinyl, 4,6-dichloro-1,3,5-triazine, 2,4-dibromo-6-((phenylamino)methyl)aniline $\mathrm{R}^{2}=\mathrm{CO}_{2} \mathrm{Bu}^{n}, \mathrm{ph}$

Scheme 31. Heck and Suzuki-Miyaura coupling reactions in the presence of $\mathrm{Fe}_{3} \mathrm{O}_{4} @ \mathrm{SiO}_{2} /$ Schiff base/Pd(II) catalyst [36].

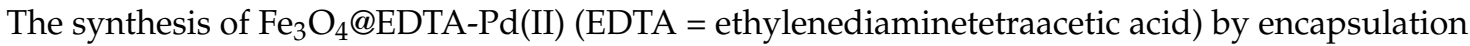
of $\mathrm{Pd}(\mathrm{II})$ into superparamagnetic NPs grafted with EDTA, and its application in Suzuki-Miyaura coupling reaction and reduction of nitro compounds in water was investigated (Scheme 32) [37]. In this work, for the first time, the possibility of using magnetic EDTA as a support for immobilizing metal catalyst was investigated. A TEM image of the obtained catalyst revealed NPs with spherical morphology (Figure 6). Furthermore, the catalyst can be recovered by use of external magnet and reused up to five times with only a very slight decrease in its activity [37].

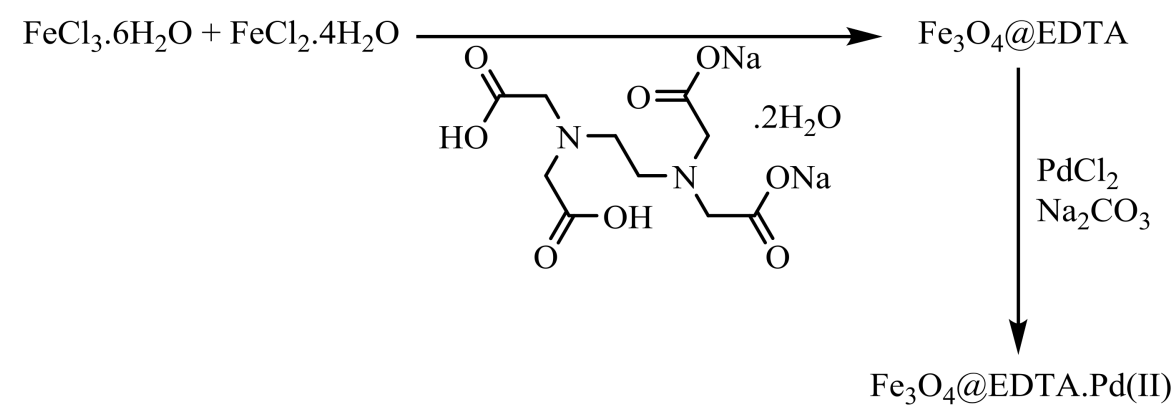

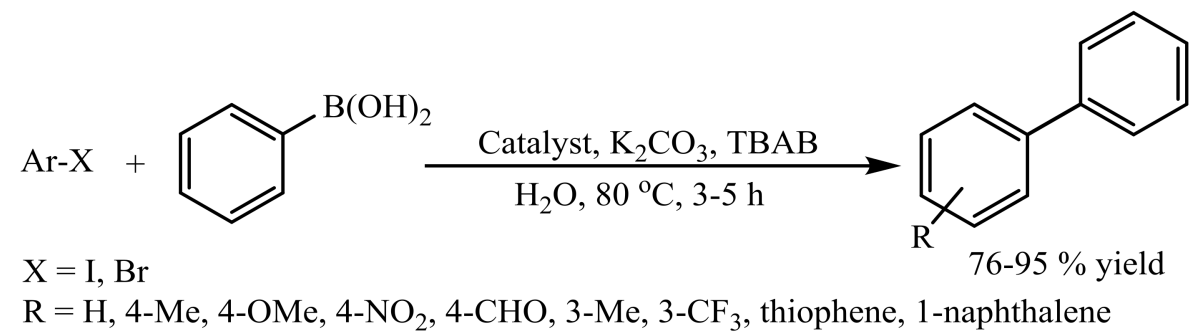

Scheme 32. Preparation of $\mathrm{Fe}_{3} \mathrm{O}_{4} @ E D T A-\mathrm{PdCl}_{2}$ and Suzuki-Miyaura reaction in the presence of the obtained catalyst [37]. 


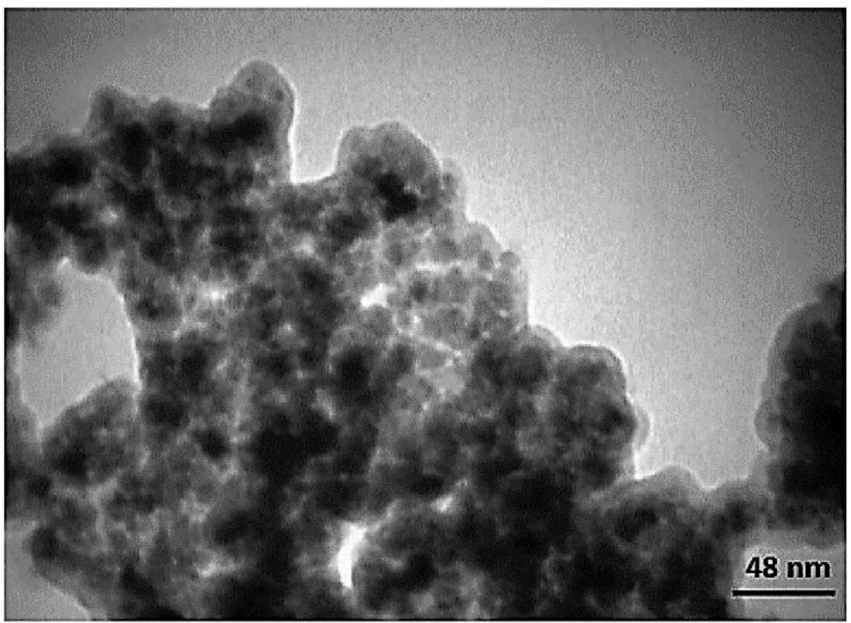

Figure 6. Transmission electron micrograph of $\mathrm{Fe}_{3} \mathrm{O}_{4} @ \mathrm{EDTA}-\mathrm{PdCl}_{2}$. Reproduced with permission from [37].

Cappelletti et al. reported the synthesis of a Pd catalyst witha superparamagnetic $\mathrm{Fe}_{3} \mathrm{O}_{4}$ core and a very thin $\mathrm{Pd}$ shell [38]. $\mathrm{Fe}_{3} \mathrm{O}_{4}$ superparamagnetic NPs (SPNPs) were synthesized through a new strategy whereby very small and narrow size distribution $\mathrm{Fe}_{3} \mathrm{O}_{4} \mathrm{NPs}$ were obtained via replacing iron(III) acetylacetonate $\left(\mathrm{Fe}(\mathrm{Acac})_{3}\right)$ as a metal source with an iron-urea complex (Fe-urea). In this approach, OA was used for stabilization of the $\mathrm{Pd}(0)$ shell (Scheme 33).
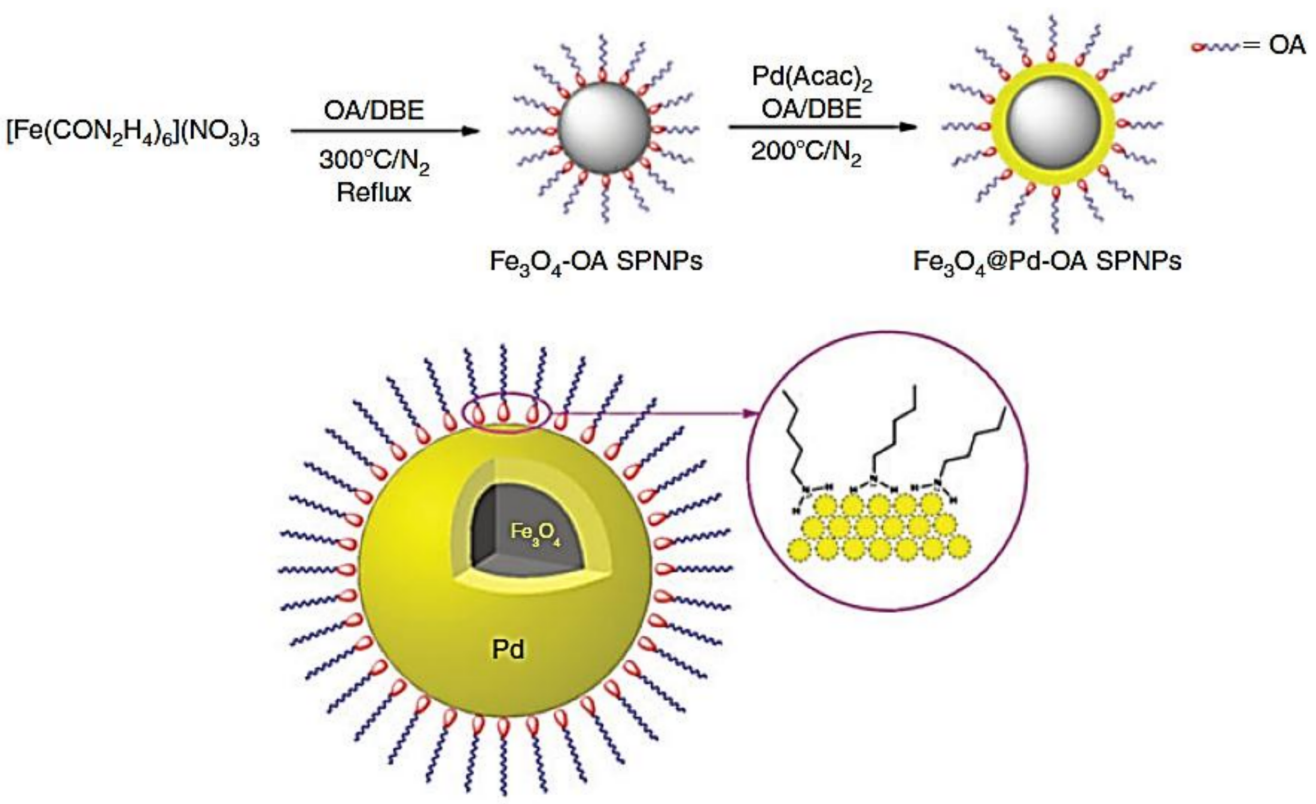

Scheme 33. Synthesis of precursors, $\mathrm{Fe}_{3} \mathrm{O}_{4}$-OA and $\mathrm{Fe}_{3} \mathrm{O}_{4} @ \mathrm{Pd}-\mathrm{OA}$ superparamagnetic nanoparticles (SPNPs) (OA, oleylamine; DBE, dibenzylether). Reproduced with permission from [38].

The resulting catalyst exhibits promising results in the Suzuki-Miyaura coupling reaction of $p$-iodoanisole with boronic acids (Scheme 34). Additionally, the catalyst can be reused for at least four cycles without significant loss in catalytic activity. 


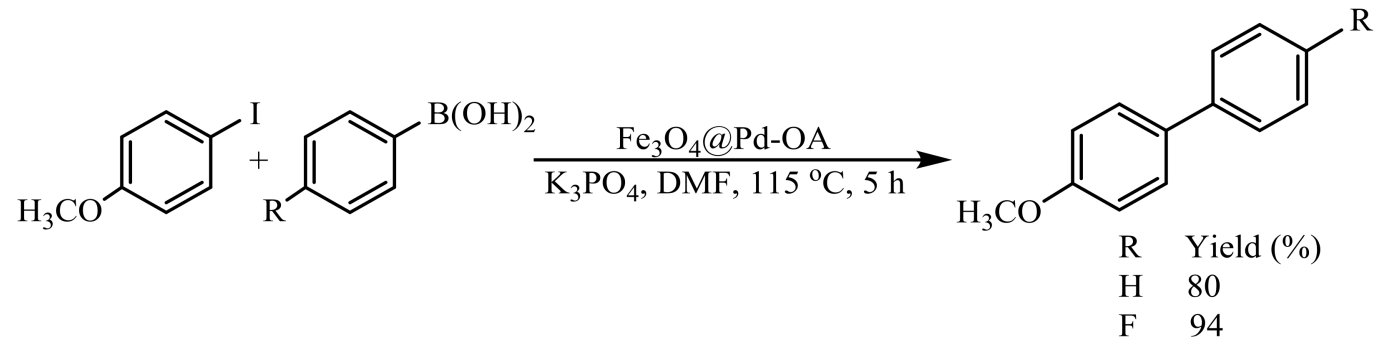

Scheme 34. Suzuki-Miyaura coupling reaction catalyzed by $\mathrm{Fe}_{3} \mathrm{O}_{4} @$ Pd-oleylamine (OA) superparamagnetic. Reproduced with permission from [38].

Singh and co-workers developed a protocol for the immobilization of $\mathrm{Pd} \mathrm{NPs}$ on $\mathrm{NiFe}_{2} \mathrm{O}_{4}$ as a heterogeneous catalyst for Suzuki-Miyaura coupling reaction [39]. $\mathrm{NiFe}_{2} \mathrm{O}_{4} \mathrm{NPs}$ were obtained using a microemulsion method. Functionalization of prepared $\mathrm{NiFe}_{2} \mathrm{O}_{4}$ with Schiff base group demonstrated immobilized bidentate ligand for complexation with Pd (Scheme 35). TEM images of $\mathrm{NiFe}_{2} \mathrm{O}_{4}$ and $\mathrm{Pd}(\mathrm{II})-\mathrm{NiFe}_{2} \mathrm{O}_{4}$ are given in Figure 7, observed aggregation in $\mathrm{Pd}(\mathrm{II})-\mathrm{NiFe}_{2} \mathrm{O}_{4}$ is due to the functionalization of surface with organic materials.

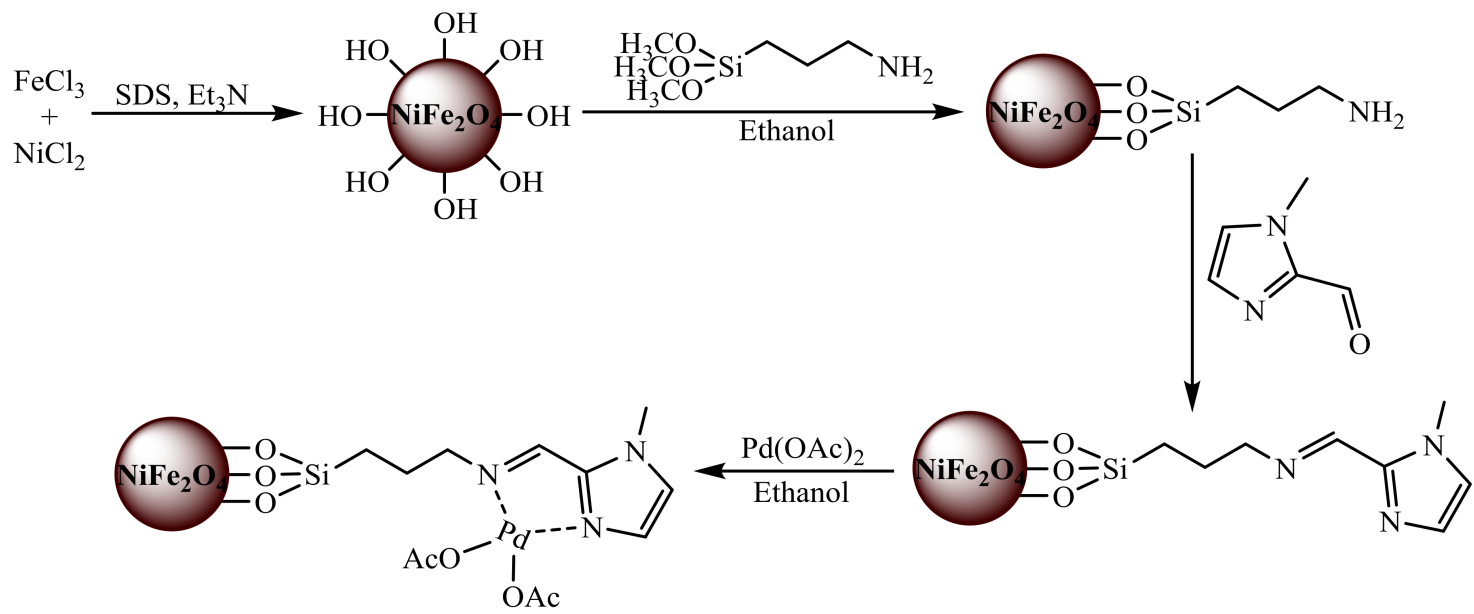

Scheme 35. Synthesis of the palladium catalyst anchored on magnetic NPs. Reproduced with permission from [39].
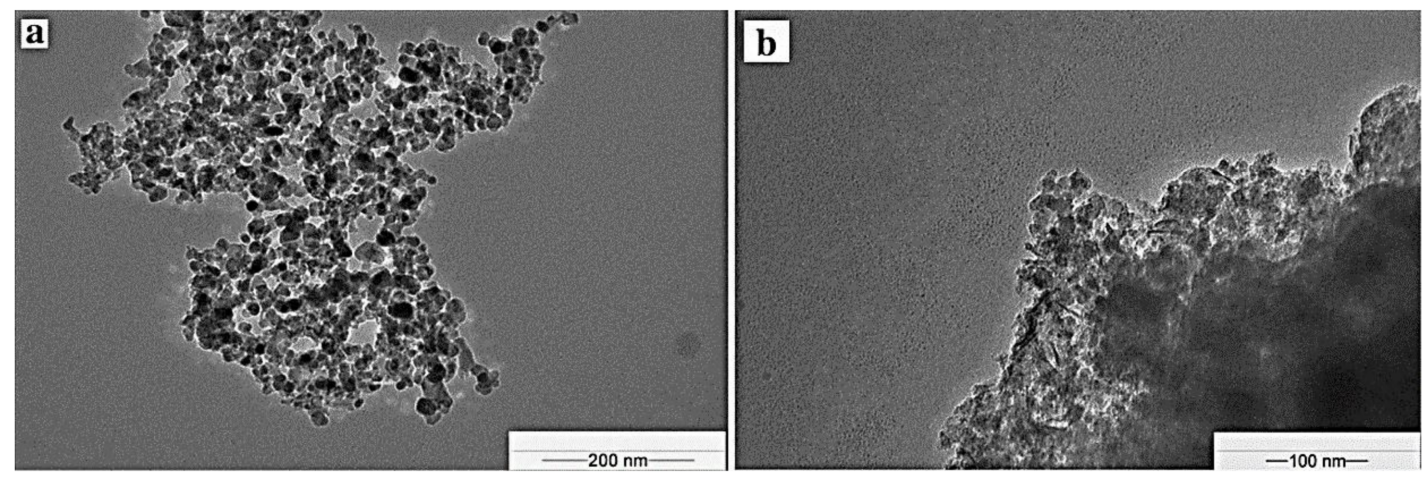

Figure 7. TEM images of (a) $\mathrm{NiFe}_{2} \mathrm{O}_{4} \mathrm{NPs}$, (b) $\mathrm{Pd}(\mathrm{II})-\mathrm{NiFe}_{2} \mathrm{O}_{4}$ catalyst. Reproduced with permission from [39].

The as-prepared catalyst can be applied in coupling reaction of aryl halides with arylboronic acids in the presence of $\mathrm{K}_{2} \mathrm{CO}_{3}$ in $\mathrm{EtOH} / \mathrm{H}_{2} \mathrm{O}$ (9:1) at $80{ }^{\circ} \mathrm{C}$ (Scheme 36). Furthermore, the reusability of the catalyst has been tested for up to five runs with a slight decrease in catalytic activity (99\% to 95\%) [39]. 


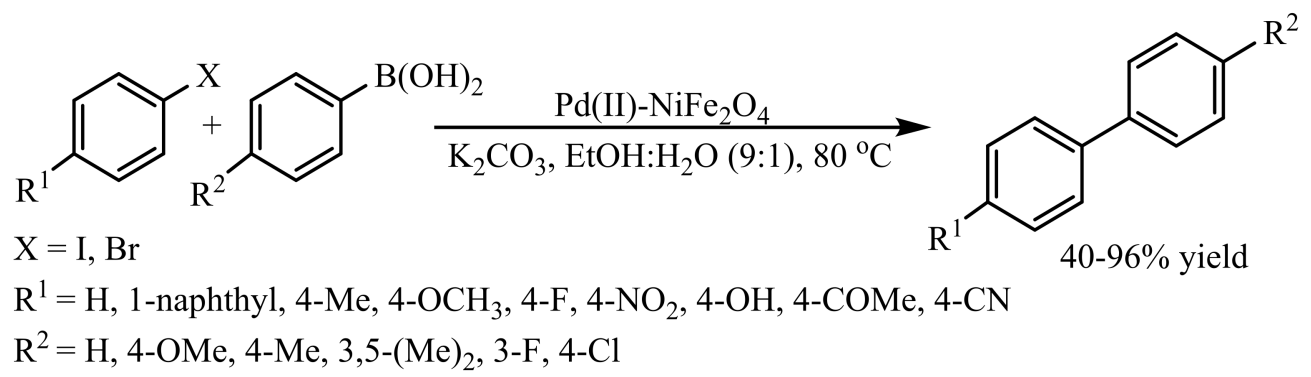

Scheme 36. Suzuki-Miyaura coupling reaction catalyzed by $\mathrm{Pd}(\mathrm{II})-\mathrm{NiFe}_{2} \mathrm{O}_{4}$.

Movassagh and co-workers, by covalent grafting of a trimethoxysilyl-functionalized C22-Pd(II) complex on silica-coated magnetic nanoparticles, prepared a magnetic nanocatalyst and investigated its catalytic activity in the Suzuki-Miyaura coupling reaction and the formation of aryl-sulfur bonds (Scheme 37) [40].

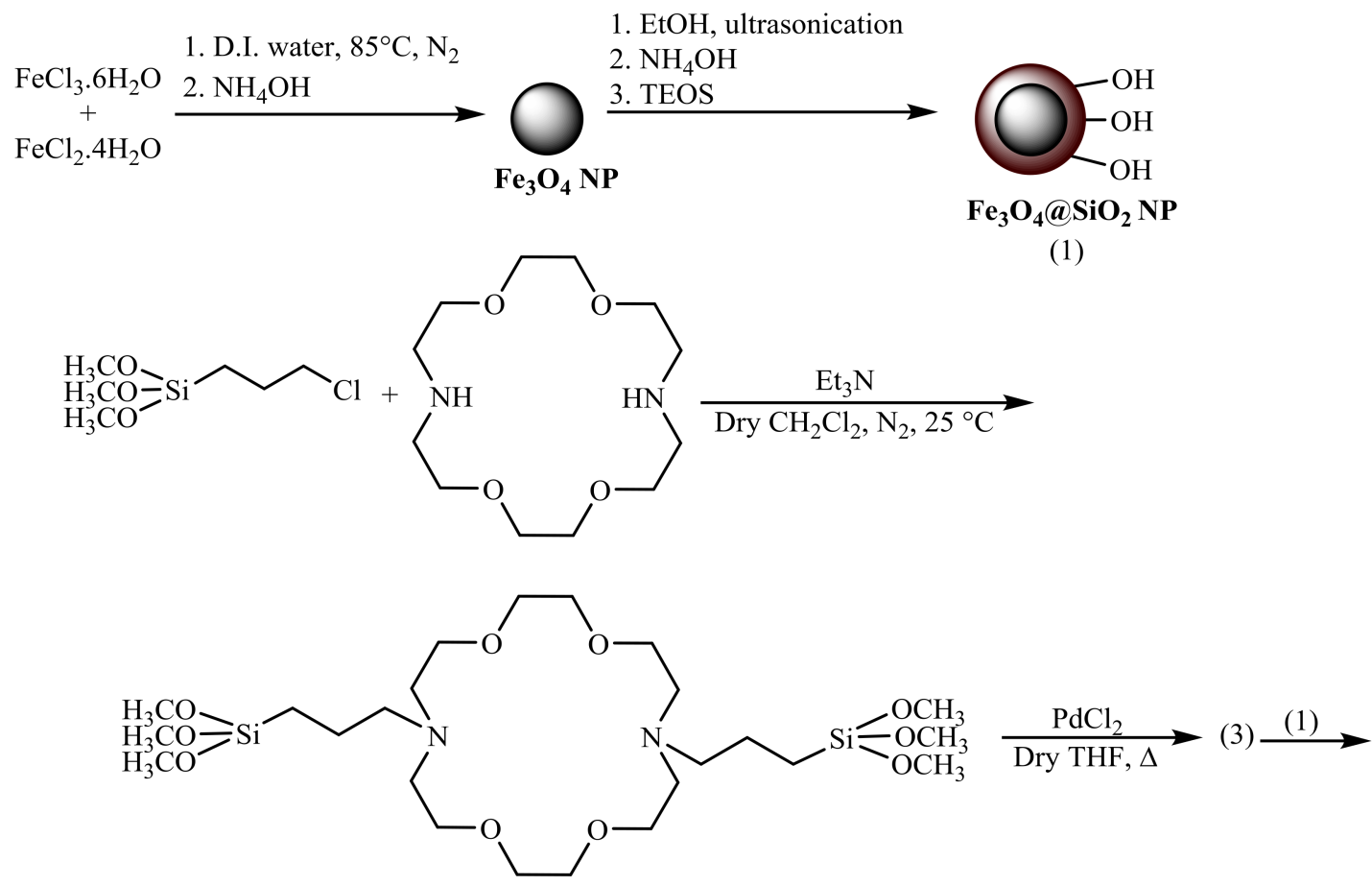

(2)

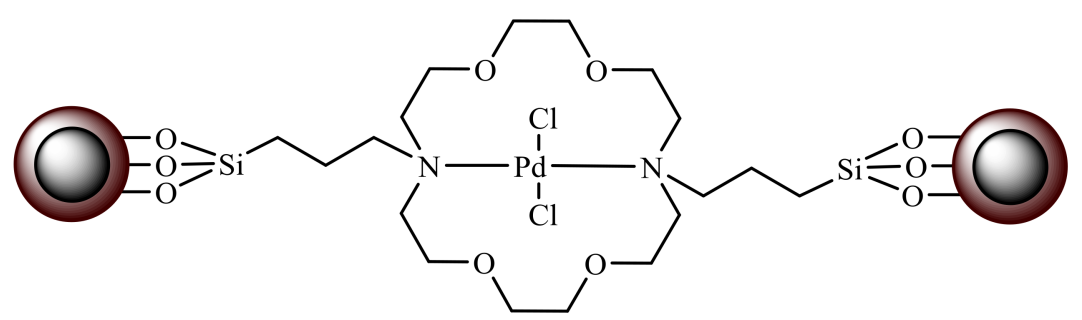

(4)

Scheme 37. Synthetic schemes of $\mathrm{Fe}_{3} \mathrm{O}_{4} \mathrm{NPs}$ and $\mathrm{Fe}_{3} \mathrm{O}_{4} @ \mathrm{SSiO}_{2}$ (1), [(MeO) $\left.)_{3} \mathrm{Si}-\mathrm{Pr}\right]_{2}-\mathrm{C} 22-\mathrm{Pd}(\mathrm{II})$ complex (3), and $\mathrm{Fe}_{3} \mathrm{O}_{4} @ \mathrm{SiO}_{2} @ \mathrm{C} 22-\mathrm{Pd}(\mathrm{II})$ catalyst (4) [40].

In the presence of $0.5 \mathrm{~mol} \%$ of this catalyst, the best results for the coupling of aryl halides with arylboronic acids were obtained with $\mathrm{NEt}_{3}$ as the base in $\mathrm{DMF} / \mathrm{H}_{2} \mathrm{O}(1: 1)$ at $75{ }^{\circ} \mathrm{C}$. This magnetic 
Pd(II)-cryptand 22 complex also showed good activity in the S-arylation coupling reaction in DMSO at $80{ }^{\circ} \mathrm{C}$ (Scheme 38). The use of this catalyst in the reaction offers several advantages, including excellent yields, short reaction time, simplicity of operation, easy separation and recyclability of the magnetic catalyst, and the ability to tolerate a wide variety of substitutions in the reagents. Moreover, the magnetic nanocatalyst could easily be recovered with no considerable change in the activity for five successive runs by magnetic separation, washing with $\mathrm{EtOH}$, and air-drying.

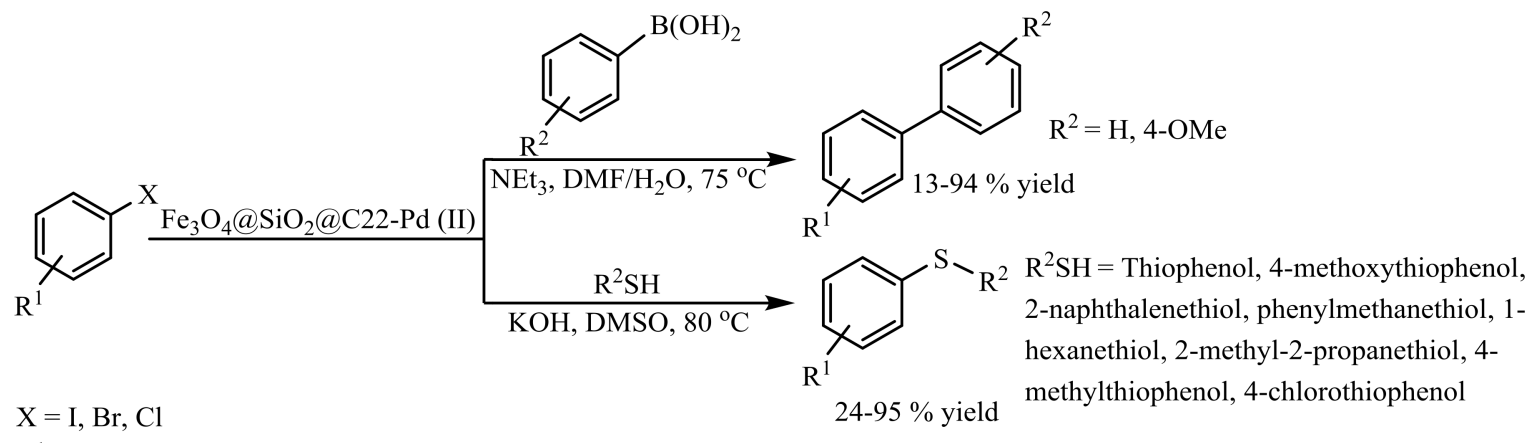

$\mathrm{R}^{1}=\mathrm{H}, 4-\mathrm{I}, 2$-thiophene, 1-naphtalene, 4-CN, 4- $\mathrm{NO}_{2}$, 4- $\mathrm{CH}_{2} \mathrm{OH}$, 4-CHO, 4-OMe, 4-Br, 2-pyridine,

Scheme 38. Suzuki-Miyaura and S-arylation coupling reaction catalyzed by $\mathrm{Fe}_{3} \mathrm{O}_{4} @ \mathrm{SiO}_{2} @ \mathrm{C} 22-\mathrm{Pd}(\mathrm{II})[40]$.

Sobhani and co-workers demonstrated that pyridine-2,6-dicarbaldehyde can be anchored on the surfaces of amino functionalized $\gamma-\mathrm{Fe}_{2} \mathrm{O}_{3} @ \mathrm{SiO}_{2}$ magnetic NPs and form a bis(imino)pyridine as an NNN pincer ligand to stabilize Pd NPs; this report presents the preparation of magnetic Pd-catalyst for Heck, Suzuki-Miyaura, and Sonogashira coupling reactions (Scheme 39) [41]. As shown in Figure 8, the nanocatalyst contained uniform, spherical morphology particles with an average diameter of about $20 \mathrm{~nm}$. TEM images of Pd-BIP- $\gamma-\mathrm{Fe}_{2} \mathrm{O}_{3} @ \mathrm{SiO}_{2}$ displayed a dark $\gamma-\mathrm{Fe}_{2} \mathrm{O}_{3}$ core surrounded by a gray silica shell with a thickness of about $4 \mathrm{~nm}$.
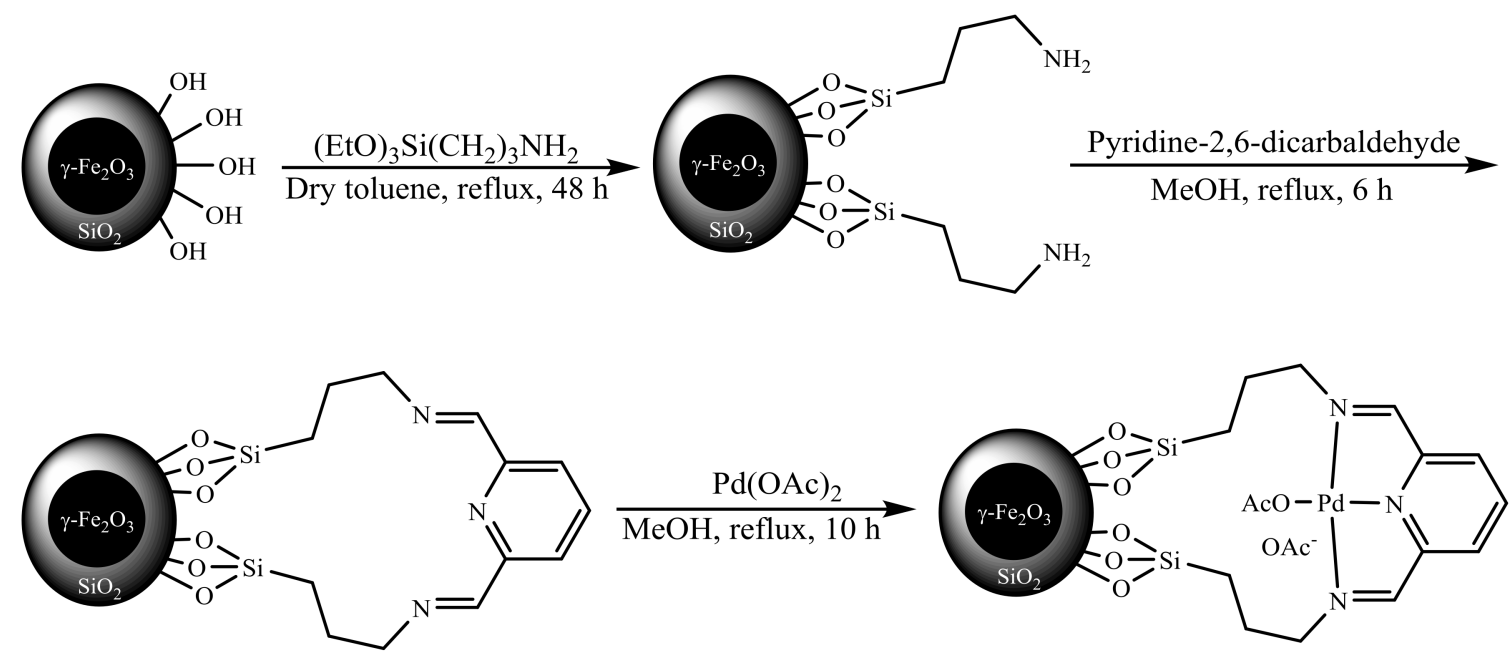

Scheme 39. Synthesis of Pd-BIP- $\gamma-\mathrm{Fe}_{2} \mathrm{O}_{3} @ \mathrm{SiO}_{2}$. Reproduced with permission from [41]. 

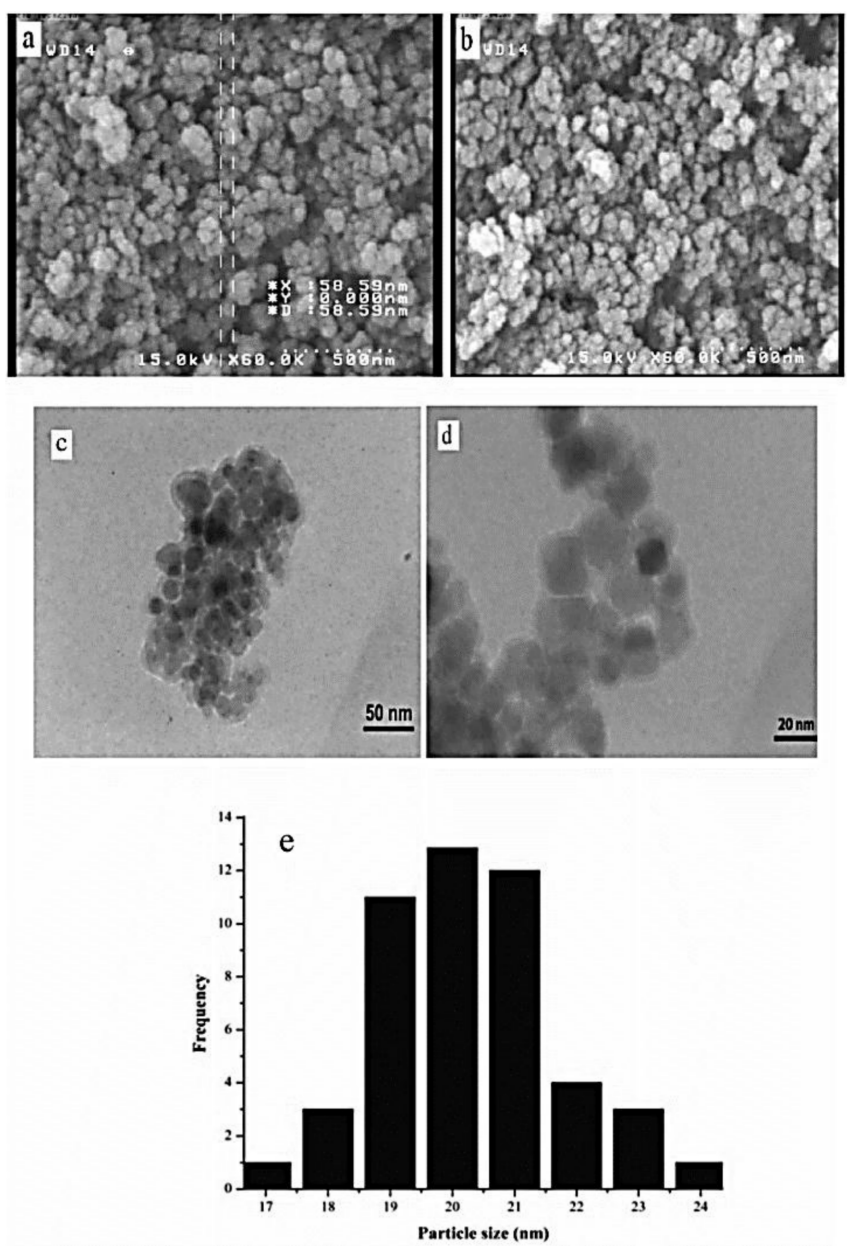

Figure 8. (a,b) SEM images, (c,d) TEM images and (e) particle size distribution histogram of $\mathrm{Pd}-\mathrm{BIP}-\gamma-\mathrm{Fe}_{2} \mathrm{O}_{3} @ \mathrm{SiO}_{2}$. Reproduced with permission from [41].

The air- and moisture-stable Pd catalyst was used in carbon-carbon coupling reactions of aryl halides with olefins, phenylboronic acid and phenylacetylene via Heck, Suzuki-Miyaura, and Sonogashira reactions. A wide range of aryl halides (iodides, bromides, and chlorides) were coupled successfully with alkyl acrylates, styrene, phenylboronic acid, and phenylacetylene to generate the corresponding products in good to high yields (Scheme 40). Pd-BIP- $\gamma-\mathrm{Fe}_{2} \mathrm{O}_{3} @ \mathrm{SiO}_{2}$ could be reused 10 times without any significant loss of its catalytic activity. The TEM image of the catalyst after 10 reuses showed well-dispersed Pd NPs with no evident aggregation (Figure 9) [41].

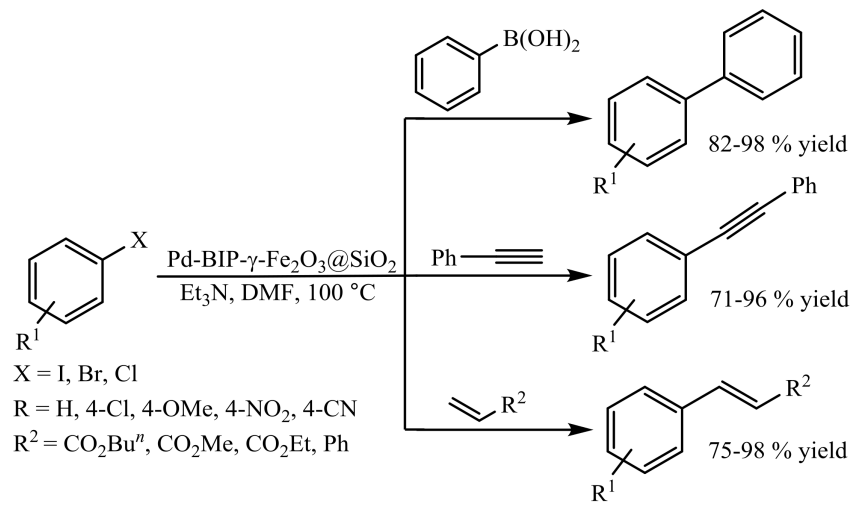

Scheme 40. Heck, Suzuki-Miyaura, and Sonogashira coupling reactions catalyzed by Pd-BIP- $\gamma$ $\mathrm{Fe}_{2} \mathrm{O}_{3} @ \mathrm{SiO}_{2}$ [41]. 


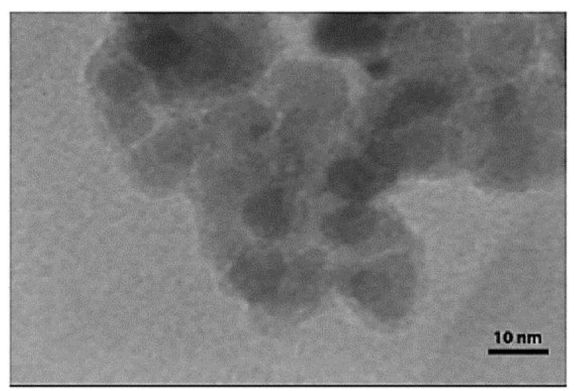

Figure 9. TEM of Pd-BIP- $\gamma-\mathrm{Fe}_{2} \mathrm{O}_{3} @ \mathrm{SiO}_{2}$ after the tenth reuse. Reproduced with permission from [41].

Karami and co-workers describe a recyclable oxime-derived palladacycle immobilized on a highly active $\mathrm{Fe}_{3} \mathrm{O}_{4}$ / oleic acid solid support for the copper-free Sonogashira cross-coupling reaction [42]. The procedure for the preparation of catalyst is shown in Scheme 41. First, oleic acid-coated $\mathrm{Fe}_{3} \mathrm{O}_{4}$ NPs were synthesized and then oxime-derived palladacycle was added to a mixture of $\mathrm{Fe}_{3} \mathrm{O}_{4}$ /oleic acid and ethanol; finally, hydrazine hydrate was dropped onto the mixture to generate a $\mathrm{Fe}_{3} \mathrm{O}_{4}$ / oleic acid/Pd catalyst. A TEM image of catalyst revealed that the palladium NPs were well dispersed on the surface of the $\mathrm{Fe}_{3} \mathrm{O}_{4}$ /oleic acid NPs with diameters from 5 to $10 \mathrm{~nm}$ and an average size of about $9.97 \mathrm{~nm}$ (Figure 10).

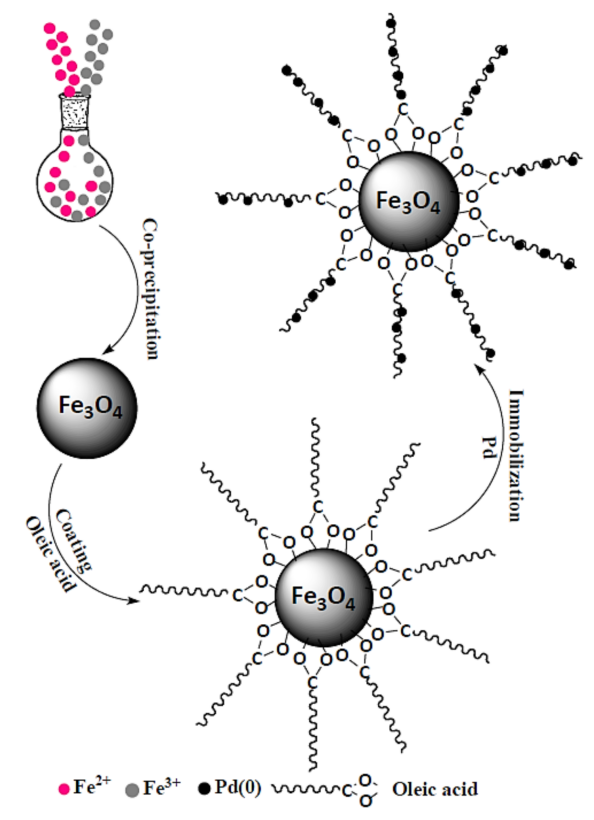

Scheme 41. Schematic of the preparation of the $\mathrm{Fe}_{3} \mathrm{O}_{4} /$ oleic acid/Pd nanocatalyst. Reproduced with permission from [42].

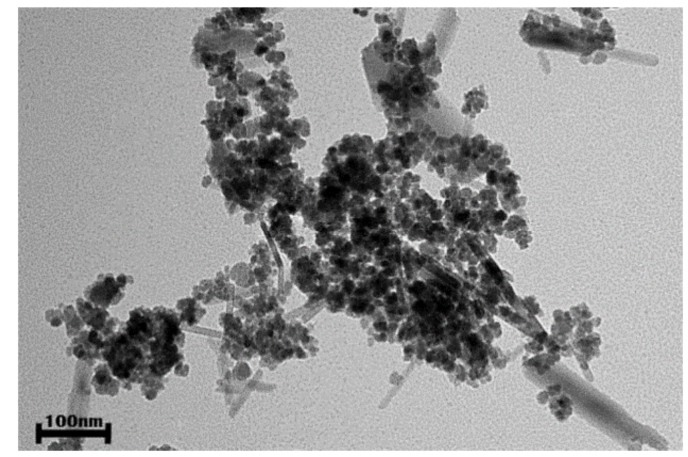

Figure 10. TEM image of $\mathrm{Fe}_{3} \mathrm{O}_{4}$ /oleic acid/Pd. Reproduced with permission from [42]. 
The activity of these supported Pd catalysts has been evaluated in a copper-free Sonogashira cross-coupling reaction between various aryl halides with phenylacetylene, whose products were obtained in high yields (Scheme 42). The $\mathrm{Fe}_{3} \mathrm{O}_{4}$ /oleic acid/Pd can be reused more than six times without loss of its activity.

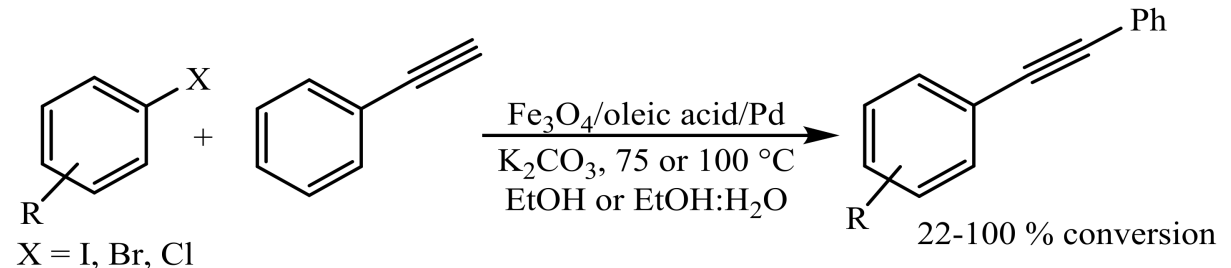

$\mathrm{R}=\mathrm{H}$, 4- $\mathrm{NH}_{2}$, 4-Me, 4-CHO, 3- $\mathrm{NO}_{2}$, 1-naphthyl, 1-thiophene, 4-COMe, 4-Br, 2-pyridinyl, 4- $\mathrm{NO}_{2}$

Scheme 42. Sonogashira cross-coupling reactions of various aryl halides with phenylacetylene catalyzed by $\mathrm{Fe}_{3} \mathrm{O}_{4}$ /oleic acid/Pd [42].

Ghorbani-Choghamarani and co-workers modified the surface of silica-coated $\mathrm{Fe}_{3} \mathrm{O}_{4} \mathrm{NPs}$ with a tridentate-Pd complex. Magnetic NPs were prepared through the coprecipitation method; coating these nanoparticles with tridentate ligand gave functionalized magnetic NPs whose subsequent reaction of $\mathrm{Pd}(\mathrm{OAc})_{2}$ with these immobilized ligands resulted in $\mathrm{Fe}_{3} \mathrm{O}_{4} @ \mathrm{PTA}-\mathrm{Pd}$ as a recyclable and efficient nanocatalyst (Scheme 43) [43]. The focus of the present research was on the investigation of the recycling, reusability, and stability of the catalyst.
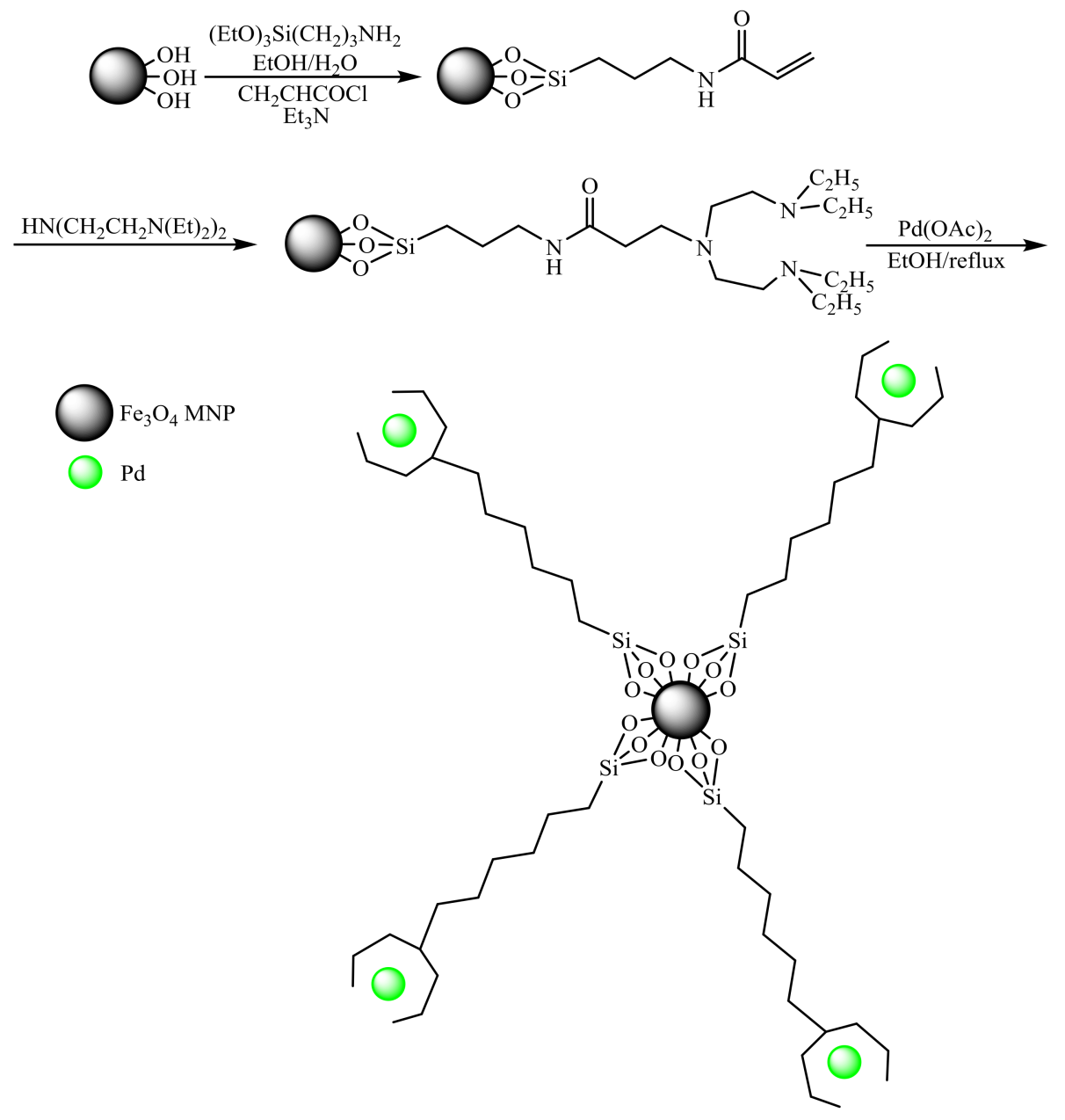

Scheme 43. Synthesis of $\mathrm{Fe}_{3} \mathrm{O}_{4} @ P T A-P d$ nanocatalyst [43]. 
The $\mathrm{Fe}_{3} \mathrm{O}_{4} @ \mathrm{PTA}-\mathrm{Pd}$ nanocatalyst was applied in Suzuki-Miyaura, Stille, and Heck cross-coupling reactions of aryl halides with tetrephenylborate, phenylboronic acid, and chlorotriphenylstannane in green solvents, which showed corresponding products in good to excellent yields. The reusability of the catalyst was investigated in a final set of experiments: after completion of the reactions, the catalyst was easily separated magnetically and reused at least five times without any significant loss in its activities. ICP-OES analysis of the recycled catalyst showed minor changes in Pd contents $(1.64 \mathrm{mmol} / \mathrm{g})$, in which only $1 \%$ leaching was observed (Scheme 44 ).

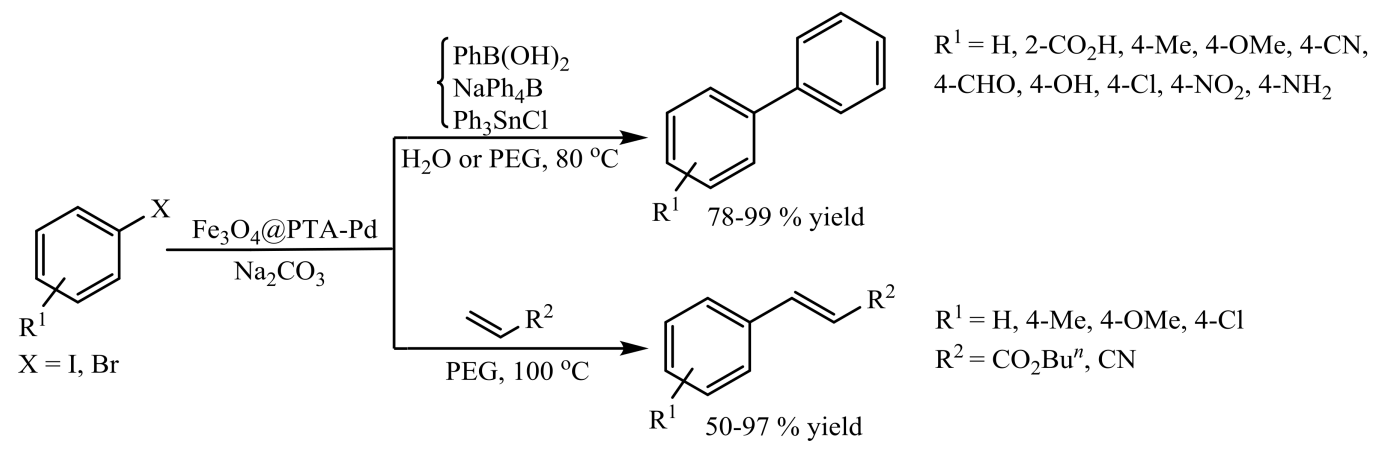

Scheme 44. Suzuki-Miyaura, Stille, and Heck cross-coupling reactions catalyzed by $\mathrm{Fe}_{3} \mathrm{O}_{4} @ P T A-P d$ nanocatalyst [43].

Asadi and co-workers synthesized a catalyst for Heck and Sonogashira reactions based on NNN Pd-complex supported on silica coated magnetic NPs (MNPs) by treatment of the magnetic NPs with (3-chloropropyl)-trimethoxysilane (3-CPTMS), followed by covalent connection with synthetic NNN ligand, gave a CPS-MNPs-NNN ligand for the formation of a complex with palladium. Finally, immobilization of the palladium species on the CPS-MNPs-NNN ligand surface afforded a CPS-MNPs-NNN-Pd catalyst (Scheme 45) [44]. TEM images of the prepared catalyst showed that the sizes of the palladium catalyst are in the range of 8-15 $\mathrm{nm}$ (Figure 11).

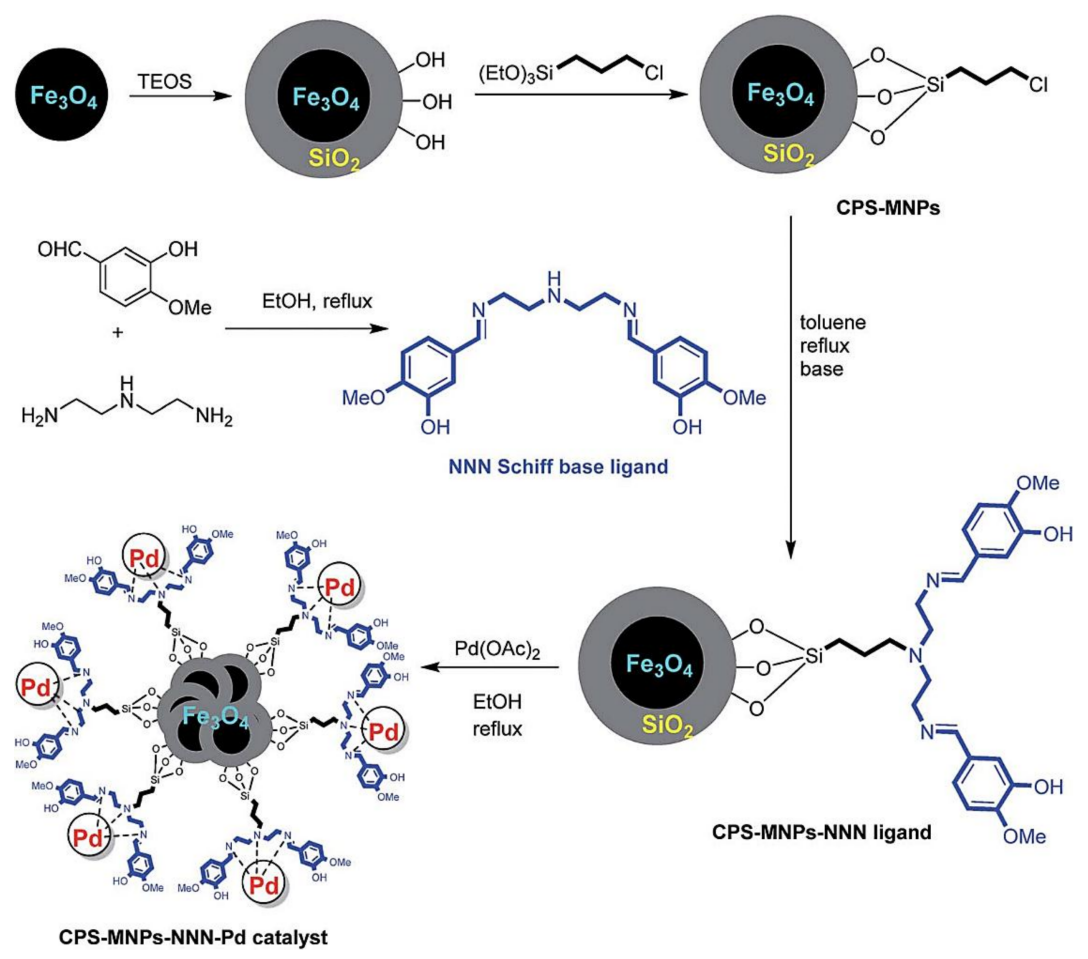

Scheme 45. A schematic illustration the preparation of CPS-MNPs-NNN-Pd catalyst. Reproduced with permission from [44]. 


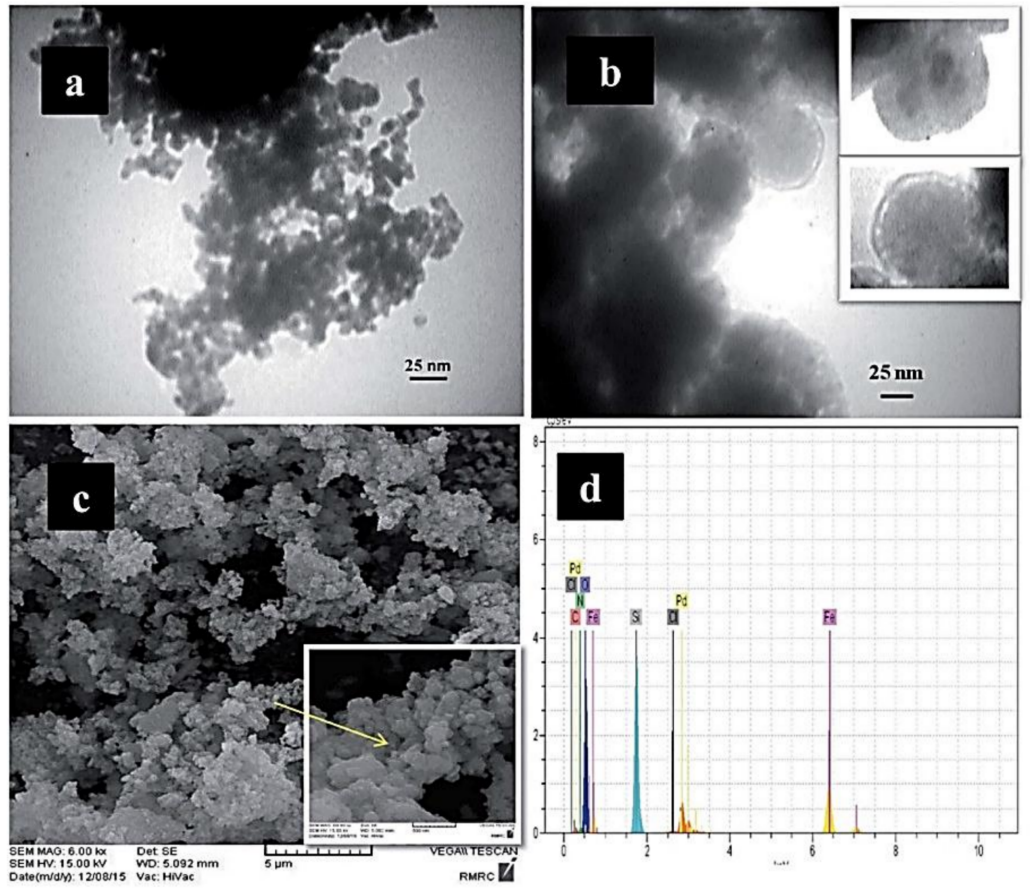

Figure 11. TEM pictures of the CPS-MNPs-NNN-Pd catalyst (a,b), SEM image of the CPS-MNPsNNN-Pd catalyst (c), EDX pattern of CPSMNPs-NNN-Pd catalyst (d). Reproduced with permission from [44].

The CPS-MNPs-NNN-Pd complex, an air- or moisture-stable catalyst was applied in C-C coupling protocols, namely Heck and Sonogashira reactions. Firstly, the catalyst was tested for Heck coupling reaction of various aryl halides with alkenes in the presence of $\mathrm{K}_{2} \mathrm{CO}_{3}$ as a base in DMF/ $\mathrm{H}_{2} \mathrm{O}(1: 2)$ at $90^{\circ} \mathrm{C}$. Furthermore, the catalyst was tested in the Sonogashira coupling reaction of various substituted aryl halides with phenylacetylene under similar conditions and generated the corresponding products in good to excellent yields (Scheme 46). A recycling experiment was performed in the Heck reaction of iodobenzene with $n$-butyl acrylate, after magnetic separation of catalyst and washing with ethanol, the catalyst was used directly in the next run and could be recycled at least five times with a negligible loss in its catalytic activity and negligible amount of Pd leaching (0.3 ppm). The TEM image of used catalyst in Figure 12 shows no morphology change of the catalyst after four runs.

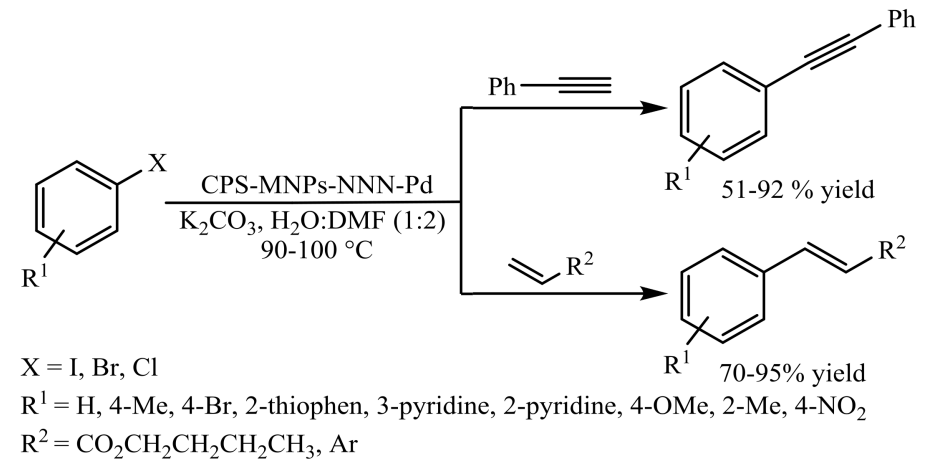

Scheme 46. Heck and Sonogashira coupling reactions in the present of CPS-MNPs-NNN-Pd catalyst [44]. 


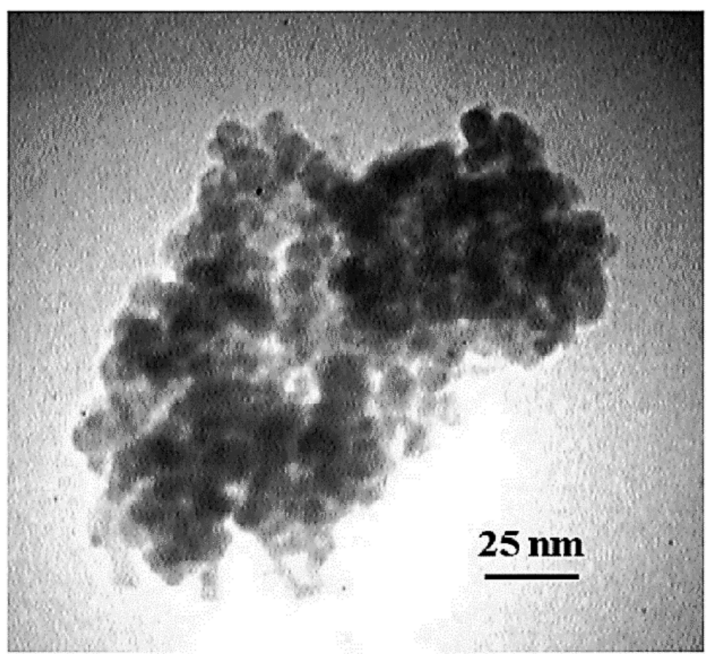

Figure 12. TEM image of CPS-MNPs-NNN-Pd catalyst after four cycles in the Heck reaction of iodobenzene with $n$-butyl acrylate. Reproduced with permission from [44].

Sobhani and co-workers reported a palladium-Schiff base complex covalently immobilized on magnetic NPs for Heck and Suzuki-Miyaura cross-coupling reactions [45]. Reaction of chloro-functionalized $\gamma-\mathrm{Fe}_{2} \mathrm{O}_{3}$ with iminopyridine, followed by addition of palladium acetate, led to preparation of the Pd-imino-Py- $\gamma-\mathrm{Fe}_{2} \mathrm{O}_{3}$ catalyst (Scheme 47). The uniform and spherical morphology of MNPs with an average diameter of about $15 \mathrm{~nm}$ was revealed from SEM and TEM images (Figure 13).

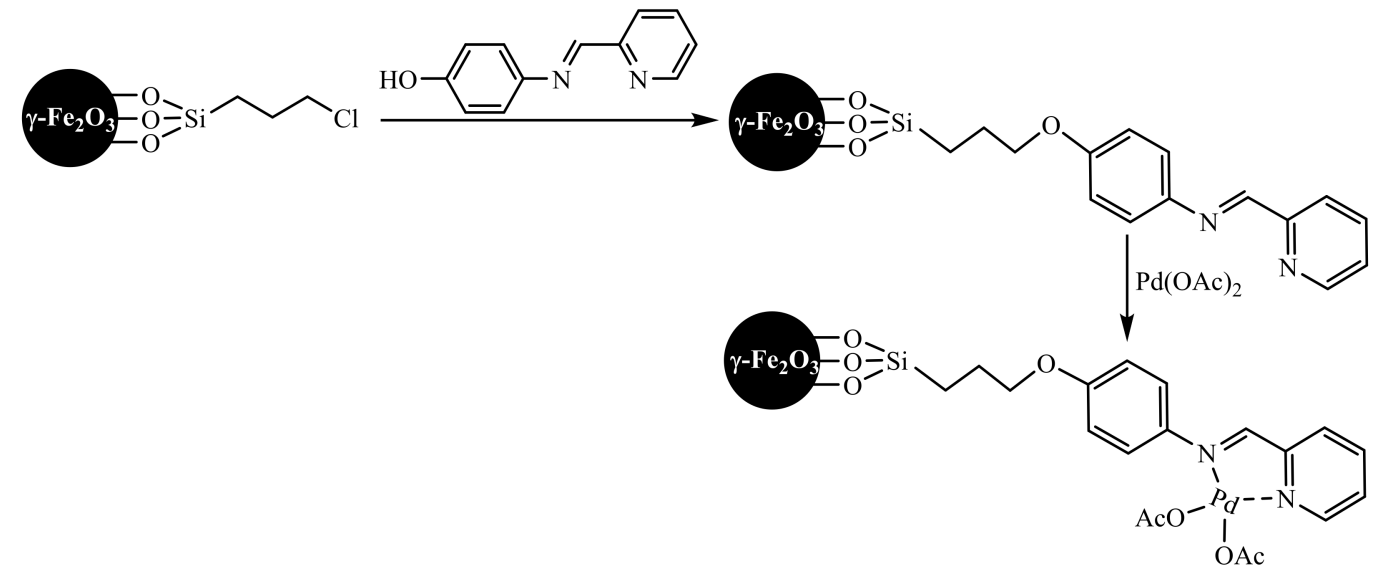

Scheme 47. Synthesis of $\mathrm{Pd}$-imino- $\mathrm{Py}-\gamma-\mathrm{Fe}_{2} \mathrm{O}_{3}$.
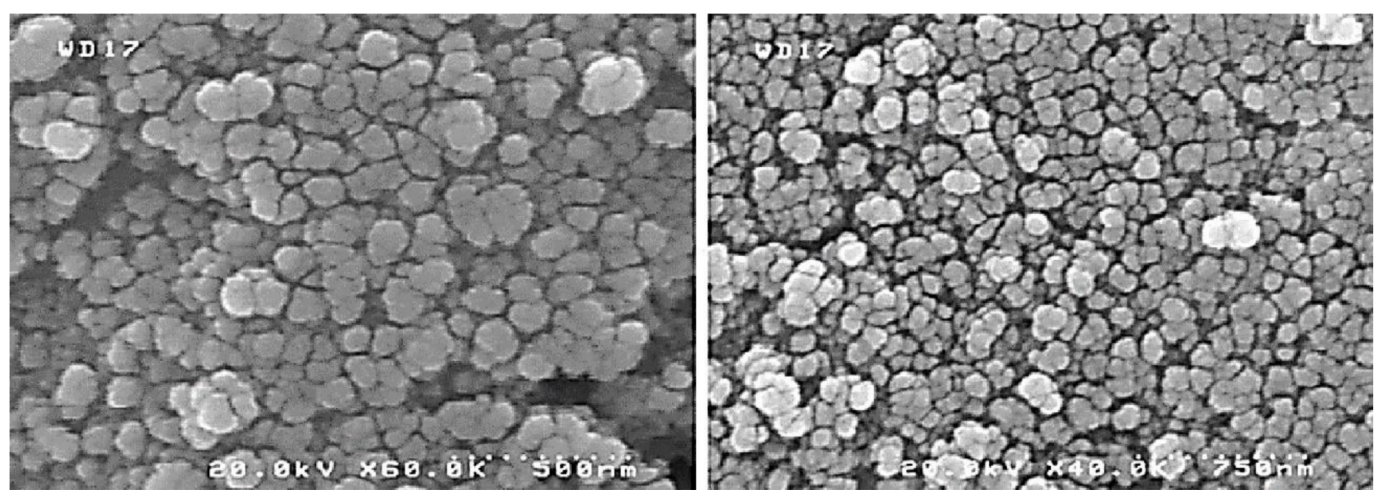

Figure 13. Cont. 


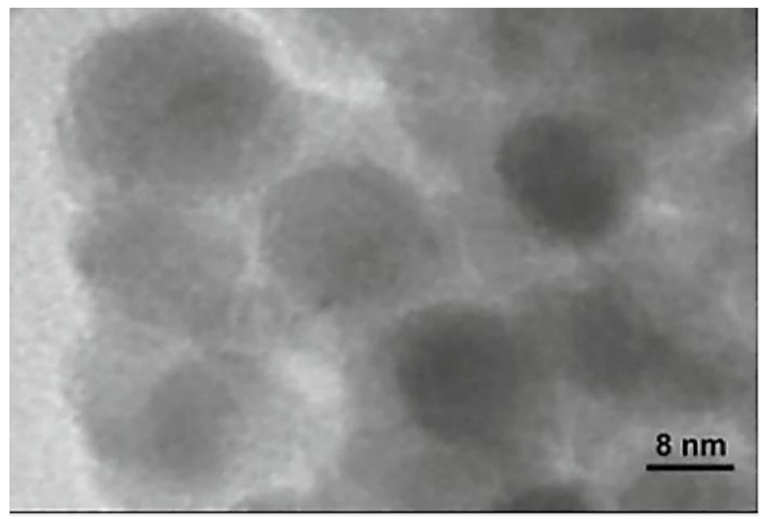

Figure 13. SEM and TEM images of Pd-imino-Py- $\gamma-\mathrm{Fe}_{2} \mathrm{O}_{3}$. Reproduced with permission from [45].

The heterogenized catalyst was first tested for Heck coupling reaction of various aryl halides with olefins in the presence of $\mathrm{Et}_{3} \mathrm{~N}$ as a base in DMF at $100{ }^{\circ} \mathrm{C}$. Furthermore, the catalyst was tested in the Suzuki-Miyaura coupling reaction of various substituted aryl halides with arylboronic acids under similar conditions as for the Heck reaction (Scheme 48). As magnetic nanoparticles were used as the solid support, the present catalyst was simply separated from the reaction mixture by an external magnet, and reused for at least eight runs without Pd leaching $(<1 \%)$ and appreciable loss of its catalytic activity. TEM image of used catalyst in Figure 14 showed no morphology change of the catalyst after eight recoveries.

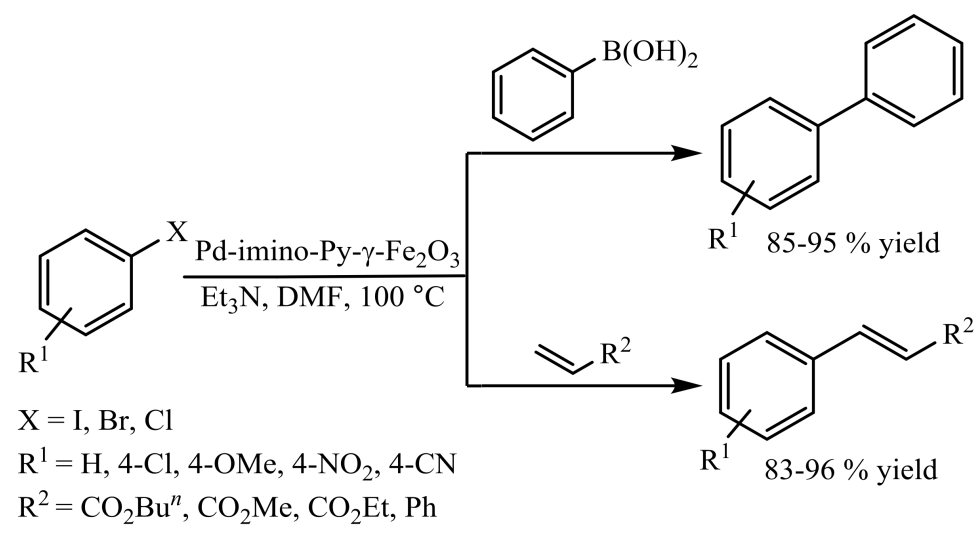

Scheme 48. Suzuki-Miyaura and Heck cross-coupling reactions catalyzed by $\mathrm{Pd}$-imino-Py- $\gamma-\mathrm{Fe}_{2} \mathrm{O}_{3}$ nanocatalyst [45].

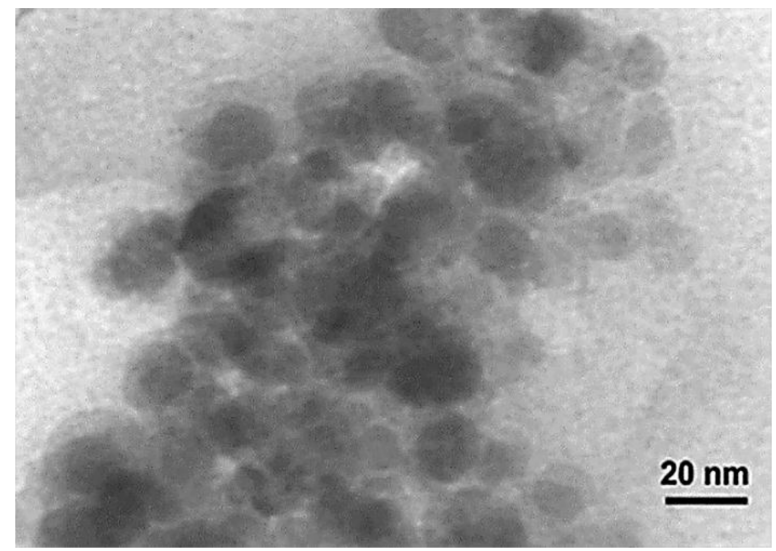

Figure 14. TEM image of Pd-imino-Py- $\gamma-\mathrm{Fe}_{2} \mathrm{O}_{3}$ after eight reuses. Reproduced with permission from [45]. 
In a separate study, the Pd-imino-Py- $\gamma-\mathrm{Fe}_{2} \mathrm{O}_{3}$ nanocatalyst was also employed for the synthesis of arylphosphonates via a $\mathrm{C}_{\mathrm{sp} 2}-\mathrm{P}$ coupling reaction in water, affording the coupling products in high yields [46]. The recyclability of the catalyst was investigated in the reaction of iodobenzene and triethylphosphite. After completion of the reaction, the catalyst could simply be recovered from the reaction mixture with a magnetic bar; after washing with EtOAc and drying, it was applied for the next reaction and showed good yield for eight runs. ICP analysis of the catalyst after eight runs showed that less than $1 \%$ of Pd metal was removed from the catalyst (Scheme 49).

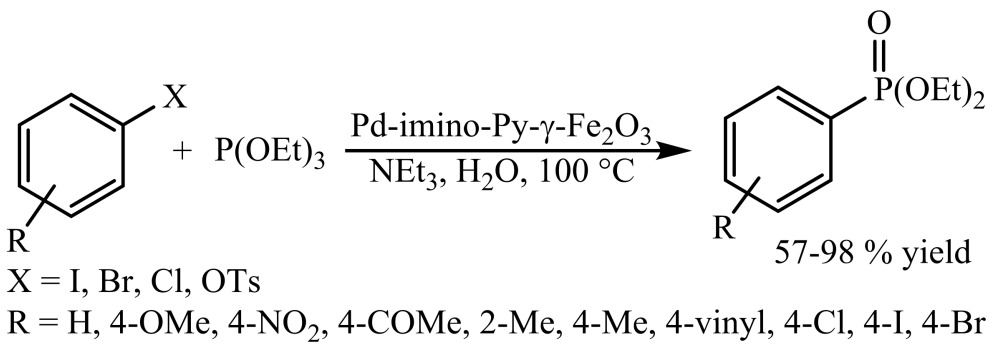

Scheme 49. Synthesis of arylphosphonates via $\mathrm{C}_{\mathrm{sp2}}-\mathrm{P}$ coupling reaction catalyzed by Pd-imino-Py$\gamma-\mathrm{Fe}_{2} \mathrm{O}_{3}$.

Panahi et al. reported the synthesis of a new magnetic reusable phosphorous ligand for the preparation of phosphanamine-functionalized magnetic NPs (PAFMNP) [47]. PAFMNP was obtained by reaction of phosphanamine-functionalized trimethoxysilyl compound (DPPPA) with magnetic NPs. The obtained material reacted with palladium chloride, leading to an efficient magnetic recyclable Pd catalyst (Scheme 50). TEM images of the Pd-PAFMNP catalyst showed nearly spherical NPs with an average particle size of $25 \mathrm{~nm}$ and good monodispersity (Figure 15).

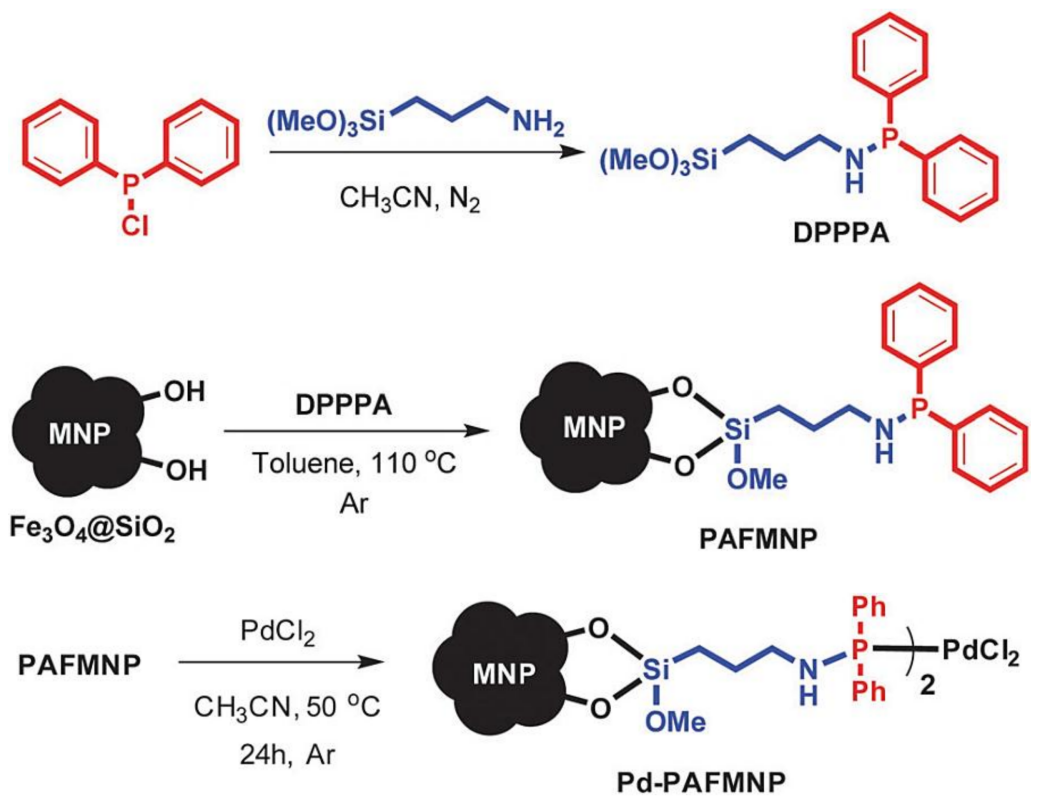

Scheme 50. Synthesis of the Pd-PAFMNP catalyst. Reproduced with permission from [47]. 

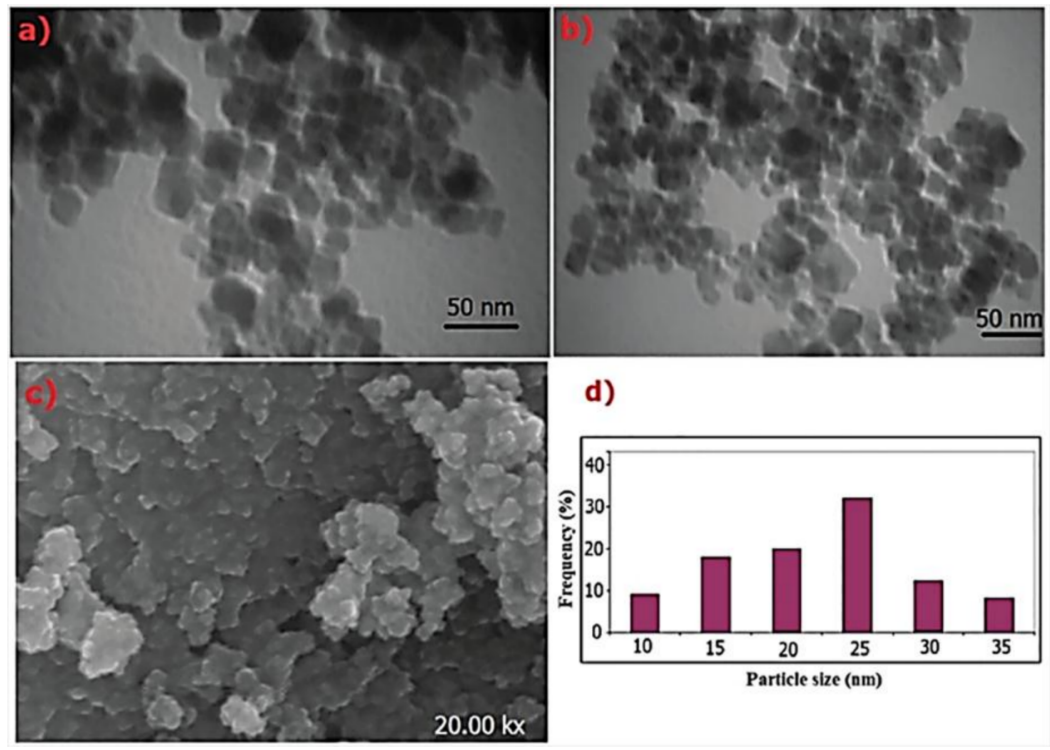

d)

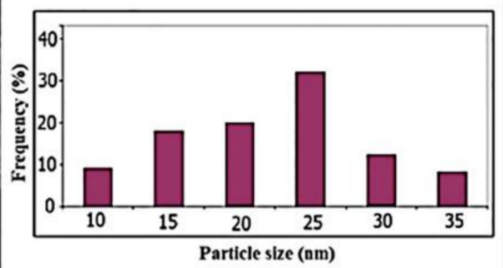

Figure 15. (a,b) TEM images of the PAFMNP ligand; (c) an SEM image of the PAFMNP ligand. (d) A histogram representing the size distribution of the PAFMNP NPs. Reproduced with permission from [47].

Pd-PAFMNP acts as an efficient magnetic recyclable catalyst for the Heck reaction of chloroarenes as inactive substrates in the presence of only $1.0 \mathrm{~mol} \%$ of catalyst (Scheme 51). The catalyst with magnetic nature could be recycled and reused at least five times without a significant loss of activity. ICP results after fifth runs showed that only $0.5 \%$ of the Pd was lost.

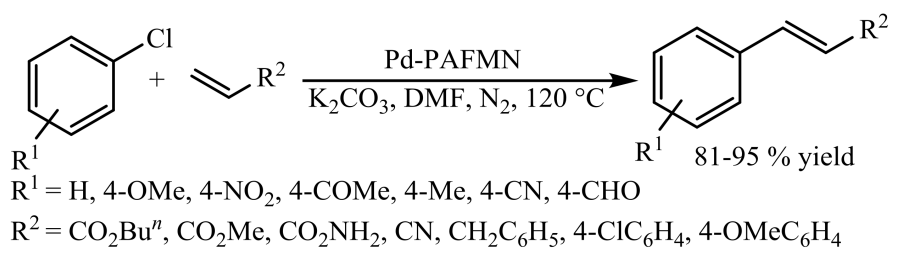

Scheme 51. Heck reaction catalyzed by Pd-PAFMNP catalyst [47].

Zolfigol and co-workers described the formation of a novel magnetic nano-palladium complex with task-specific nano-magnetic Schiff base ligand, wherein 2-aminoethyl dihydrogen phosphate instead of the usual coating agents for coating of nano-magnetic $\mathrm{Fe}_{3} \mathrm{O}_{4}$ was introduced (Scheme 52) [48]. The Pd-based nano-magnetic catalyst consisted of particles of less than $50 \mathrm{~nm}$ (Figure 16).

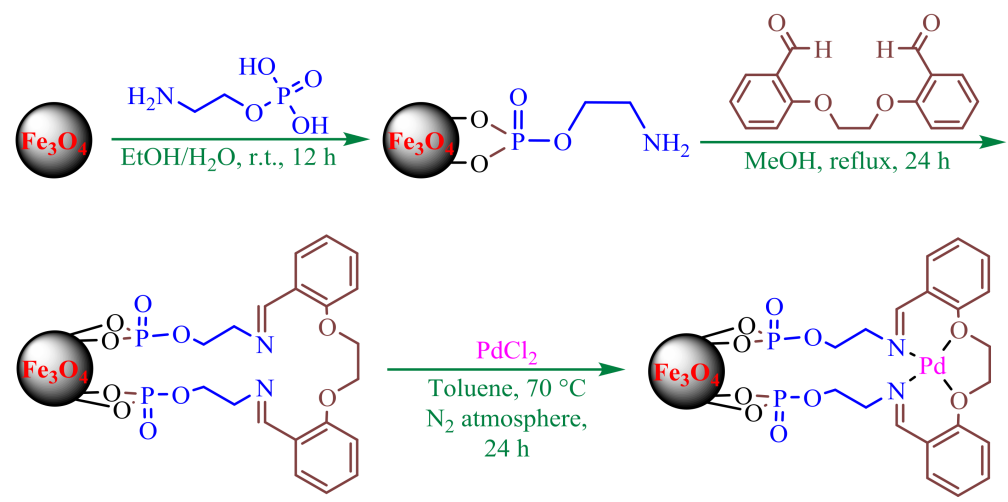

Scheme 52. Preparation of novel task-specific nano-magnetic Schiff base ligand with phosphate spacer and its Pd nano-magnetic heterogeneous catalyst [48]. 

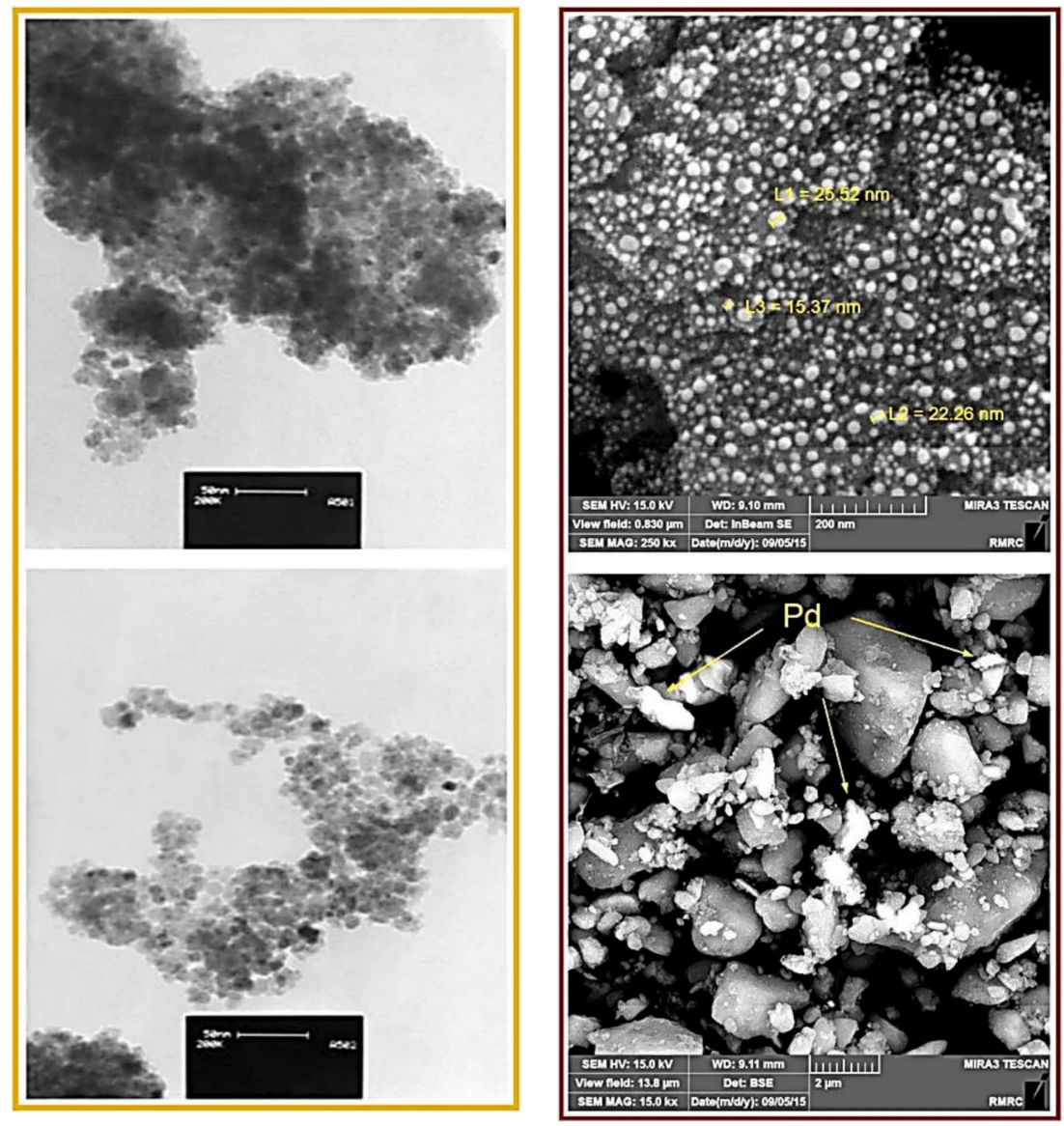

Figure 16. TEM and SEM images of the magnetic nano-palladium Schiff base complex. Reproduced with permission from [48].

The resulting catalyst showed high activity in the Sonogashira and Heck C-C coupling reactions (Scheme 53). The catalyst was recycled nine times without any significant loss of its initial catalytic activity, confirming the high stability of the prepared catalyst.

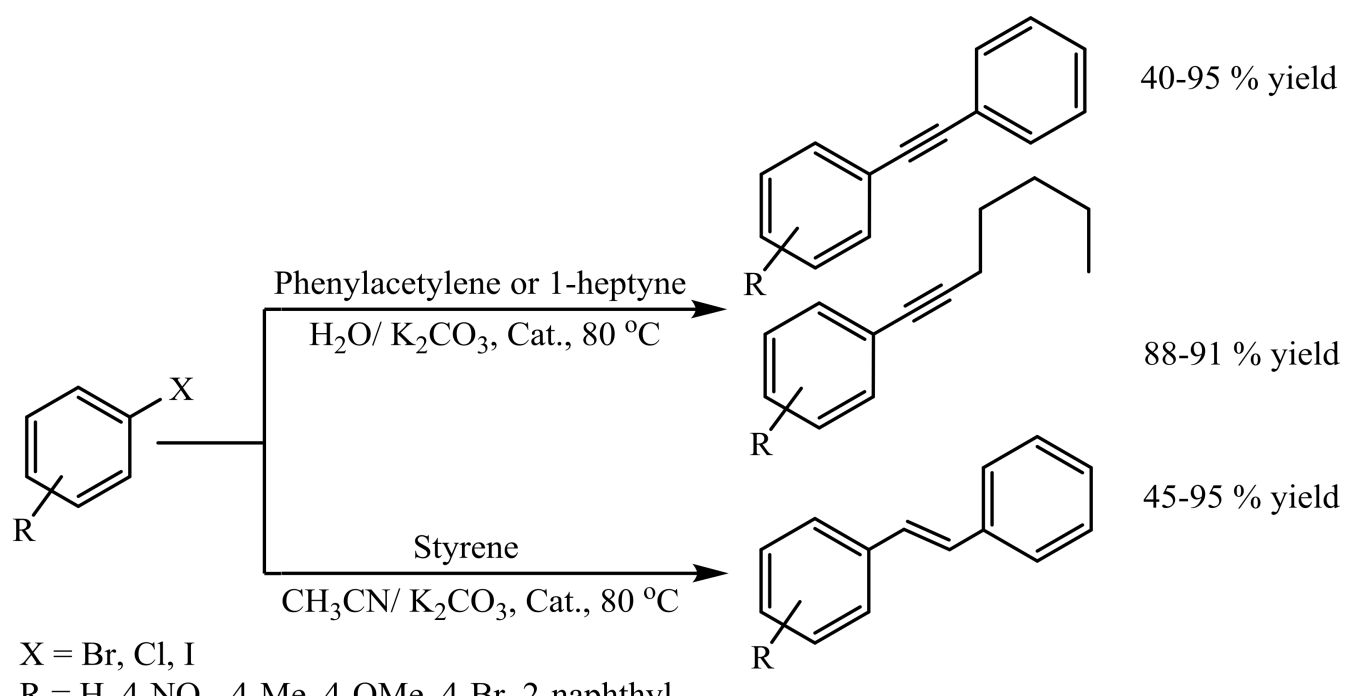

Scheme 53. Applicability of the magnetic nano-palladium Schiff base complex in C-C coupling reactions [48]. 
Ghorbani-Choghamarani and co-workers reported the Schiff base complex of palladium immobilized on magnetic NPs. $\mathrm{Fe}_{3} \mathrm{O}_{4}$ NPs were synthesized through a co-precipitation procedure: the coating of $\mathrm{Fe}_{3} \mathrm{O}_{4}$ NPs with APTES followed by the reaction of 5-bromosalicylaldehyde with amino groups led to a 5-bromosalicylaldehyde Schiff base supported on $\mathrm{Fe}_{3} \mathrm{O}_{4}$ NPs (Schiff-base@MNPs) for the formation of a complex with palladium. The resulting Schiff-base-Pd@MNPs catalyst was composed of quite homogeneous and quasi-spherical particles with an average diameter of about $10 \mathrm{~nm}$ (Figure 17) [49].

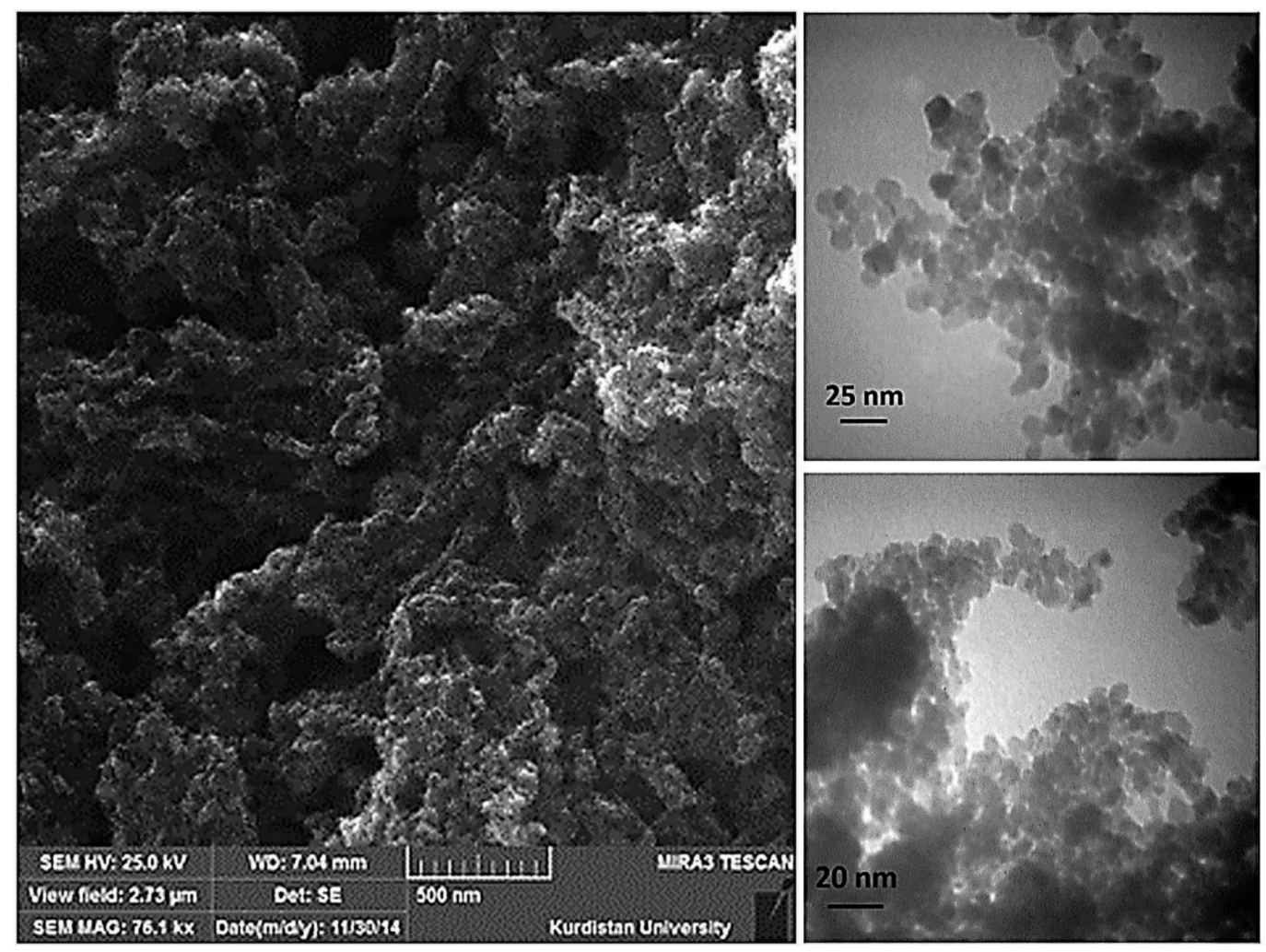

Figure 17. SEM and TEM images of Schiff-base-Pd@MNPs. Reproduced with permission from [49].

The Schiff-base-Pd@MNPs acted as recyclable nanocatalyst for C-C bond formation through Heck and Suzuki-Miyaura reactions. The Suzuki-Miyaura reaction of various aryl halides and phenylboronic acid was studied in the presence of $\mathrm{K}_{2} \mathrm{CO}_{3}$ in poly(ethylene glycol) (PEG)-400 at $60{ }^{\circ} \mathrm{C}$ to furnish diverse biaryl products in yields of $92-97 \%$. Also, coupling aryl halides with butyl acrylate through Heck reaction was conducted in the presence of $\mathrm{K}_{2} \mathrm{CO}_{3}$ in DMF at $120{ }^{\circ} \mathrm{C}$ and pure products were obtained in 88-97\% yields (Scheme 54). In addition, this catalyst could be separated from the reaction mixture by employing a magnetic bar, followed by washing with diethyl ether, and could be reused for up to six runs without any significant loss of its activity or palladium leaching with average isolated yield for six runs in $93.5 \%$. 


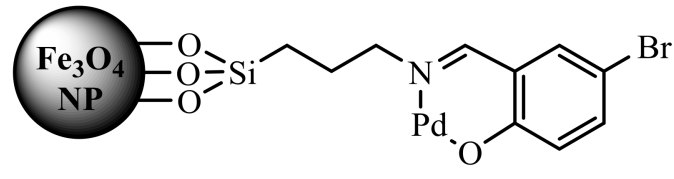

Schiff-base-Pd@MNPs

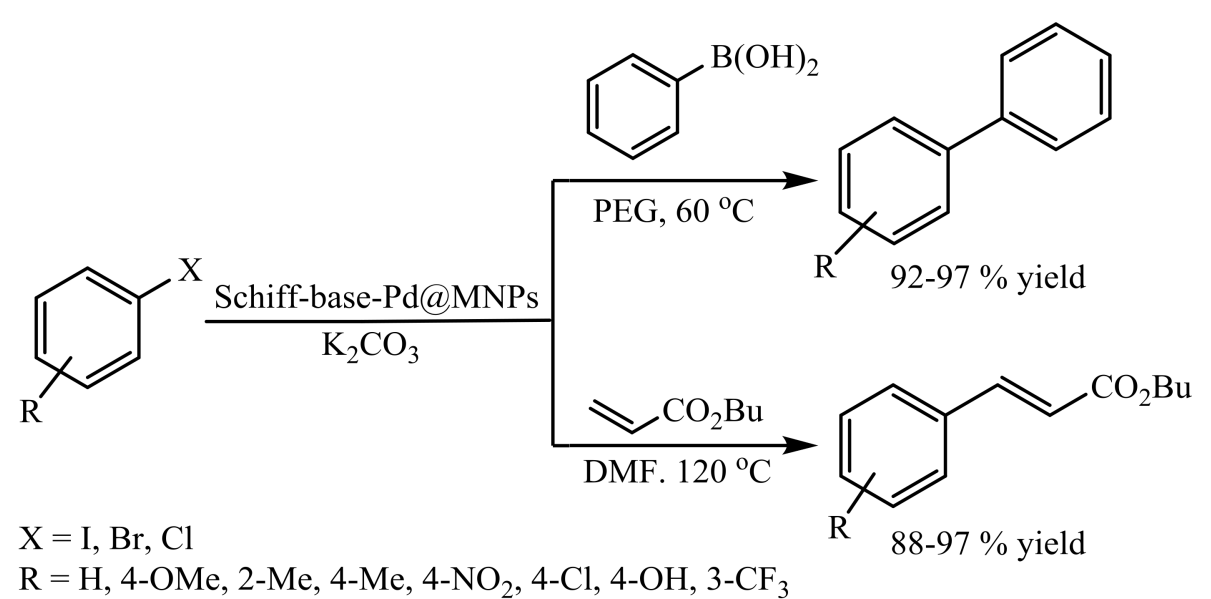

Scheme 54. Schiff-base-Pd@MNPs catalyzed C-C coupling through Suzuki-Miyaura and Heck reactions [49].

In another study, the same authors synthesized a catalyst for amination of aryl halides, Heck and Suzuki-Miyaura reactions based on palladium supported on magnetite $\left(\mathrm{Pd}(0)-\mathrm{ABA}-\mathrm{Fe}_{3} \mathrm{O}_{4}\right)$ by pretreatment of the magnetite particles with (3-aminopropyl) trimethoxysilane (APTES). By immobilizing isatoicanhydride to the surface of amino-functionalized magnetic NPs fixed ligand system was obtained for coordination with palladium(II) (Scheme 55) [50]. A TEM image of the obtained catalyst shows spherical and quite homogeneous NPs with an average size of about 15-25 nm (Figure 18).

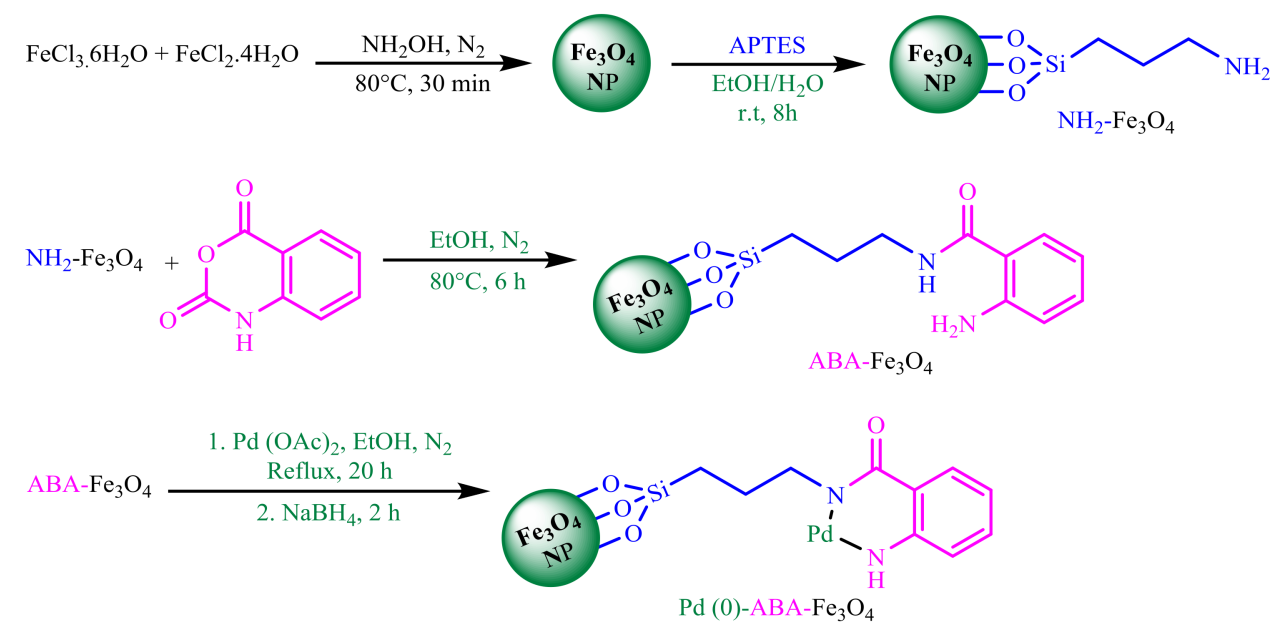

Scheme 55. Synthesis of $\mathrm{Pd}(0)-\mathrm{ABA}-\mathrm{Fe}_{3} \mathrm{O}_{4}$ NPs. Reproduced with permission from [50]. 

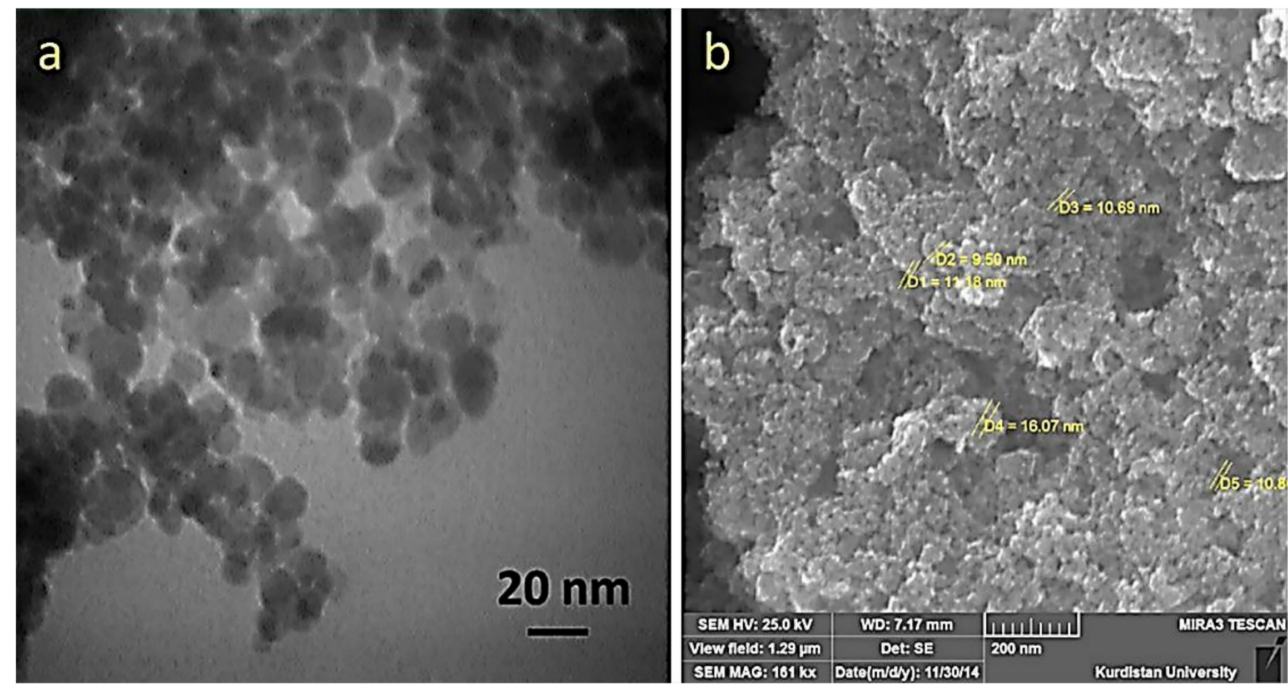

Figure 18. TEM (a) and SEM (b) image of $\mathrm{Pd}(0)-\mathrm{ABA}-\mathrm{Fe}_{3} \mathrm{O}_{4}$. Reproduced with permission from [50].

The $\mathrm{Pd}(0)-\mathrm{ABA}-\mathrm{Fe}_{3} \mathrm{O}_{4}$ catalyst was applied for the amination of aryl halides, Heck and Suzuki-Miyaura reactions. The Suzuki-Miyaura reaction was carried out in water or PEG using phenylboronic acid $\left(\mathrm{PhB}(\mathrm{OH})_{2}\right)$ or sodium tetraphenyl borate $\left(\mathrm{NaBPh}_{4}\right)$. Also $\mathrm{Pd}(0)-\mathrm{ABA}-\mathrm{Fe}_{3} \mathrm{O}_{4}$ has been used for Heck reaction of butyl acrylate, styrene or acrylonitrile with aryl halides in the presence of $\mathrm{Na}_{2} \mathrm{CO}_{3}$ as the base in DMF at $120{ }^{\circ} \mathrm{C}$ (Scheme 56). Recycling experiments conducted for the coupling reaction of 4-nitrobromobenzene with phenylboronic acid and sodium tetraphenyl borate, after completion the reaction, the catalyst was easily separated using an external magnet washed with diethyl ether and was used over five runs without any significant loss of its activity.

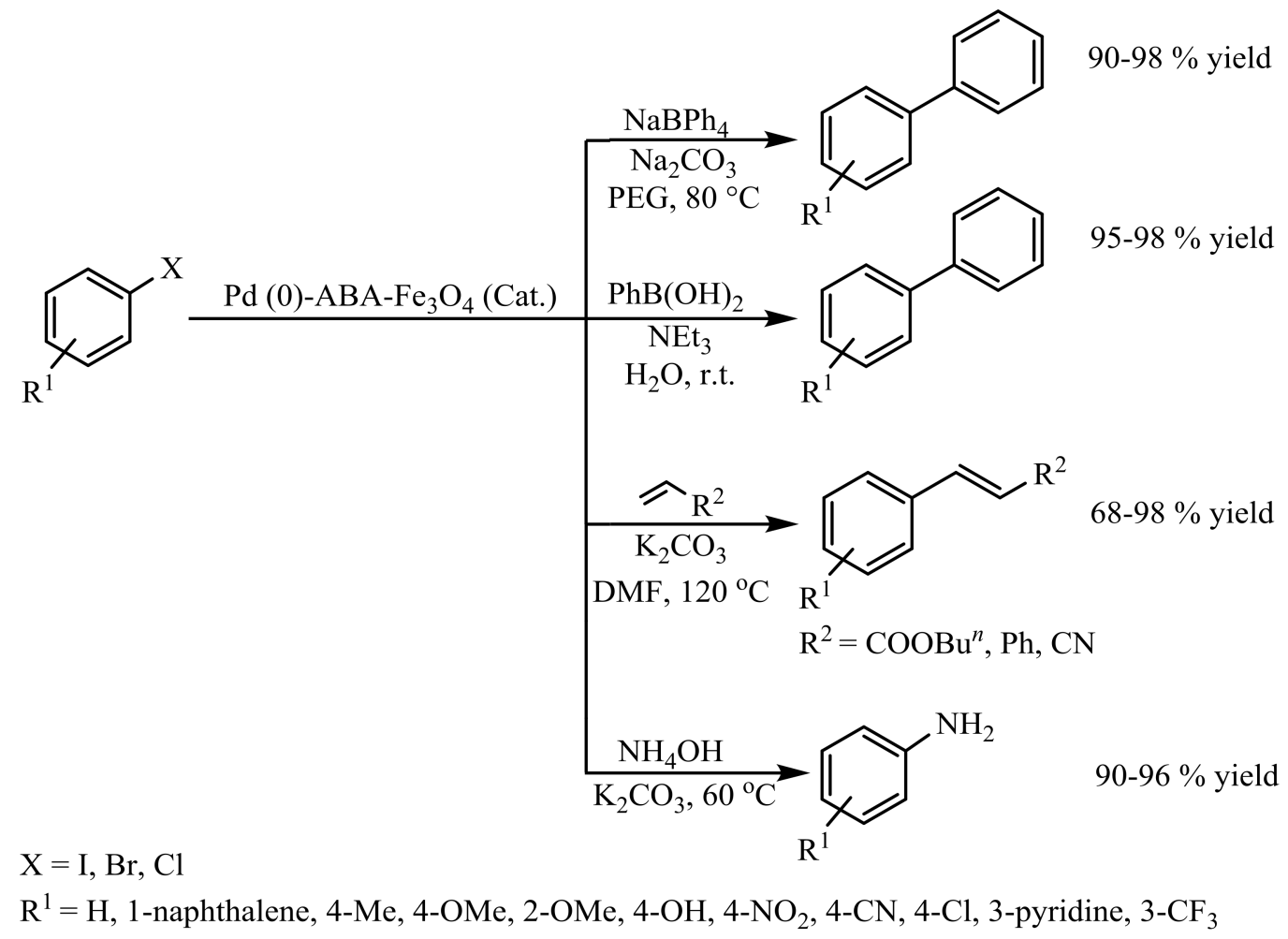

Scheme 56. $\mathrm{Pd}(0)-\mathrm{ABA}-\mathrm{Fe}_{3} \mathrm{O}_{4}$ catalyzed Heck and Suzuki-Miyaura reactions [50]. 
Hajipour and co-workers reported the preparation of a methionine-functionalized chitosan- $\operatorname{Pd}(0)$ complex. The magnetic catalyst was obtained by functionalization of chitosan with methionine, followed by treatment with $\mathrm{Fe}_{3} \mathrm{O}_{4} \mathrm{NPs}$; finally, $\mathrm{Fe}_{3} \mathrm{O}_{4}-\mathrm{CS}$-methionine reacted with palladium acetate and led to high palladium loadings (Scheme 57) [51]. A TEM image of the catalyst (ImmPd-MNPs) showed near-spherical Pd NPs that accumulated onto the magnetic functionalized chitosan with good monodispersity (Figure 19).

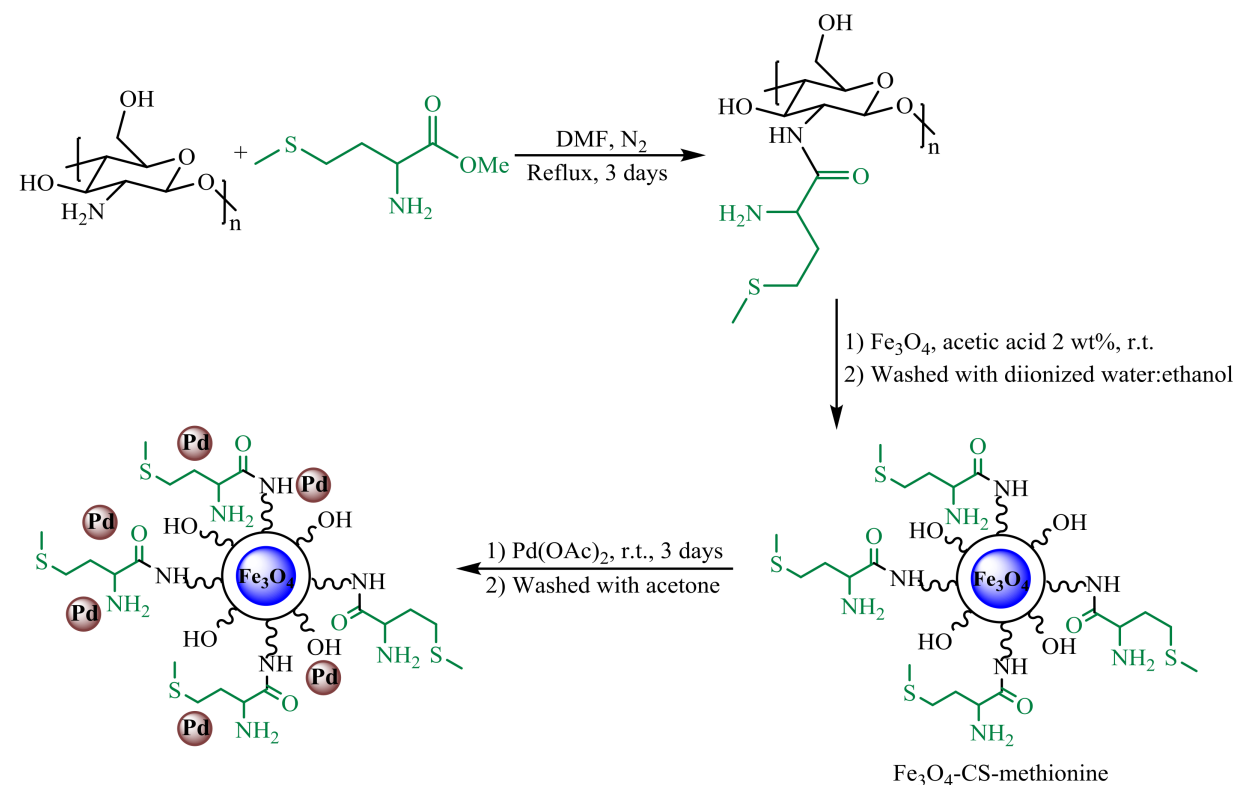

Scheme 57. Synthetic paths for the preparation of ImmPd-MNPs catalyst [51].

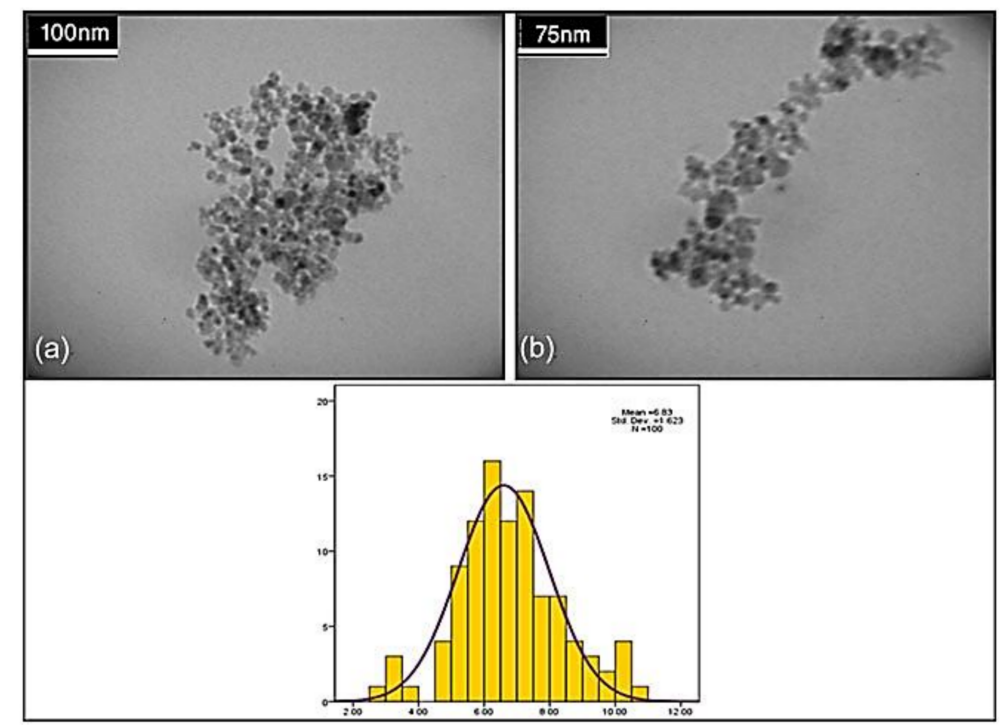

Figure 19. (a) TEM image of ImmPd(0)-MNPs catalyst showing the morphology of Pd nanoparticles on the magnetic chitosan support. Beneath is the histogram of the particle size distribution. (b) TEM image of ImmPd(0)-MNPs catalyst after eight reuses. Reproduced with permission from [51].

The ImmPd-MNPs catalyst was found to be active for Heck reactions of aryl iodides and aryl bromides under green reaction conditions. A high yield of alkene derivatives was achieved in the presence of $0.21 \mathrm{~mol} \%$ of nanocatalyst using water as the solvent, $\mathrm{K}_{2} \mathrm{CO}_{3}$ as the base and the phase-transfer reagent TBAB (Scheme 58). The recyclability of the catalyst was evaluated with six consecutive coupling reactions without loss of its activity. 


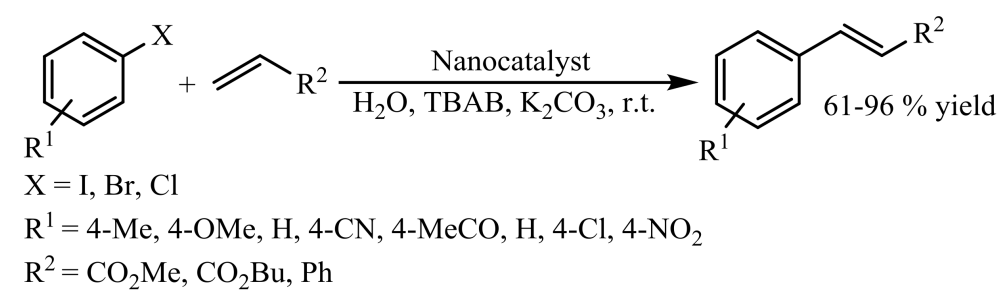

Scheme 58. ImmPd(0)-MNPs-catalyzed Heck reaction between various aryl halides and olefins [51].

Ghorbani-Choghamarani and co-workers published a moisture- and air-stable palladium complex supported on $\mathrm{Fe}_{3} \mathrm{O}_{4}$ magnetic NPs (Pd-SBTU@ $\mathrm{Fe}_{3} \mathrm{O}_{4}$ ). Modification of magnetic core with 3-chloropropyltrimethoxysilane followed by addition of $S$-benzylisothiourea led to a covalently fixed ligand system that was coordinated to palladium(II) (Scheme 59) [52]. The SEM image of Pd-SBTU@ $\mathrm{Fe}_{3} \mathrm{O}_{4}$ showed quasi-spherical particles with an average diameter of about $20 \pm 5 \mathrm{~nm}$ (Figure 20).

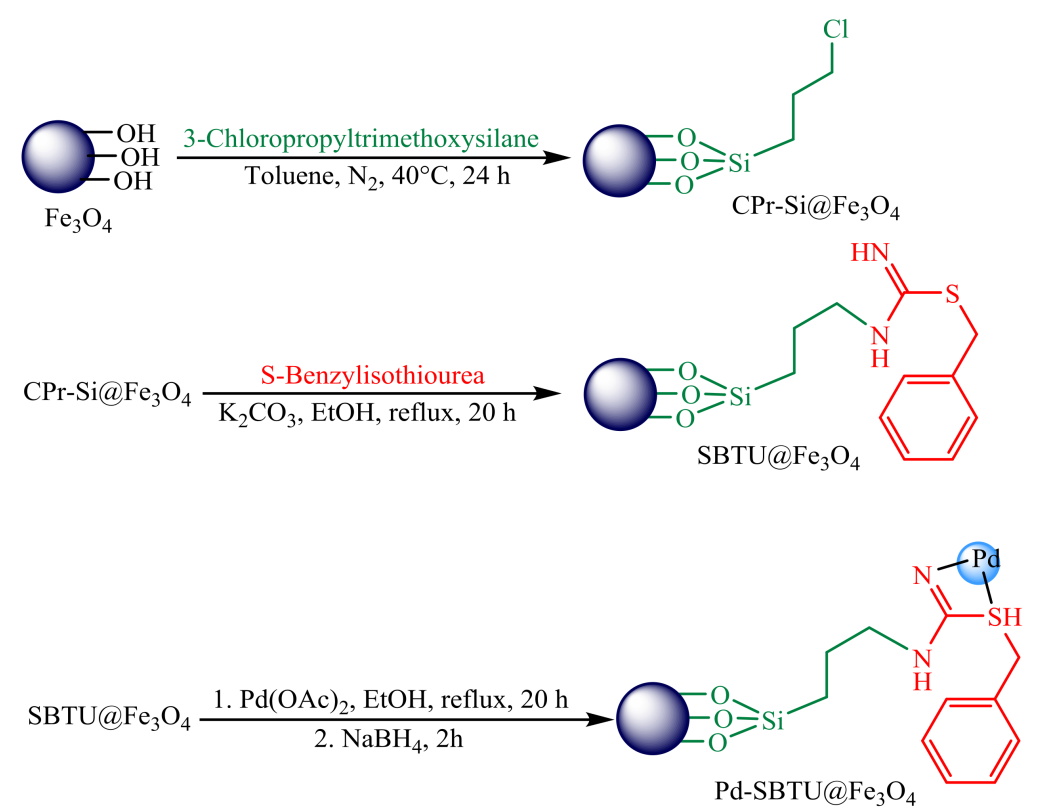

Scheme 59. Synthesis of Pd-SBTU@ $\mathrm{Fe}_{3} \mathrm{O}_{4}$. Reproduced with permission from [52].

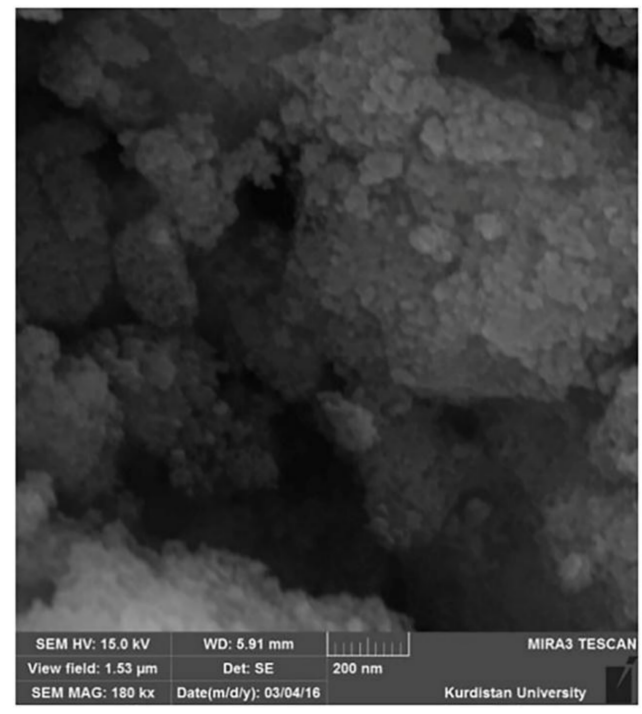

Figure 20. SEM image of Pd-SBTU@ $\mathrm{Fe}_{3} \mathrm{O}_{4}$. Reproduced with permission from [52]. 
The catalyst Pd-SBTU@ $\mathrm{Fe}_{3} \mathrm{O}_{4}$ performed as an organometallic reusable nanocatalyst in the synthesis of polyhydroquinolines and Suzuki-Miyaura coupling reaction. In the presence of this catalyst, the best results for Suzuki-Miyaura cross-coupling of different aryl halides with phenylboronic acid were obtained with $\mathrm{K}_{2} \mathrm{CO}_{3}$ as the base in PEG-400 as a green solvent at $60{ }^{\circ} \mathrm{C}$ (Scheme 60). Furthermore, the catalyst could be easily recovered using an external magnet and reused five times without any significant loss of its activity.

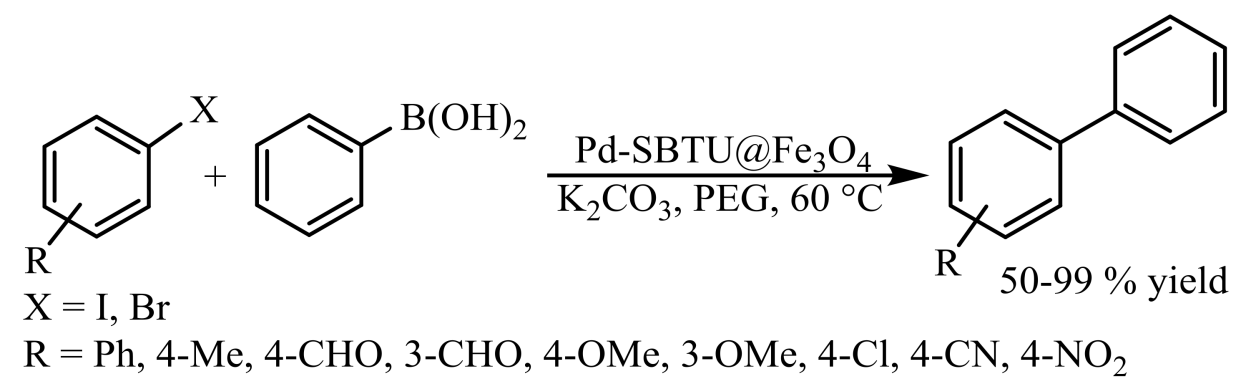

Scheme 60. Pd-SBTU@ $\mathrm{Fe}_{3} \mathrm{O}_{4}$-catalysed Suzuki-Miyaura reaction [52].

Akhlaghinia and coworker described the formation of a magnetic organometallic catalyst wherein a thiophene methanimine-palladium Schiff base complex was immobilized on decorated $\gamma-\mathrm{Fe}_{2} \mathrm{O}_{3}$ with 2-aminoethyl dihydrogen phosphate $\left(\gamma-\mathrm{Fe}_{2} \mathrm{O}_{3} / \mathrm{AEPH}_{2}\right.$-TC-Pd) (Scheme 61) [53]. This nanocomposite has spherical morphology with an average diameter of about $15 \mathrm{~nm}$ (Figure 21).

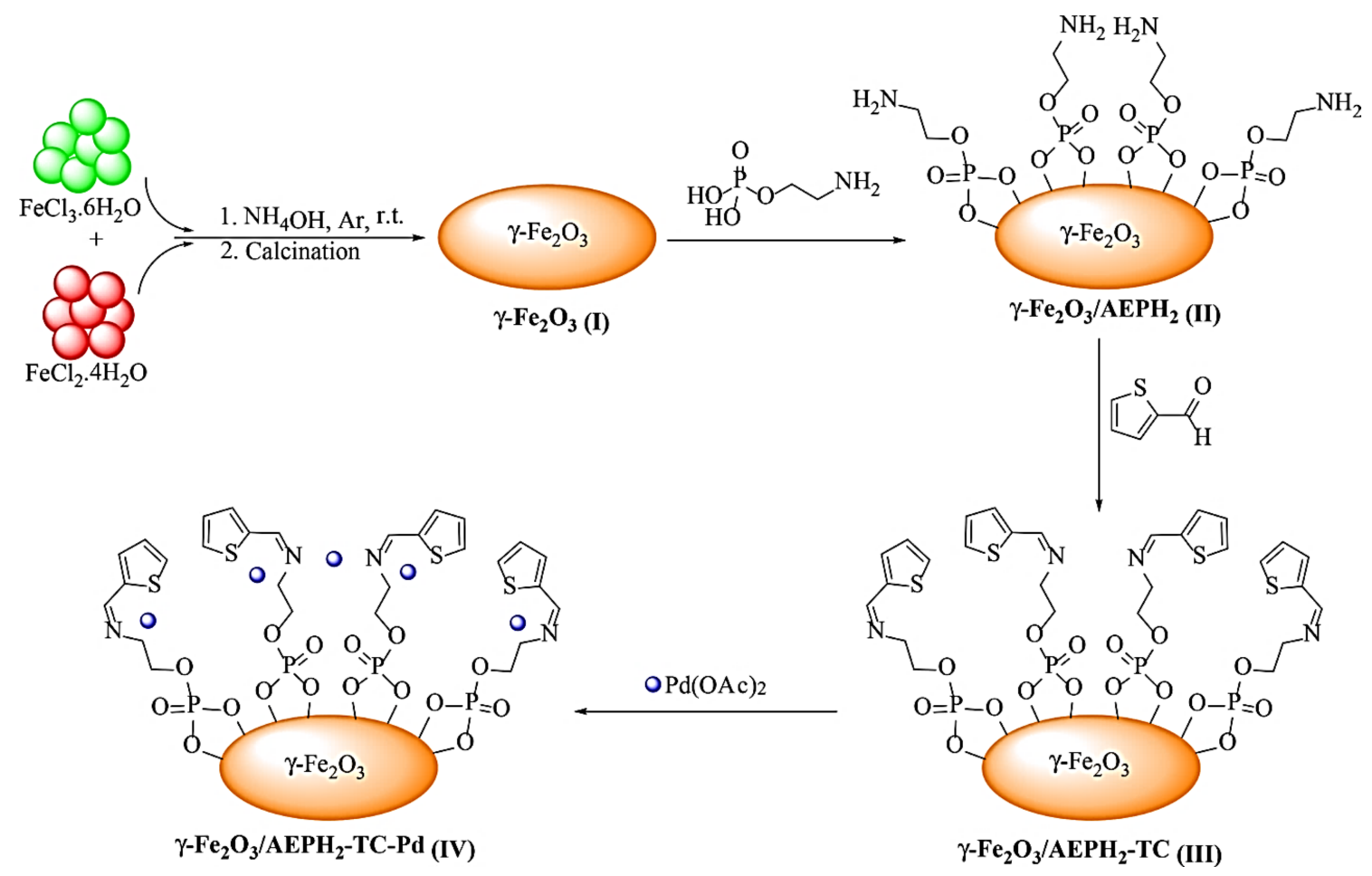

Scheme 61. An overview on the synthesis of $\gamma-\mathrm{Fe}_{2} \mathrm{O}_{3} / \mathrm{AEPH}_{2}-\mathrm{TC}-\mathrm{Pd}$ nanocatalyst. Reproduced with permission from [53]. 

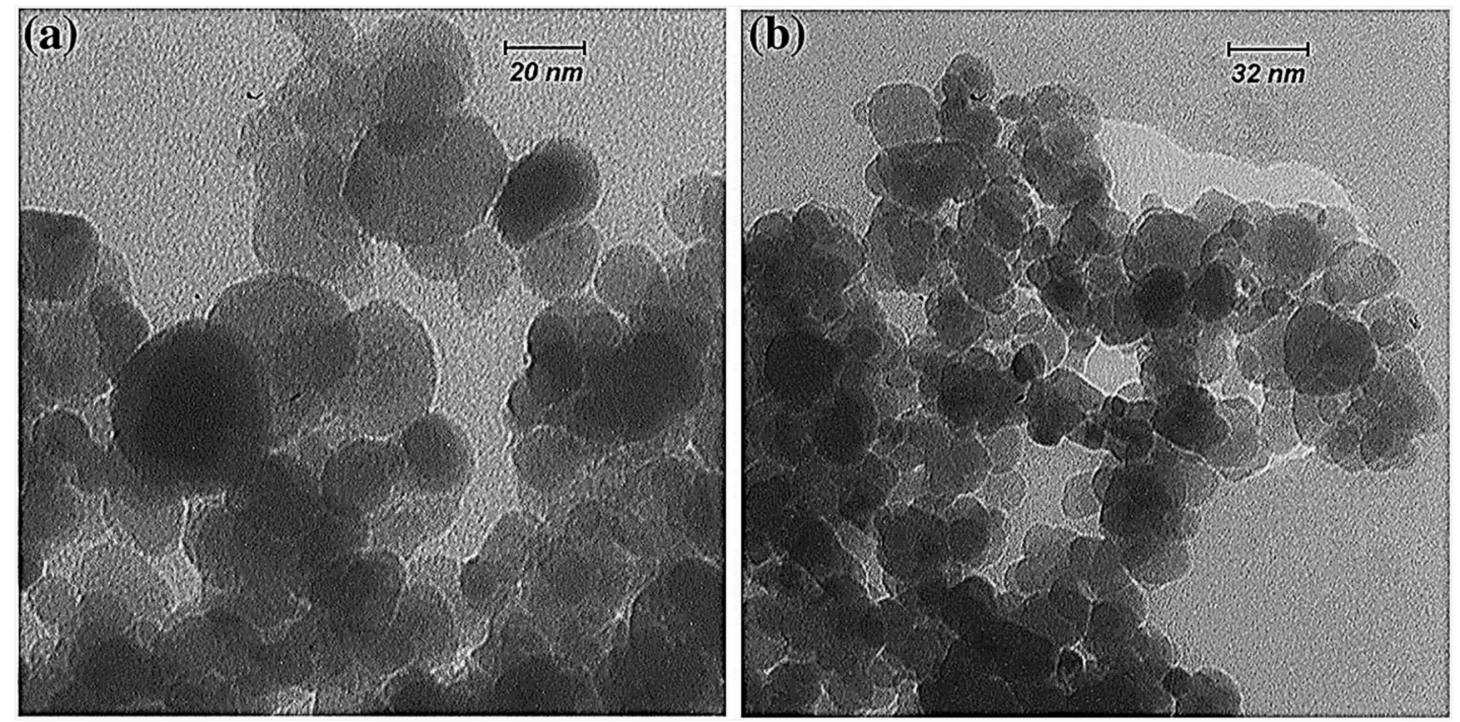

Figure 21. TEM images of $\gamma-\mathrm{Fe}_{2} \mathrm{O}_{3} / \mathrm{AEPH}_{2}-\mathrm{TC}-\mathrm{Pd}$. Reproduced with permission from [53].

The catalyst exhibited high activities for Suzuki-Miyaura and Heck cross-coupling reactions in aqueous media (Scheme 62). Also, this catalyst can be separated from the reaction mixture by using a magnetic bar and then washing it with ethanol, and can subsequently be reused at least nine times without a significant decrease in activity. The authors believed that the high catalytic activity of this catalyst could be attributed to the nature of the applied ligand with stability against air and moisture, and the stabilizer acted to prevent agglomeration of palladium NPs.

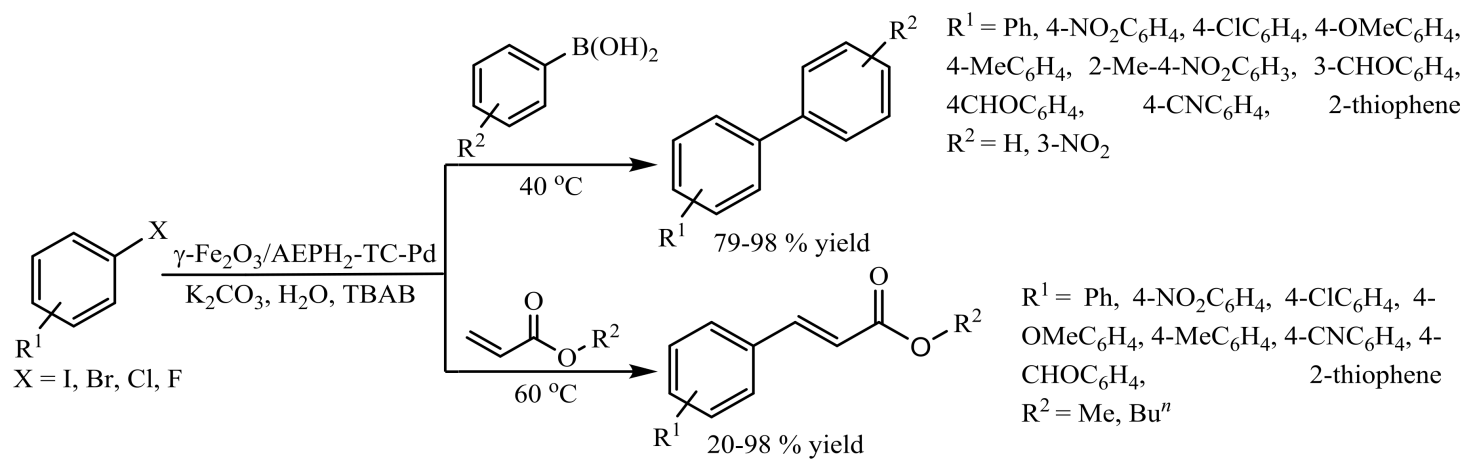

Scheme 62. Suzuki-Miyaura and Heck cross-coupling reactions in the presence of $\gamma$ - $\mathrm{Fe}_{2} \mathrm{O}_{3} / \mathrm{AEPH}_{2}$-TC-Pd nanocatalyst [53].

Manjunatha and co-workers, using an anchoring Schiff base-palladium(II) complex on magnetic NPs, synthesized a magnetically separable SB-Pd@MNPs catalyst (Scheme 63) [54]. The SB-Pd@MNPs nanomagnetic catalyst was prepared in four steps. 1 was prepared from a 2:1 molar ratio of $\mathrm{Fe}^{3+}$ and $\mathrm{Fe}^{2+}$ with ammonium hydroxide as base. Chemical co-precipitation. 3 was prepared via functionalization of 1 with 2 in $\mathrm{EtOH}-\mathrm{H}_{2} \mathrm{O}$ mixture at $40{ }^{\circ} \mathrm{C}$. Then, 5 was synthesized from the reaction between 4 and 3 in toluene at $110^{\circ} \mathrm{C}$. In the final step, $\mathbf{5}$ was treated with palladium(II) acetate in ethanol at $78{ }^{\circ} \mathrm{C}$ to afford the desired SB-Pd@MNPs nanomagnetic catalyst (6). 
(a)

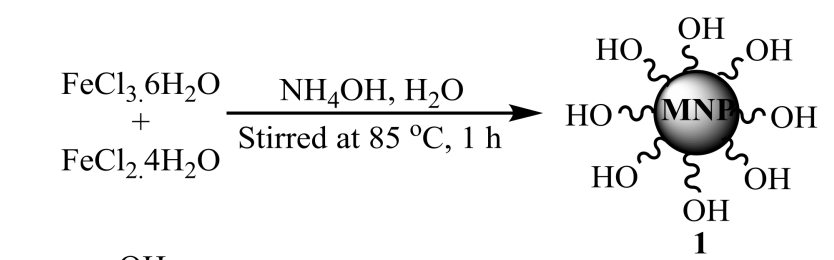

(b)

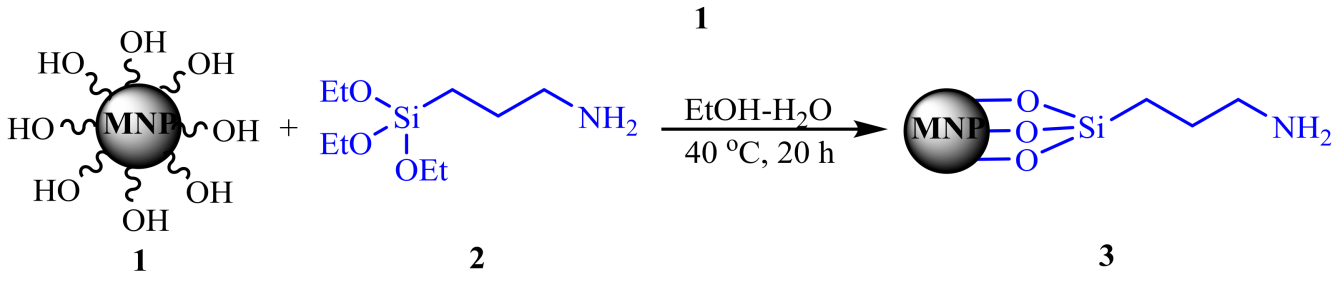

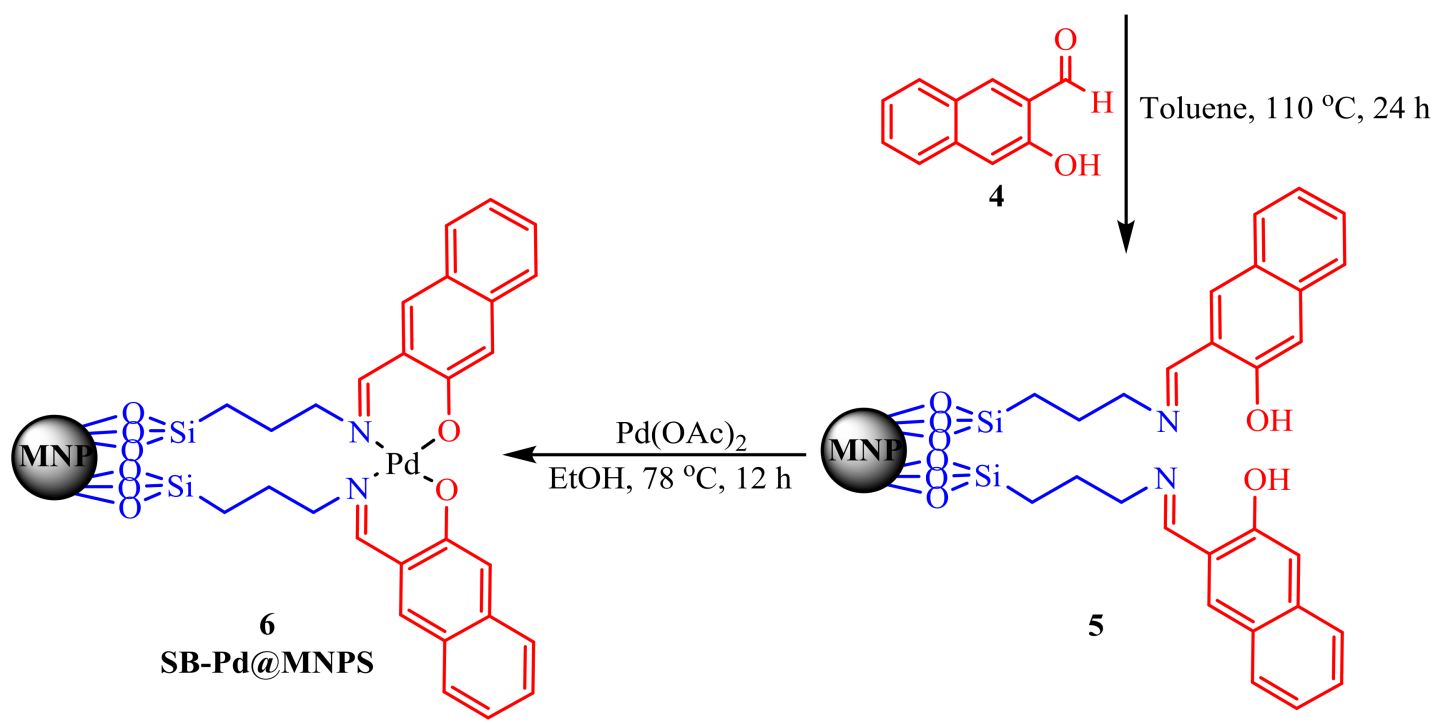

Scheme 63. Synthetic route to (a) MNPs (1) and (b) SB-Pd@MNPs nanomagnetic catalyst (6). Reproduced with permission from [54].

The SB-Pd@MNPs nanomagnetic catalyst was found to be an efficient catalyst for Suzuki-Miyaura cross-coupling of various aryl halides with phenylboronic acid and for the reduction of nitroarenes in aqueous medium at room temperature. The best yields were obtained by carrying out the reaction at room temperature in $\mathrm{EtOH}: \mathrm{H}_{2} \mathrm{O}(1: 1)$ as the solvent with $\mathrm{Na}_{3} \mathrm{PO}_{4} \cdot 12 \mathrm{H}_{2} \mathrm{O}$ as the base (Scheme 64). The procedure was obtained for cross-coupling and reduction reactions by carrying out the reaction at ambient temperature and in water as an environmentally benign solvent. The catalyst can be recovered by external magnetic separation and reused up to five cycles without loss of catalytic activity.

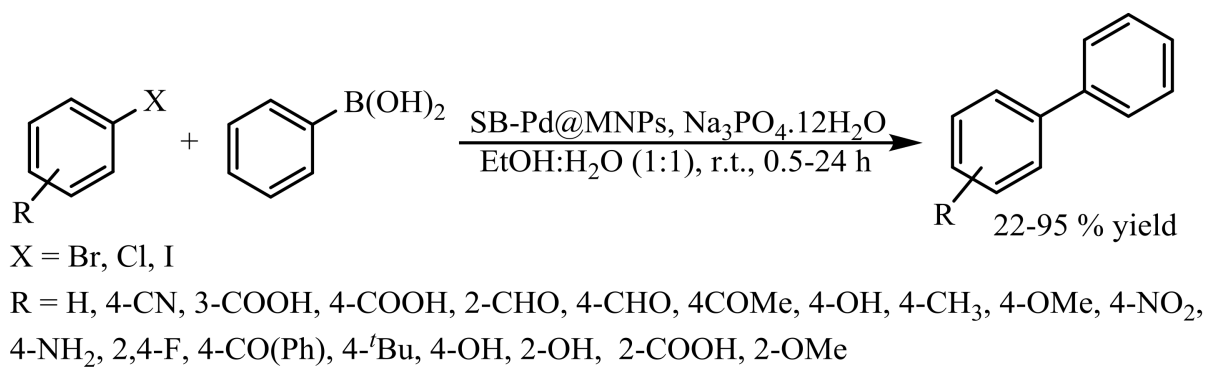

Scheme 64. Suzuki-Miyaura cross-coupling reactions between aryl halides and phenylboronic acid catalyzed by SB-Pd@MNPs nanomagnetic catalyst [54]. 


\subsection{Magnetic NanoparticleSupported N-Heterocyclic Carbene Complexes}

In recent years, $\mathrm{N}$-heterocyclic carbene (NHC) ligands, due to their high stability against heat, moisture, and air, have attracted increasing interest in the field of Pd-catalyzed C-C coupling reactions. Immobilization of NHC-Pd catalysts on heterogeneous supports, by allowing facile recycling, enhanced the turnover numbers of the catalyst. A palladium bis- $N$-heterocyclic carbene complex was immobilized on polystyrene-modified carbon-coated iron NPs by Reiser and co-workers (Scheme 65) [55]. The authors suggested the encapsulation of palladium NPs in the polystyrene matrix of the support.<smiles>Cc1cc(C)c(-n2ccnc2)c(C)c1</smiles>

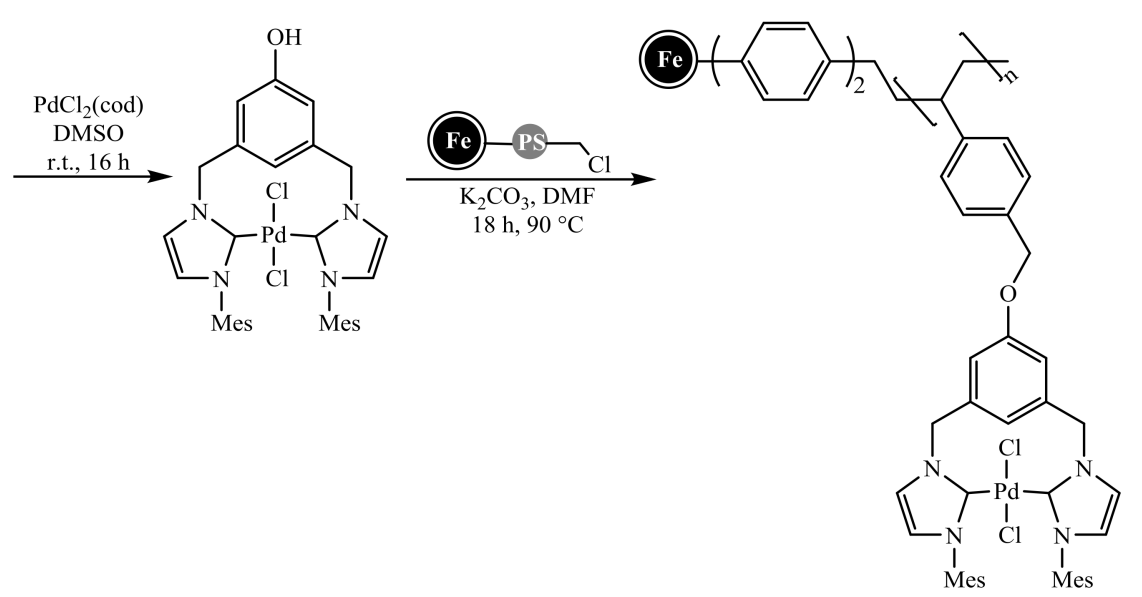

Scheme 65. Synthesis of polystyrene-modified, carbon-coated iron NPs supported palladium complex. Reproduced with permission from [55].

The catalytic activity and recyclability of obtained catalyst has been tested in Suzuki-Miyaura cross-coupling reactions of aryl halides and phenylboronic acid in toluene by using $\mathrm{Cs}_{2} \mathrm{CO}_{3}$ as the base under microwave irradiation (Scheme 66). An external magnetic was utilized to recycle the catalyst, and the effectiveness of the catalyst is retained for at least four cycles.

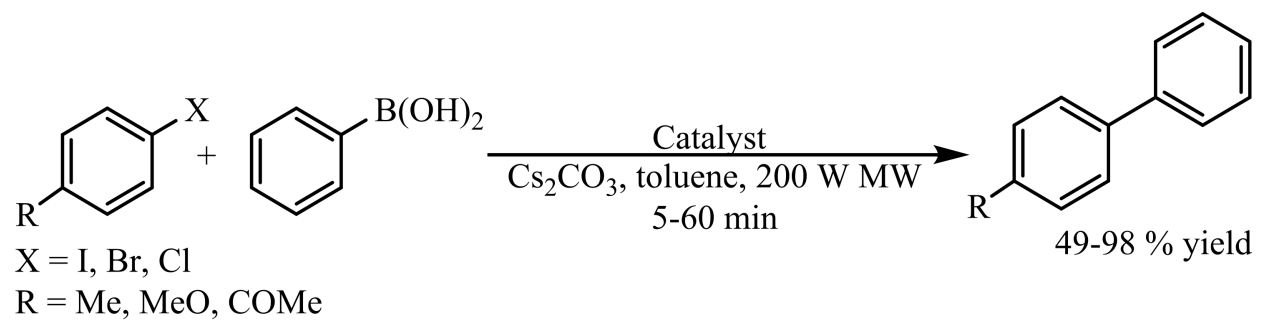

Scheme 66. Suzuki-Miyaura reaction catalyzed by carbon coated iron NPs supported palladium complex under microwave conditions.

Khosropour and co-workers reported designation and preparation of SPIONs (superparamagnetic iron oxide NPs)-bis(NHC)-palladium(II) as Pd-NHC-tagged MNPs [56]. Reaction of amino 
functionalized $\mathrm{Fe}_{3} \mathrm{O}_{4}$ with 1,3,5-trichlorotriazine (TCT) was studied by controlling the temperature, followed by replacing $N$-methylimidazole with two other chlorides, resulting in the preparation of a bidentate NHC ligand via the formation of a C-N bond between imidazole and triazine parts (Scheme 67). Finally, SPIONs-bis(NHC)-palladium(II) diacetate was prepared from the reaction between supported $\mathrm{N}$-heterocyclic carbene ligand with $\mathrm{Pd}(\mathrm{OAc})_{2}$ in DMSO.

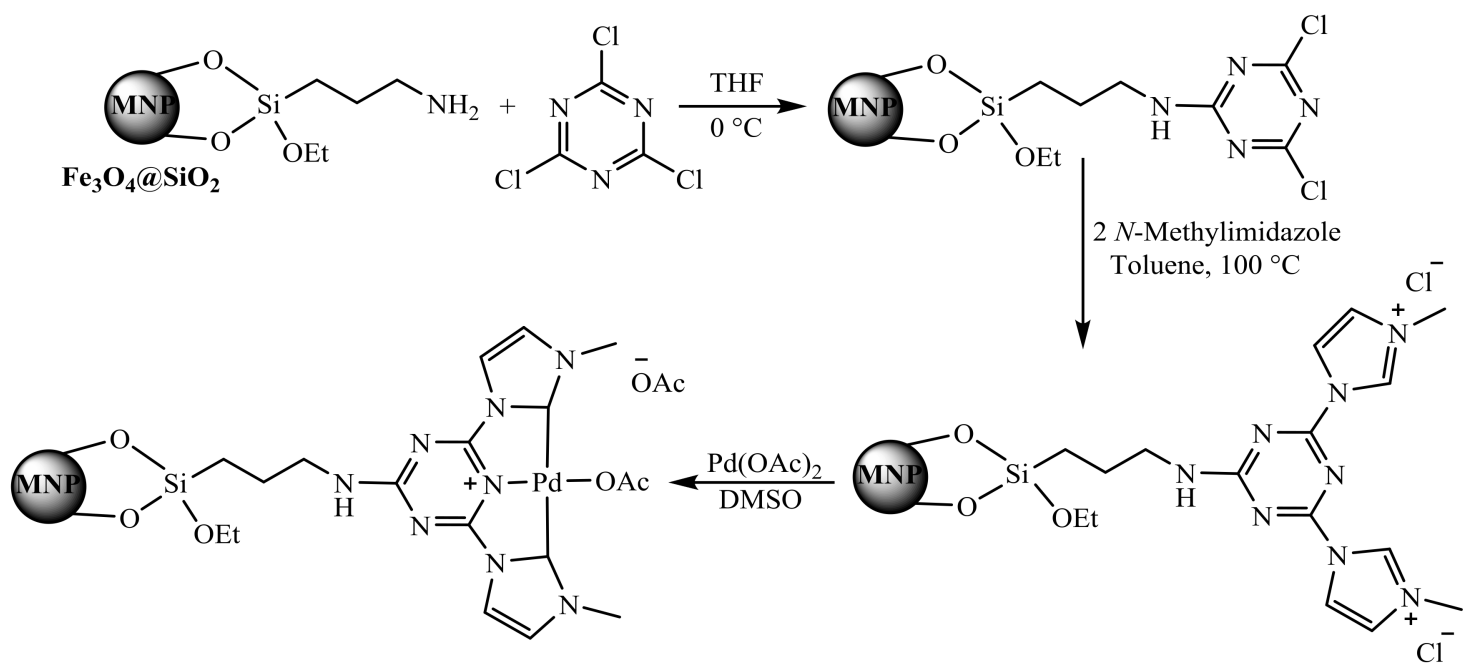

Scheme 67. Synthesis of the catalyst SPIONs-bis(NHC)-palladium(II) diacetate. Reproduced with permission from [56].

The obtained Pd-NHC complex acted as a powerful nanocatalyst in Heck and Suzuki-Miyaura C-C coupling reactions under heating or microwave irradiation, which provided high yields and TOF (Scheme 68). Moreover, the catalyst could be recovered by using an external magnet and reused for seven runs without any change in catalytic activity.

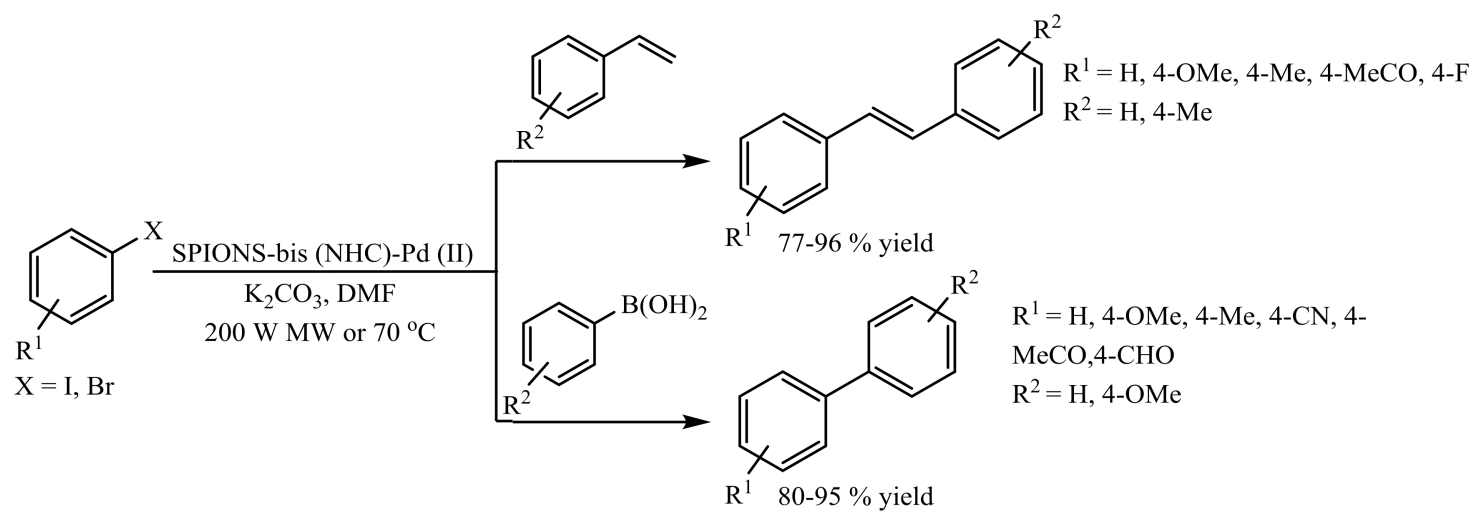

Scheme 68. Suzuki-Miyaura and Heck cross coupling reactions in the presence of SPIONS-bis (NHC)-Pd(II) [56].

Direct synthesis of imidazolinium salt supported on magnetic NPs and immobilization of $\mathrm{Pd}(\mathrm{OAc})_{2}$ onto the surface of modified $\mathrm{Fe}_{3} \mathrm{O}_{4} \mathrm{NPs}$ has been reported by Wilczewska and Misztalewska [57]. Nanocatalyst (MNP@NHC-Pd) was prepared by direct synthesis of imidazolinium salt on amino functionalized $\mathrm{Fe}_{3} \mathrm{O}_{4} \mathrm{NPs}$ through the "grafting from" immobilization in a three-step approach followed by a reaction with a solution of $\mathrm{Pd}(\mathrm{OAc})_{2}$ and aqueous solution of $\mathrm{Na}_{2} \mathrm{CO}_{3}$ in DMF (Scheme 69). In this work, the silane shell was prepared by condensation reaction of APTMS ((3-aminopropyl)-trimethoxysilane) on the surface of the MNP. 


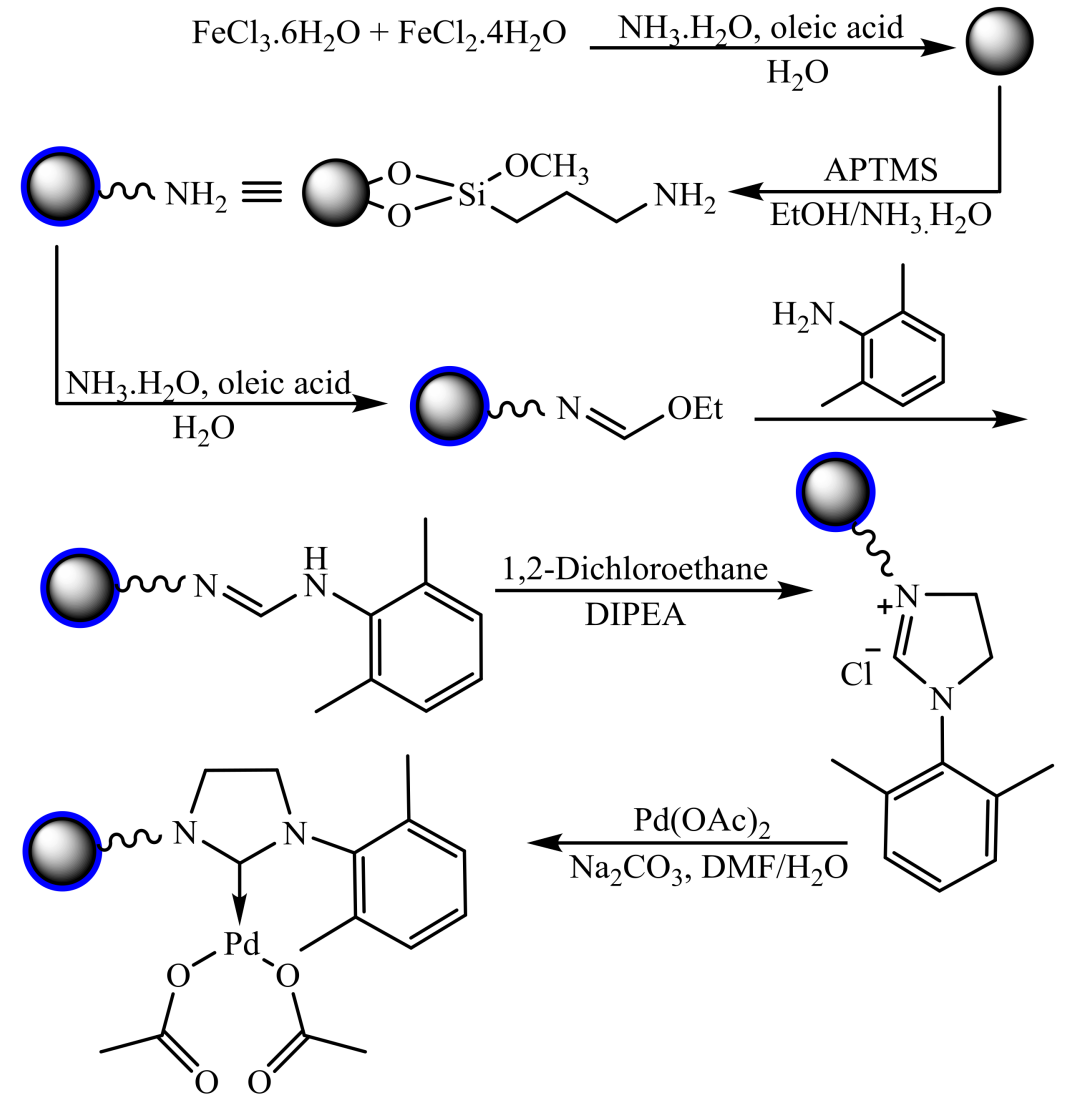

Scheme 69. Synthesis of MNP@NHC-Pd. Reproduced with permission from [57].

The activity of obtained MNP@NHC-Pd has been evaluated in the Heck coupling reaction of various aryl halides and vinyl compounds in the presence of $\mathrm{NaHCO}_{3}$ as the base in $\mathrm{DMF}$ (Scheme 70). The supported catalyst can be removed from the reaction mixture and reused at least five times without loss of its activity.

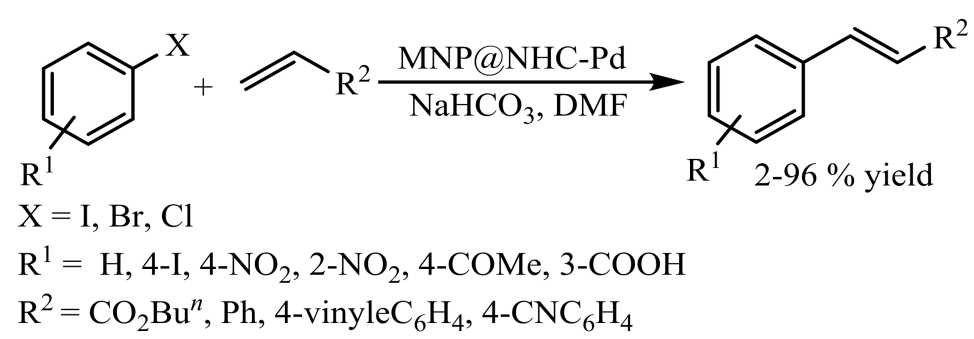

Scheme 70. Heck coupling reaction of various aryl halides and vinyl compounds under MNP@NHC-Pd.

Wang et al. prepared a palladium catalyst with $\mathrm{N}$-heterocyclic carbene (NHC) ligand on polymer magnetic carrier with different sources of $\mathrm{Pd}$ salts, $\mathrm{Pd}(\mathrm{OAc})_{2}$ and $\left(\mathrm{PdCl}_{2}\right.$ and 3-Cl-pyridinyl) and investigated the catalytic activity and stability of the obtained catalyst in a Suzuki-Miyaura cross-coupling reaction [58]. Magnetic carriers were synthesized through mini-emulsion polymerization; after modification of the surface of these magnetic carriers with 1-arylimidazole, different palladium salts were employed for the preparation of catalyst- 1 and catalyst- 2 (Scheme 71). Catalyst- 1 showed high catalytic activity in the reaction of phenylboronic acids with aryl bromides in the ethanol-water solution (Scheme 72). The catalytic activity of catalyst-1 slightly decreased after 21 runs, whereas 
catalyst-2 showed more stability and activity, as performed for Suzuki-Miyaura reaction with aryl chlorides at $100{ }^{\circ} \mathrm{C}$.

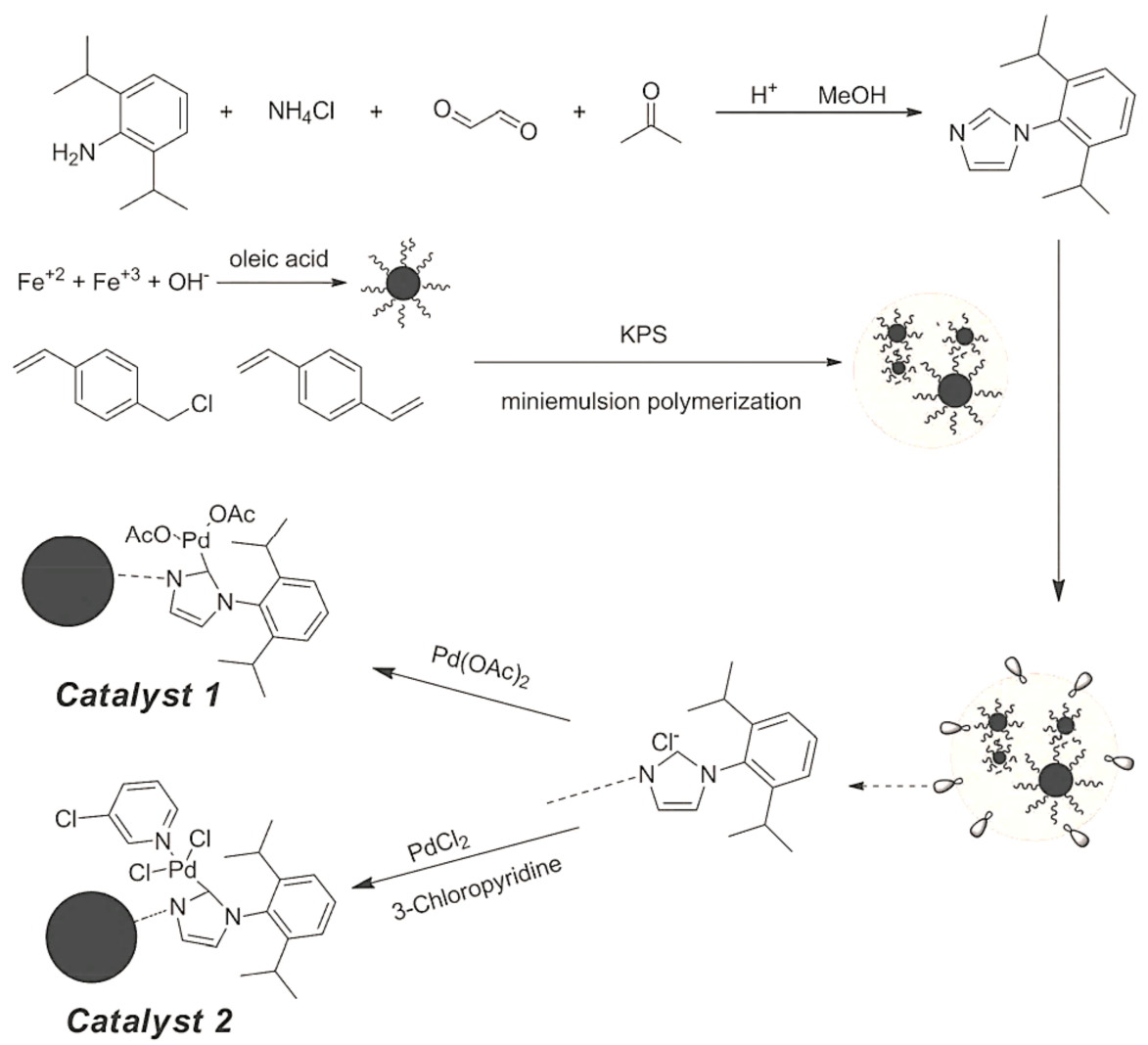

Scheme 71. The preparation procedures of magnetic palladium catalysts. Reproduced with permission from [58].

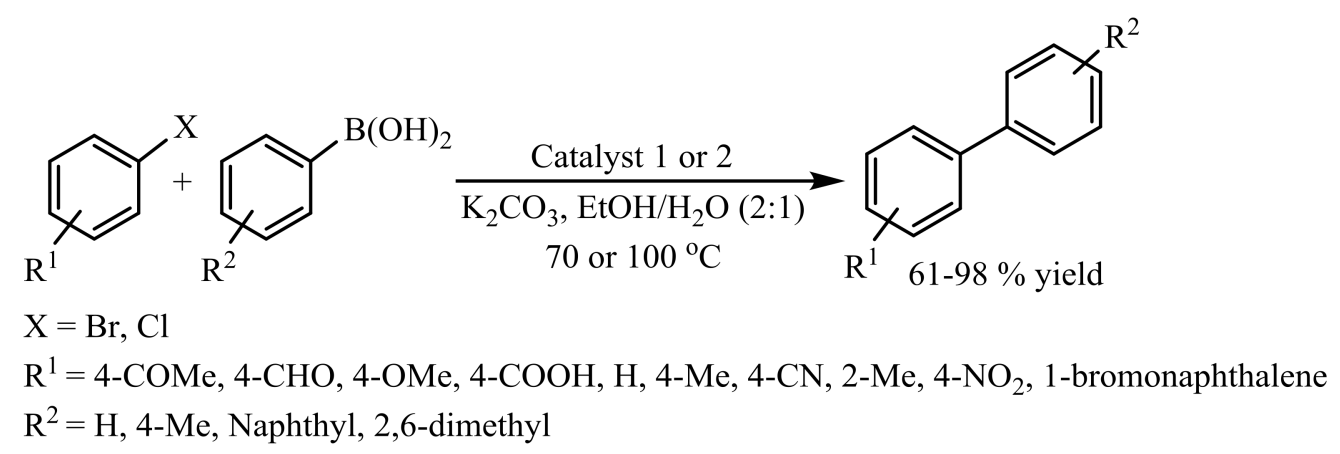

Scheme 72. Catalytic efficiencies of magnetic catalysts 1 and 2 in Suzuki-Miyaura coupling reaction.

Martínez-Olid and co-workers reported mono- or bis-(NHC) complexes of palladium and a magnetically recoverable catalyst based on these complexes for the Suzuki-Miyaura reaction [59]. The precatalysts were based on a PEPPSI-type complex and a bis(NHC) related compound. Synthesized palladium complexes containing alkoxyorganosilyl groups undergo condensation reactions with magnetic core/shell $\gamma-\mathrm{Fe}_{2} \mathrm{O}_{3} /$ silica particles, and, through covalent immobilization, yielded magnetically recoverable catalysts based on mono- or bis-(NHC) complexes of palladium (MNP-2 and -4). Comparative studies of the catalytic performance of complexes and their immobilization were conducted. For this purpose, unsupported ( 2 and 4 ) and supported complexes (MNP-2 and -4 ) were tested in the Suzuki-Miyaura reaction of 4-halotoluenes and phenylboronic acid in a 1:1 mixture of Tx (a 0.21 wt \% aqueous solution of Triton ${ }^{\mathrm{TM}} \mathrm{X}-405$ ) and ethanol. Overall, the magnetic catalysts 
with high performance and magnetic recovery ability were found to be more reactive than the homogeneous complexes. A comparative study of two heterogeneous catalysts revealed that the bis(NHC) immobilized complex with lower Pd loading is a robust catalyst that can operate under very mild conditions, even for the activation of chloroarenes, whereas its analog based on the mono(NHC) compound rapidly deactivates (Scheme 73).

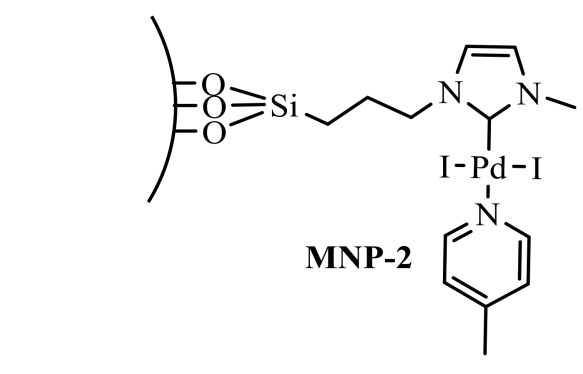<smiles>CC1O[Si]2(CCCN3C=CN(C)C3[R7](Br)(Br)C3N(C)C=CN3CCC[As]34OC(C)C(O3)C(C)O4)CC1O2</smiles>

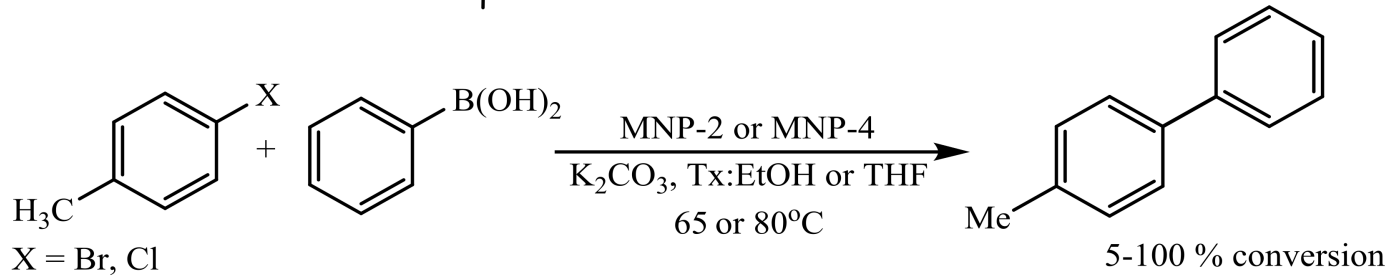

Scheme 73. Comparison of catalysts (MNP-2 and MNP-4) for the Suzuki-Miyaura reaction of 4-halotoluenes with phenylboronic acid.

The immobilization of a palladium NHC complex on magnetic iron oxide NPs was achieved by Hajipour and co-workers [60]. They first anchored phenyl-1H-imidazole on the surface of silica modified $\mathrm{Fe}_{3} \mathrm{O}_{4}$ NPs and finished the complex formation by treatment with $\mathrm{NaPdCl}_{3}$. FE-SEM and EDX results showed the presence of Pd NPs in the catalyst and TEM images revealed well-defined dispersed spherical palladium particles with a size of about 15-35 $\mathrm{nm}$ in a silica bed (Figure 22).
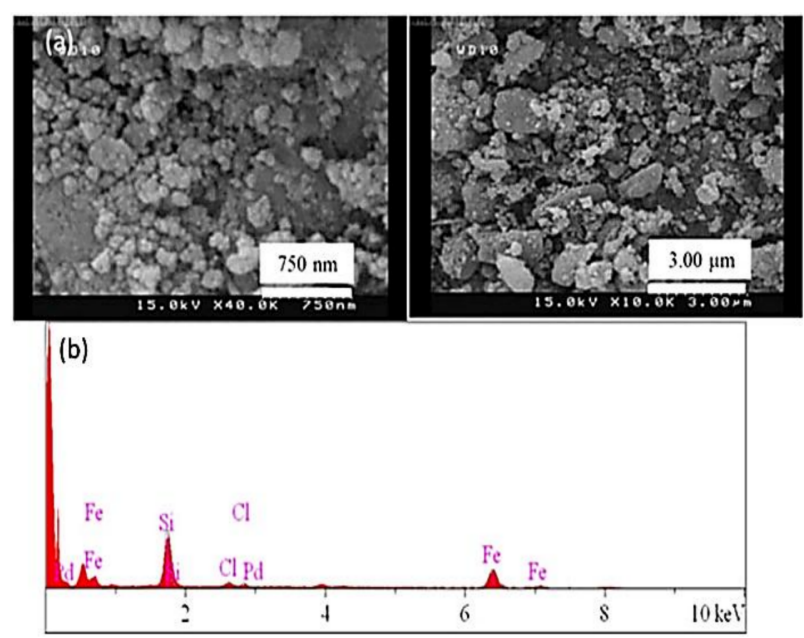
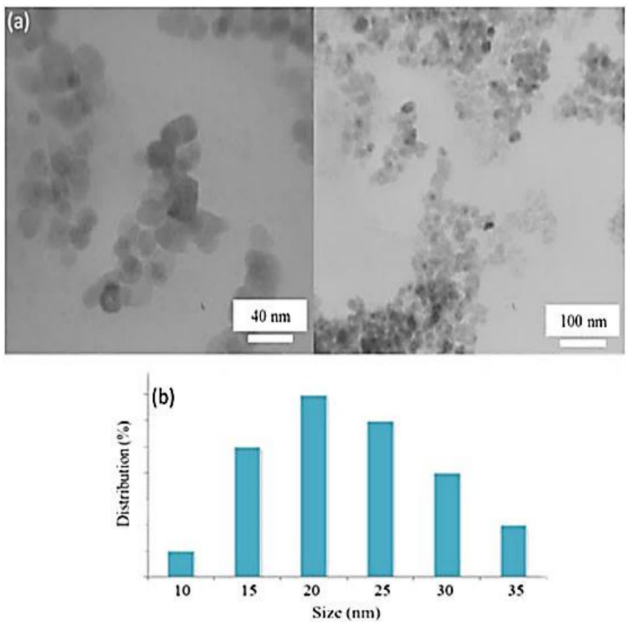

Figure 22. Left. (a) FE-SEM images and (b) SEM-EDX, right. (a) TEM images and (b) particle size distribution for magnetic iron oxide NPs- $N$-heterocyclic carbine-palladium(II). Reproduced with permission from [60].

An air- and moisture-stable catalyst was found to be an efficient and robust recyclable catalyst in the Heck and Suzuki-Miyaura cross-coupling reactions under mild conditions and products were obtained in good to excellent yields (Scheme 74). At the end of each reaction, catalyst recycling was performed; the catalyst was separated using a magnetic field, washed with ethanol and acetone, 
and reused at least 10 times without significant loss of its catalytic activity (90\% yield after the tenth run) or Pd leaching (less than 1\%).

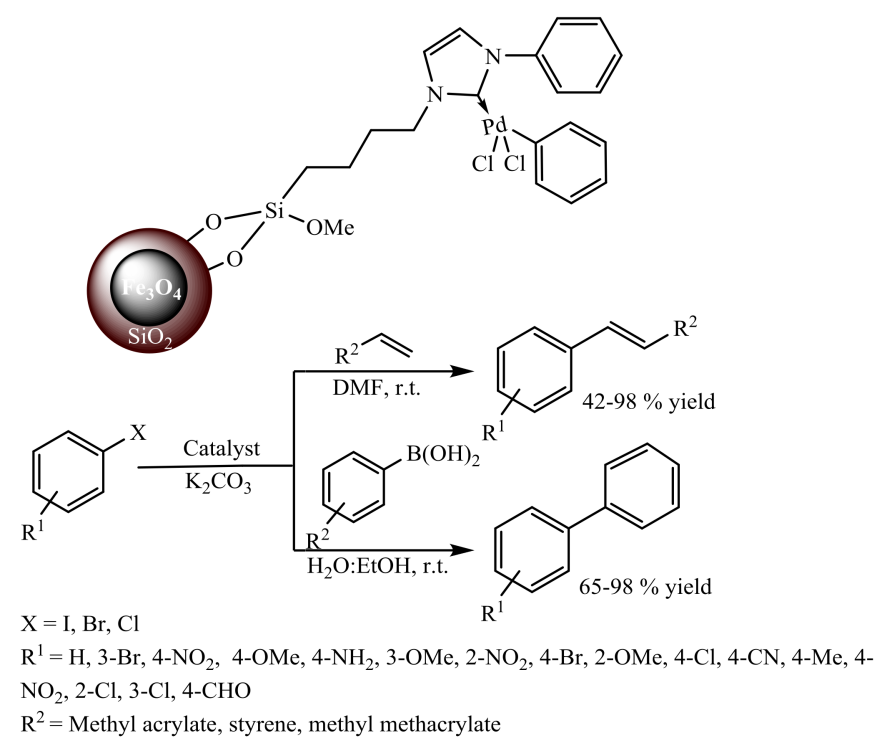

Scheme 74. Suzuki-Miyaura and Heck cross-coupling in the presence of magnetic iron oxide NPs-N-heterocyclic carbine-palladium(II) [60].

Faregh-Alamdari and co-workers synthesized a catalyst for a Suzuki-Miyaura cross-coupling reaction based on bis( $N$-heterocyclic carbene) palladium complex supported on silica-coated magnetic NPs (MNPs) by treatment of the magnetic NPs (D) with thionylchloride. In this approach, the Pd-NHC complex (C) was prepared from the reaction of a hydroxyl-functionalized bis-imidazolium ionic liquid (B) with $\mathrm{Pd}(\mathrm{OAc})_{2}$ (Scheme 75) [61].

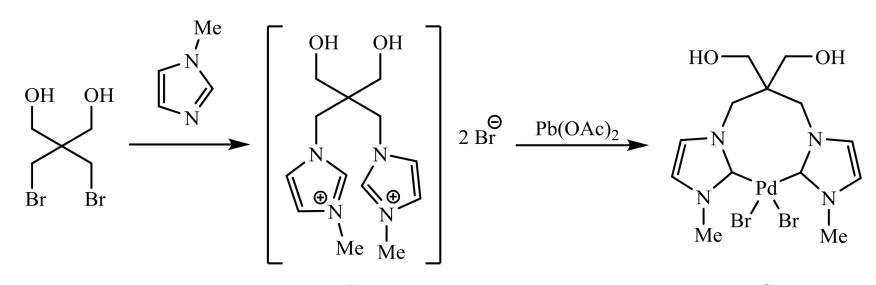

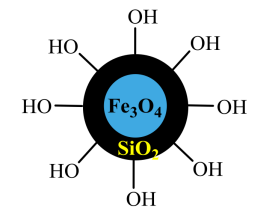

D

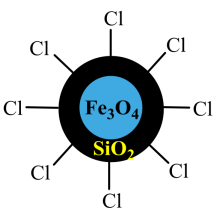

E
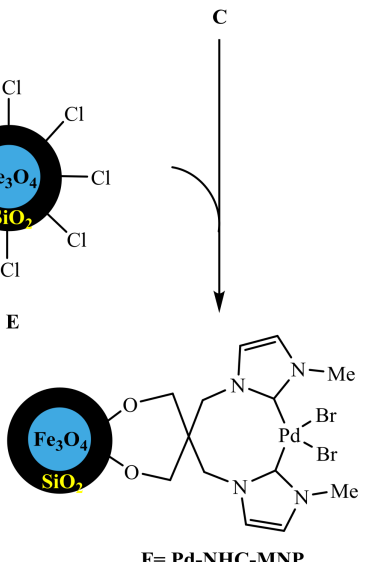

Scheme 75. Synthetic route toward synthesis of Pd-NHC-MNP catalyst. Reproduced with permission from [61].

The Pd-NHC-MNP catalyst was applied for the Suzuki-Miyaura reaction of various aryl halides and arylboronic acids in the presence of $\mathrm{K}_{2} \mathrm{CO}_{3}$ in $\mathrm{DMF} / \mathrm{H}_{2} \mathrm{O}(2: 1)$ at $80{ }^{\circ} \mathrm{C}$ to furnish diverse biaryl 
products after $0.8-2.15 \mathrm{~h}$ in yields of $58-99 \%$ (Scheme 76 ). Also, this catalyst can be magnetically separated from the reaction mixture of 4-iodoanisole and phenylboronic acid and washed thoroughly with acetone, diethyl ether, and water, and subsequently reused in six reaction runs with only a slight decrease in yield ( $97 \%$ to $88 \%$ ).

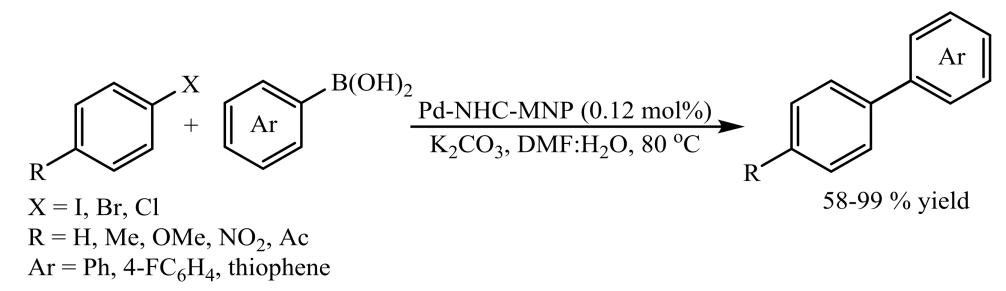

Scheme 76. Suzuki-Miyaura cross-coupling reactions of aryl halides and arylboronic acids catalyzed by Pd-NHC-MNP.

Sharma and co-workers synthesized a novel homogeneous $\operatorname{Pd}(\mathrm{II})$ catalyst incorporating a chelating thioether-NHC ligand. Moreover, to overcome the issue of the reusability of the catalyst and study the catalytic activity of the homo- and heterogeneous versions of the catalyst, the Pd complex was supported on aminopropyl-functionalized silica-coated magnetite NPs (Scheme 77) [62].
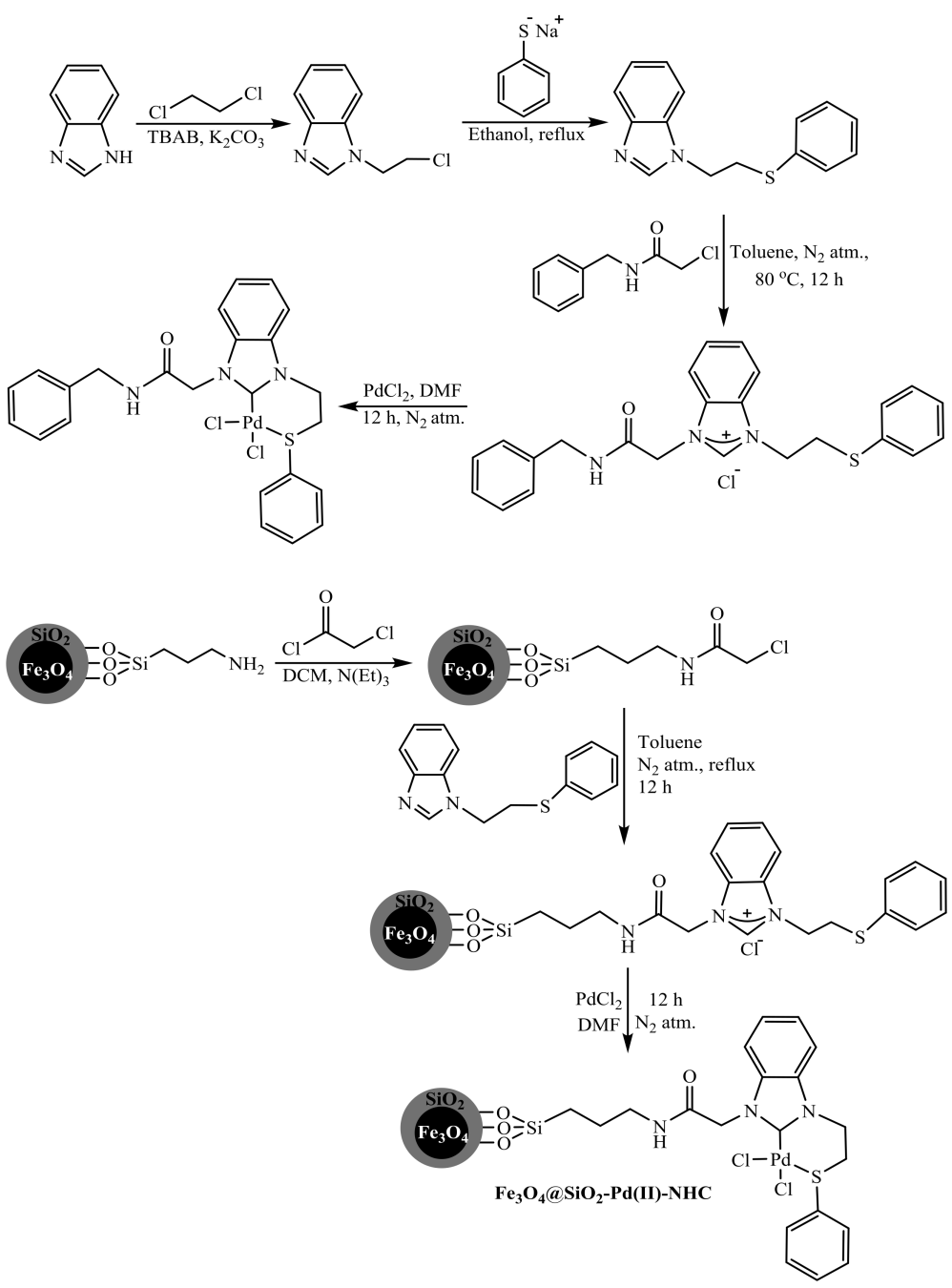

Scheme 77. Strategy used for the preparation of $\mathrm{Pd}$ (II)-NHC complex and solid-supported magnetically retrievable $\mathrm{Fe}_{3} \mathrm{O}_{4} @ \mathrm{SiO}_{2}-\mathrm{Pd}(\mathrm{II})-\mathrm{NHC}$ catalyst. Reproduced with permission from [62]. 
The catalyst was applied for the coupling reactions of various aryl/heteroaryl bromides in water in the presence of $\mathrm{K}_{2} \mathrm{CO}_{3}$ at room temperature (Scheme 78). Pd leaching was investigated by ICP for both $\mathrm{Pd}(\mathrm{II})-\mathrm{NHC}$ complex 1 and $\mathrm{Pd}(\mathrm{II})-\mathrm{NHC}$ catalyst $\mathrm{Fe}_{3} \mathrm{O}_{4} @ \mathrm{SiO}_{2}-\mathrm{Pd}(\mathrm{II})-\mathrm{NHC}$. The results revealed the homogeneity of the $\mathrm{Pd}(\mathrm{II})-\mathrm{NHC}$ complex; also, the negligible concentration of palladium in $\mathrm{Fe}_{3} \mathrm{O}_{4} @ \mathrm{SiO}_{2}-\mathrm{Pd}(\mathrm{II})-\mathrm{NHC}$ showed the largely heterogeneous nature of this catalyst. A comparative study of the catalytic activity of the homo- and heterogeneous versions of the catalyst demonstrated higher catalytic activity in terms of catalyst loading for Pd(II)-NHC complex, but deactivated after one cycle. However, recycling experiments for $\mathrm{Fe}_{3} \mathrm{O}_{4} @ \mathrm{SiO}_{2}-\mathrm{Pd}(\mathrm{II})-\mathrm{NHC}$ showed that the catalyst was easily separated from the reaction medium by using an external magnet and showed its activity for up to seven cycles.

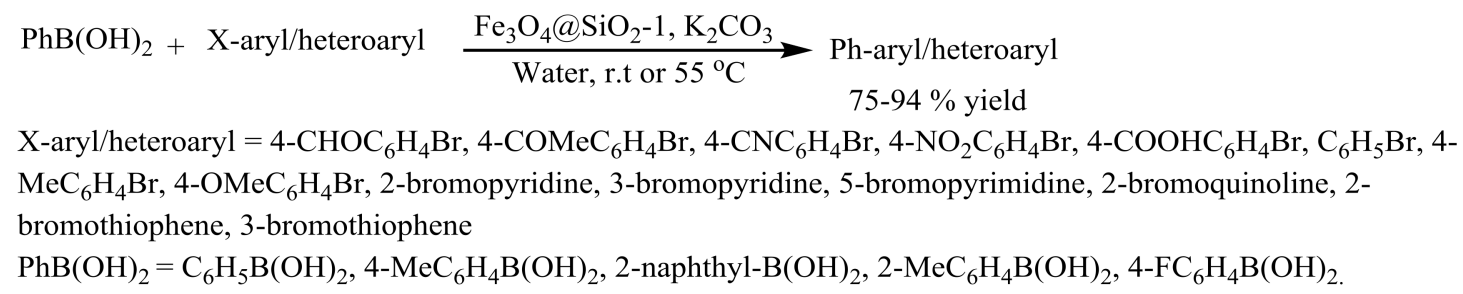

Scheme 78. Catalytic investigation of $\mathrm{Fe}_{3} \mathrm{O}_{4} @ \mathrm{SiO}_{2}-\mathrm{Pd}(\mathrm{II})-\mathrm{NHC}$ catalyst in the Suzuki-Miyaura coupling of aryl/heteroaryl bromides with arylboronic acids [62].

Martín and co-workers reported the core-shell $\mathrm{Fe}_{3} \mathrm{O}_{4} @ \mathrm{Pd}$ superparamagnetic NPs (MNPs) by metal complex thermal decomposition and investigated the role of different stabilizers such as oleylamine (OA), triphenylphosphine (TPP) and triphenylamine (TPA) in the synthesis and catalytic activity of MNPs [63]. Among the three stabilizers, the OA with dual function (both reducing and stabilizing) was capable of producing spherical Pd NPs with small size and uniform shell around the magnetite core, which is confirmed with HRTEM, TGA, magnetic behavior, and dark-field images (Figure 23). In addition to the roles described above, OA prevents the oxidation of the $\operatorname{Pd}(0)$ shell.
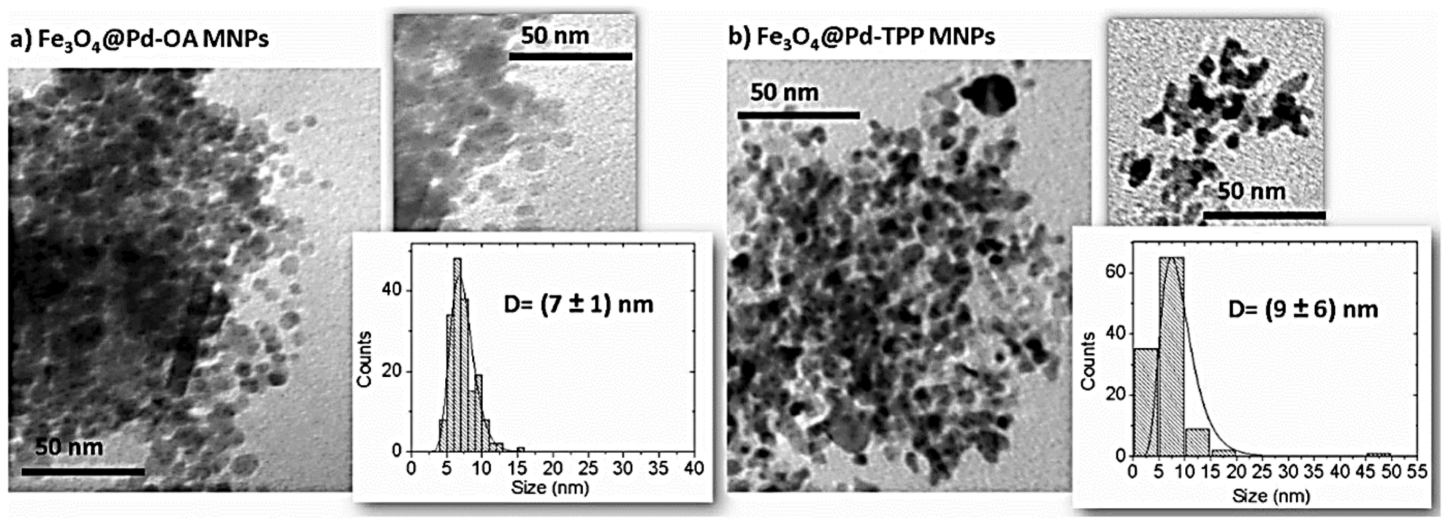

Figure 23. TEM micrographs for core-shell $\mathrm{Fe}_{3} \mathrm{O}_{4} @ \mathrm{Pd}-\mathrm{OA}(\mathbf{a})$ and $\mathrm{Fe}_{3} \mathrm{O}_{4} @ \mathrm{Pd}-\mathrm{TPP}(\mathbf{b})$. Reproduced with permission from [63].

The resulting core-shell MNPs catalyst was demonstrated to be highly active for Heck and Suzuki-Miyaura coupling reactions for the synthesis of stilbenes and biaryl compounds (Scheme 79). In addition, the recyclability of $\mathrm{Fe}_{3} \mathrm{O}_{4} @ \mathrm{Pd}-\mathrm{OA}$ MNPs was evaluated in a C-C coupling reaction and showed good activity for at least four cycles. 

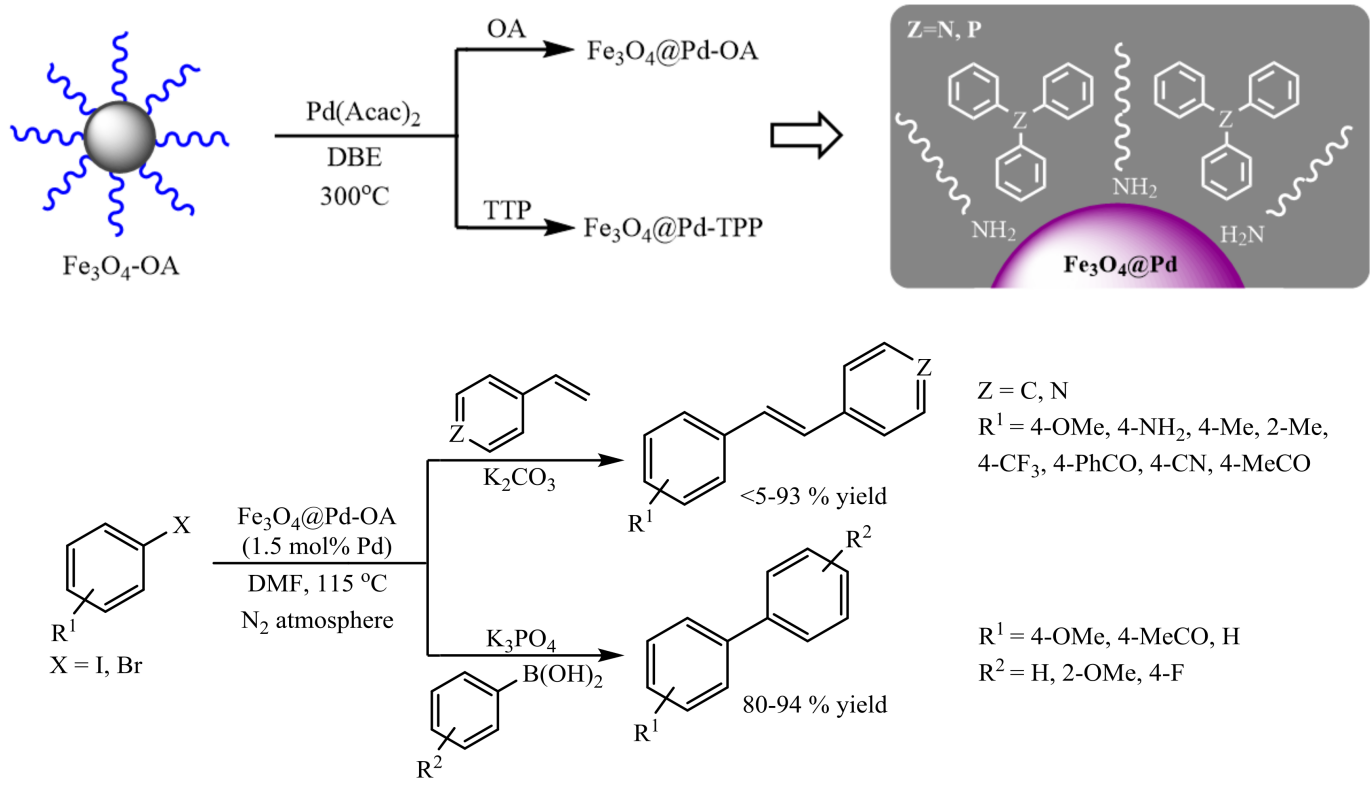

Scheme 79. Catalytic activity of $\mathrm{Fe}_{3} \mathrm{O}_{4} @ P d-\mathrm{OA}$ in Heck coupling and Suzuki-Miyaura cross-coupling reactions. Reproduced with permission from [63].

Rafiee and Mehdizadeh modified the surface of silica-coated $\mathrm{Fe}_{3} \mathrm{O}_{4}$ NPs with a palladium $N$-heterocyclic carbene complex of vitamin B1. The $\mathrm{Fe}_{3} \mathrm{O}_{4} \mathrm{NPs}$ were synthesized through a co-precipitation procedure, hydrolyzing TEOS in the presence of these NPs followed by covalent connection with thiamine hydrochloride (VB1) to obtain an $\mathrm{N}$-heterocyclic carbene ligand for the formation of complex with palladium [64]. The resulting nanocomposite was composed of well-dispersed spherical Pd NPs with average size $<5 \mathrm{~nm}$ (Figure 24).
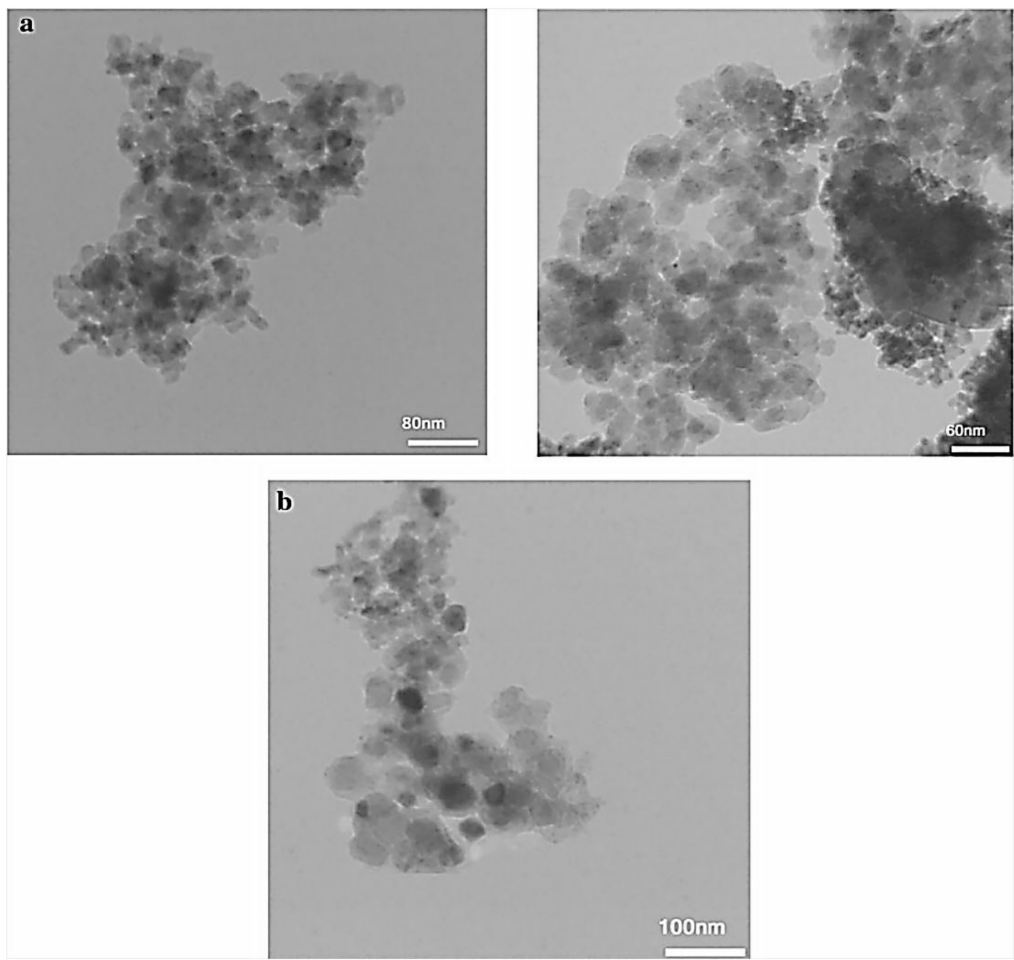

Figure 24. TEM images of fresh (a) and four-times reused $\mathrm{Fe}_{3} \mathrm{O}_{4} @ \mathrm{SiO}_{2} @ V B 1-\mathrm{Pd}$ nanocatalyst (b). Reproduced with permission from [64]. 
This catalyst was active in the Suzuki-Miyaura coupling reaction of aryl halides with substituted arylboronic acids in the presence of $\mathrm{Fe}_{3} \mathrm{O}_{4} @ \mathrm{SiO}_{2} @ \mathrm{VB} 1-\mathrm{Pd}$ in EtOH at $60^{\circ} \mathrm{C}$ resulted in the formation of biaryl products in $55-99 \%$ yield (Scheme 80 ). After completion of the reaction, the catalyst separated magnetically from the reaction mixture. After washing with ethanol and drying, it was applied for the next reaction and showed good yield and suitable time for five runs.
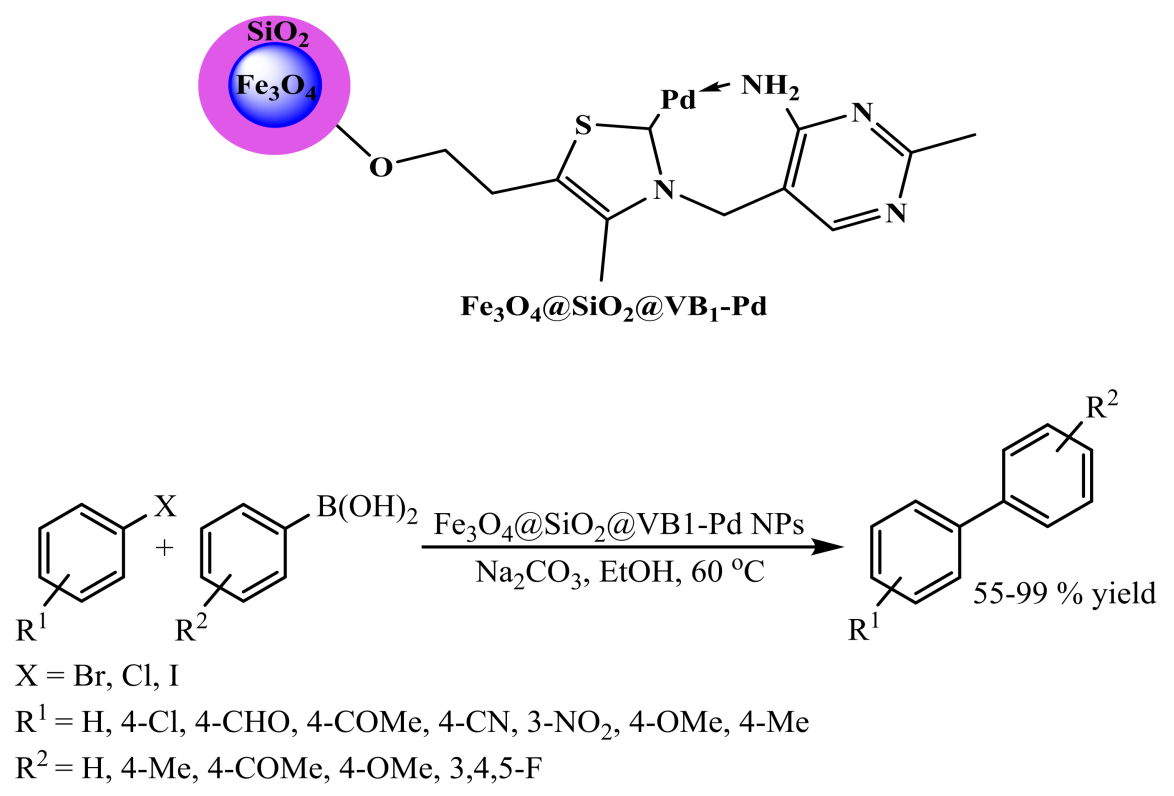

Scheme 80. The synthesis of various biphenyl derivatives using $\mathrm{Fe}_{3} \mathrm{O}_{4} @ \mathrm{SiO}_{2} @ V B 1-\mathrm{Pd}$ catalyst [64].

\subsection{Magnetic Porous Nanocomposites}

In 2010, Thiel and co-workers prepared a heterogeneous catalyst for the Suzuki-Miyaura cross-coupling reaction by covalent grafting of a trimethoxysilyl-functionalized palladium(II) phosphane complex on silica-coated maghemite NPs (Scheme 81) [65].

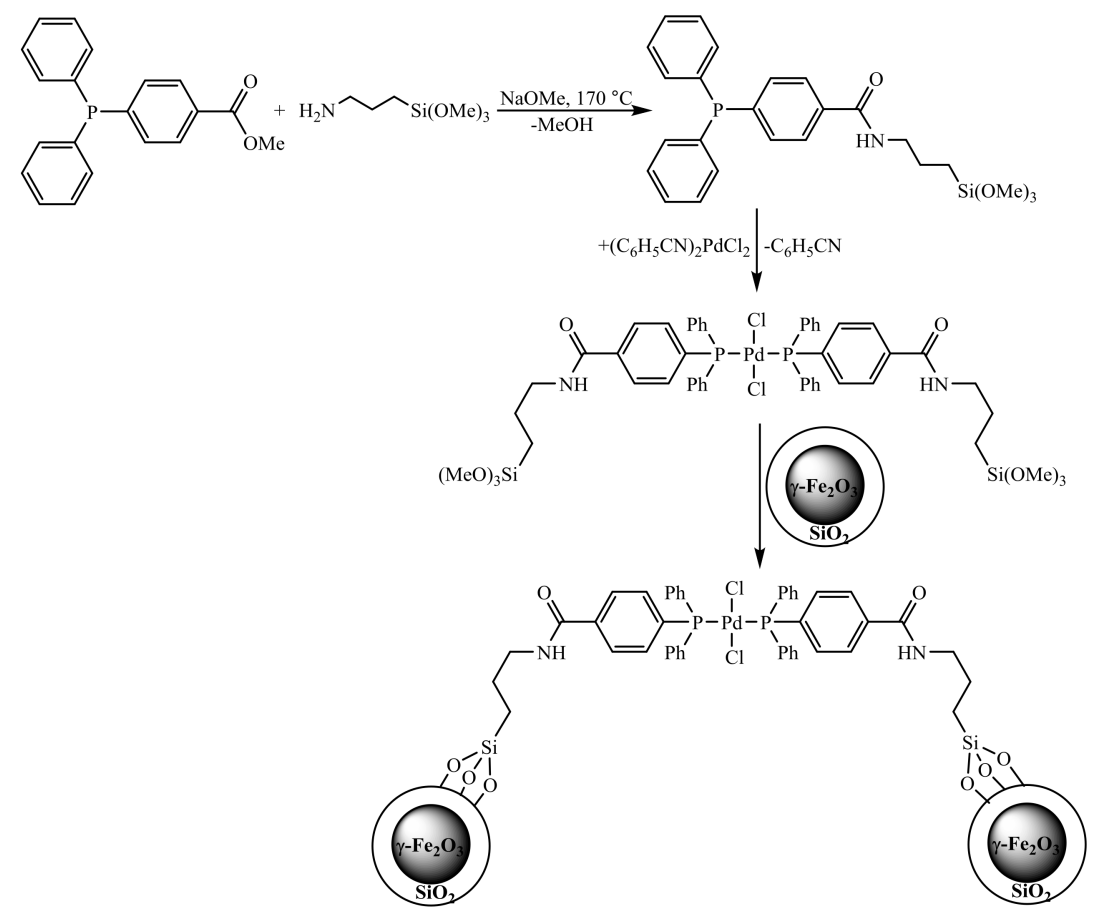

Scheme 81. Magnetic mesoporous silica nanosphere immobilized Pd complex [65]. 
This heterogeneous nanocatalyst in dioxane and in the presence of $\mathrm{Cs}_{2} \mathrm{CO}_{3}$ at $80{ }^{\circ} \mathrm{C}$ catalyzed a coupling reaction of aryl iodides or bromides with phenylboronic acid (Scheme 82). The authors reported the efficiency of this catalyst, by comparison of the activity and stability between this reported catalyst and heterogenized catalysts such as Pd supported on commercially available silica gel and mesoporous MCM-41 in a Suzuki-Miyaura reaction. The $\mathrm{PPh}_{3}-\mathrm{Pd} @ \mathrm{SiO}_{2} / \mathrm{Fe}_{2} \mathrm{O}_{3}$ could easily be recovered by a magnet, and after washing and drying, it can be reused seven times without a marked loss of its catalytic activity.

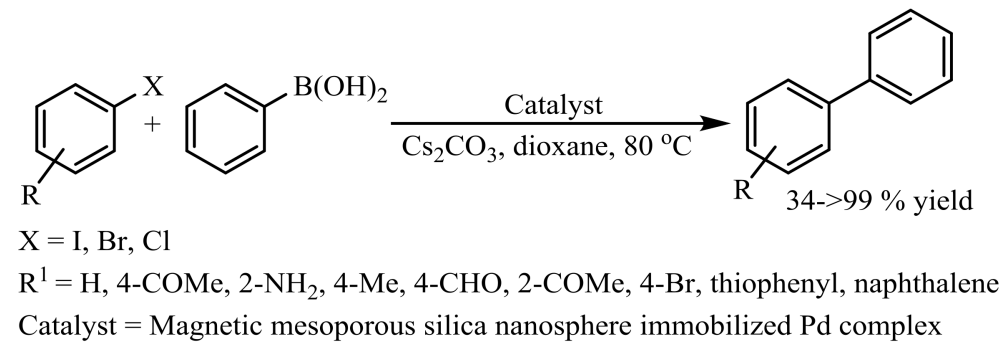

Scheme 82. Suzuki-Miyaura cross coupling of aryl halides and phenylboronic acid in the presence of magnetic mesoporous silica nanosphere immobilized Pd complex [65].

Dong and co-workers, through the functionalization of core-shell magnetic mesoporous material with a $\mathrm{Pd}(\mathrm{II})$ complex, prepared a recyclable catalyst for a Suzuki-Miyaura cross-coupling reaction [66]. Refluxing 2,6-diformyl-4-methylphenol with APTES in toluene, followed by the addition of mesoporous material $\mathrm{Fe}_{3} \mathrm{O}_{4} @ \mathrm{SiO}_{2} @ \mathrm{mSiO}_{2}$, resulted in the preparation of ligand-functionalized magnetic mesoporous; finally, treating this material with $\mathrm{Pd}(\mathrm{OAc})_{2}$ led to the formation of a magnetic mesoporous Pd(II) complex (Scheme 83).

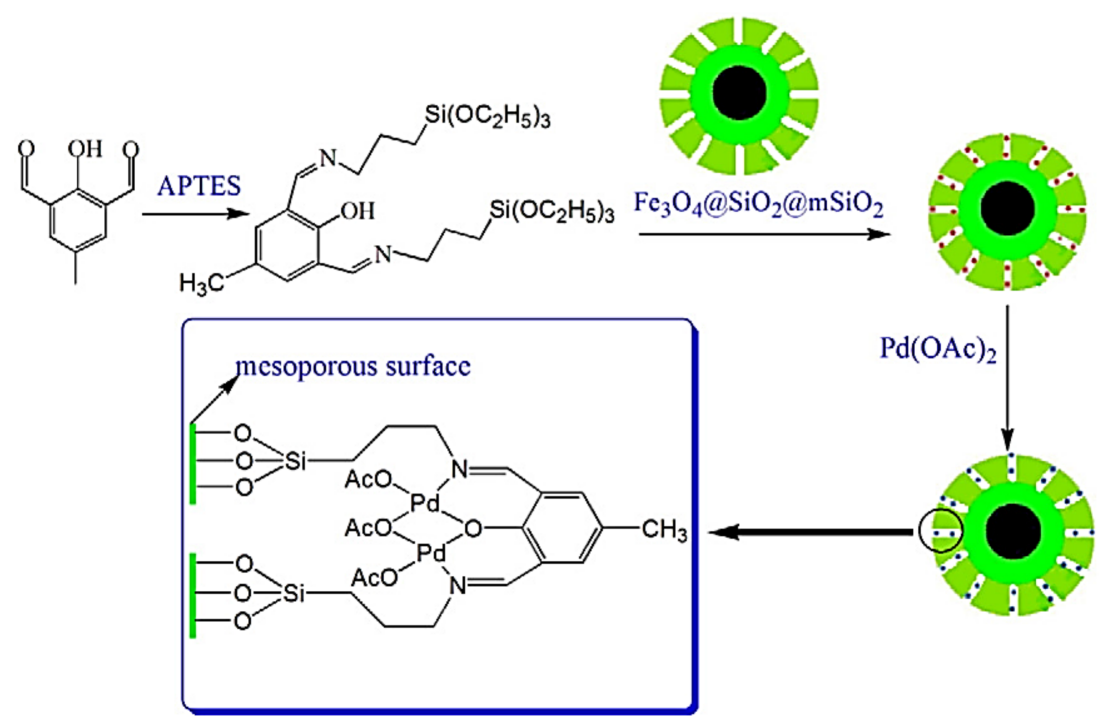

Scheme 83. Preparation of the $\mathrm{Fe}_{3} \mathrm{O}_{4} @ \mathrm{SiO}_{2} @ \mathrm{mSiO}_{2}-\mathrm{Pd}(\mathrm{II})$ catalyst. Reproduced with permission from [66].

Suzuki-Miyaura cross-coupling reaction between aryl halides and arylboronic acids with $0.5 \mathrm{~mol}$ $\%$ of obtained catalyst, in the presence of $\mathrm{K}_{2} \mathrm{CO}_{3}$ in $\mathrm{EtOH}$ at $80^{\circ} \mathrm{C}$, resulted in the preparation of biaryls products in excellent yields ( $\mathrm{Scheme} 84$ ). $\mathrm{Fe}_{3} \mathrm{O}_{4} @ \mathrm{SiO}_{2} @ \mathrm{mSiO}_{2}-\mathrm{Pd}(\mathrm{II})$ acted as an efficient and reusable catalyst that could provide high conversion even after six catalytic runs. 


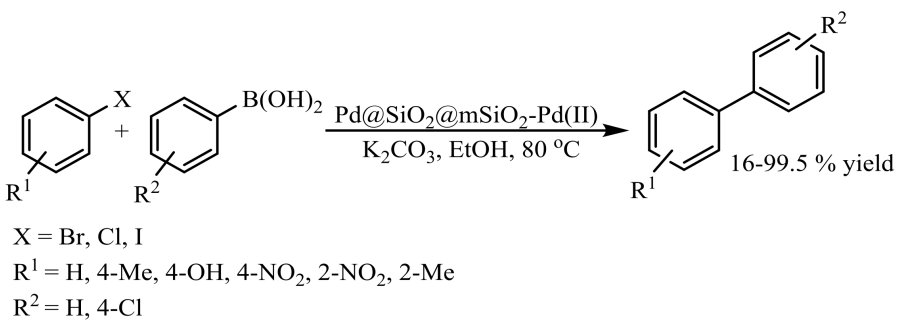

Scheme 84. The Suzuki-Miyaura cross coupling reactions of aryl halides with arylboronic acids using the $\mathrm{Fe}_{3} \mathrm{O}_{4} @ \mathrm{SiO}_{2} @ \mathrm{mSiO}_{2}-\mathrm{Pd}(\mathrm{II})$ catalyst [66].

Preparation of hollow magnetic mesoporous spherical catalyst was achieved by $\mathrm{Ma}$ and co-workers [67]. They anchored the Schiff base ligand, $N, N^{\prime}$-bis(3-salicylidenaminopropyl)amine (salpr), on the surface of the hollow magnetic mesoporous spheres (HMMS) and finished the complex formation by treatment of the resulting materials with $\mathrm{PdCl}_{2}$ (Scheme 85). The TEM images in Figure 25 reveal HMMS with a diameter of about $250 \mathrm{~nm}$ via a layer of $\mathrm{SiO}_{2}$ with a thickness of about $40 \mathrm{~nm}$. A TEM image of the HMMS-salpr-Pd showed palladium NPs with an average size of about $5 \mathrm{~nm}$ on the surface of a hollow magnetic silica sphere.

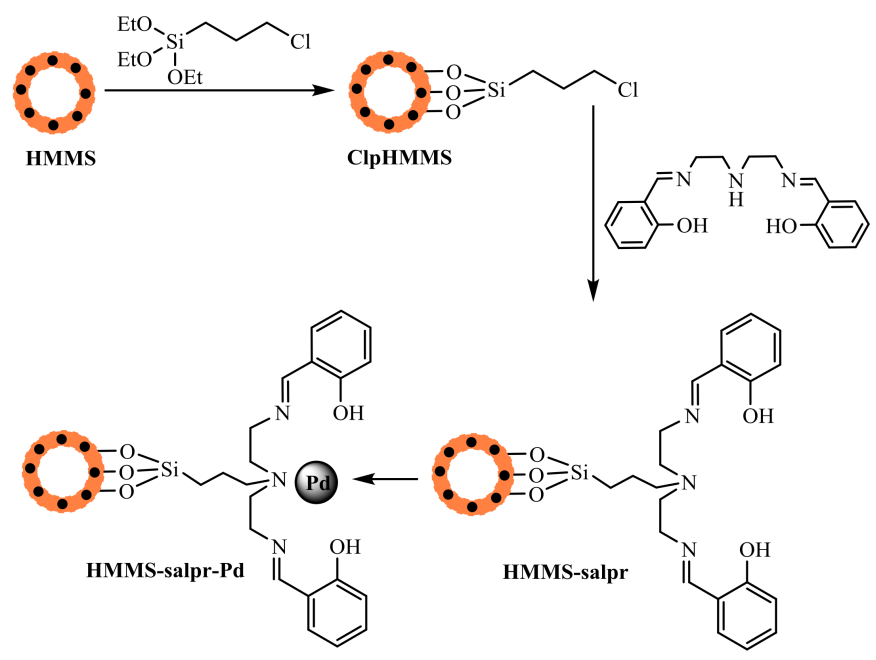

Scheme 85. Preparation of the catalysts [67].

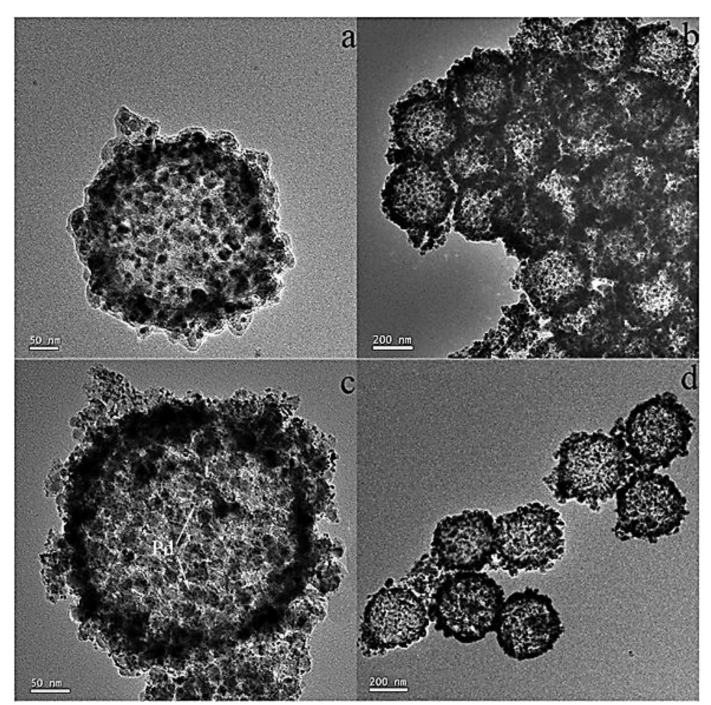

Figure 25. TEM images of (a,b) HMMS and (c) HMMS-salpr-Pd and (d) HMMS-salpr-Pd after six reuses [67]. 
A magnetic mesoporous catalyst was tested for Suzuki-Miyaura coupling reactions and showed very good to excellent yields (Scheme 86). After the transformations, HMMS-salpr-Pd was recovered simply using an external magnet and could be recycled six times without any loss of activity.

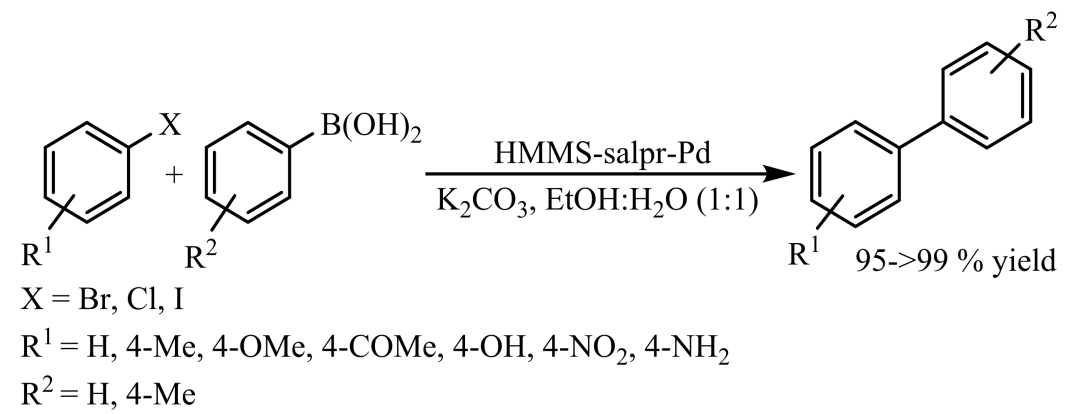

Scheme 86. HMMS-salpr-Pd catalyst for Suzuki-Miyaura coupling reaction [67].

Nikoorazm and co-workers prepared a $\mathrm{Fe}_{3} \mathrm{O}_{4} @ \mathrm{MCM}-41 @ P d-S P A T B$ catalyst by immobilizing $\mathrm{Pd}(0)-S$-propyl-2-aminobenzothioate complex onto functionalized magnetic nanoporous MCM-41 (Scheme 87) [68].

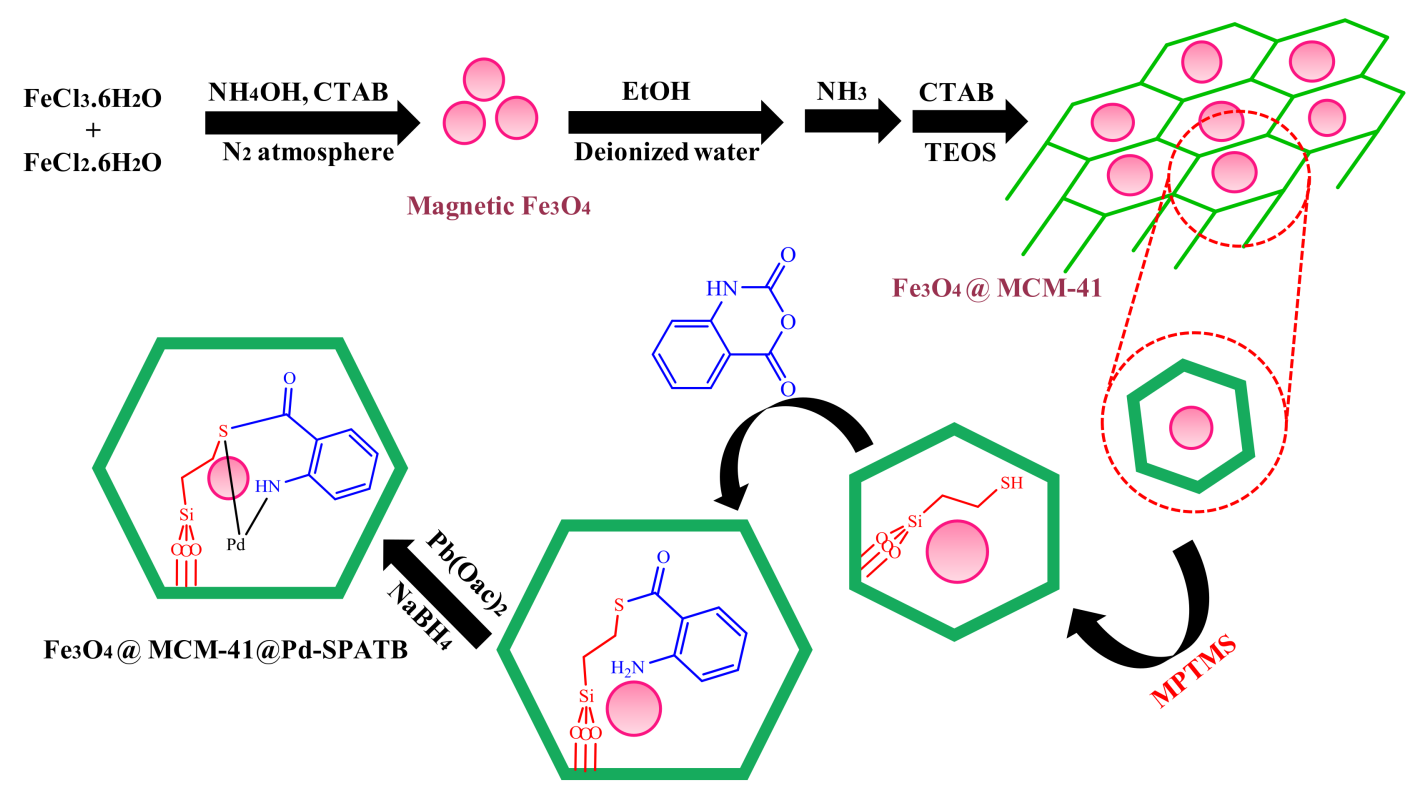

Scheme 87. Synthesis of $\mathrm{Fe}_{3} \mathrm{O}_{4} @ \mathrm{MCM}-41 @ P d-S P A T B$. Reproduced with permission from [68].

The resulting nano-organometallic catalyst was tested with various substrates for Suzuki-Miyaura, Still, and Heck couplings in PEG-400 as green solvent. The best result in Suzuki-Miyaura reaction of iodobenzene with phenylboronic acid was obtained with $\mathrm{K}_{2} \mathrm{CO}_{3}$ as the base at $80{ }^{\circ} \mathrm{C}$. Meanwhile, completion of the reaction for less reactive aryl chlorides requires a higher temperature $\left(100{ }^{\circ} \mathrm{C}\right)$. Under the optimized conditions, aryl halides coupled with phenylboronic acid and the biphenyl derivatives were obtained in high yields and a short reaction time. In the case of a Still reaction of iodobenzene and $\mathrm{Ph}_{3} \mathrm{SnCl}, \mathrm{K}_{2} \mathrm{CO}_{3}$ was selected as the proper base at $80{ }^{\circ} \mathrm{C}$. After optimization, aryl halides coupled with $\mathrm{Ph}_{3} \mathrm{SnCl}$ in excellent yields. Finally, high yield and high conversion for Heck reaction of iodobenzene and $n$-butyl acrylate were obtained in the presence of $\mathrm{K}_{2} \mathrm{CO}_{3}$ as the base at $120^{\circ} \mathrm{C}$. Under the optimized conditions, aryl halide derivatives coupled with $n$-butyl acrylate in high yields (Scheme 88). In addition, the catalyst can be easily separated from the reaction mixture by applying an external magnet and can be reused for five sequential runs with no remarkable loss of stability and activity. 


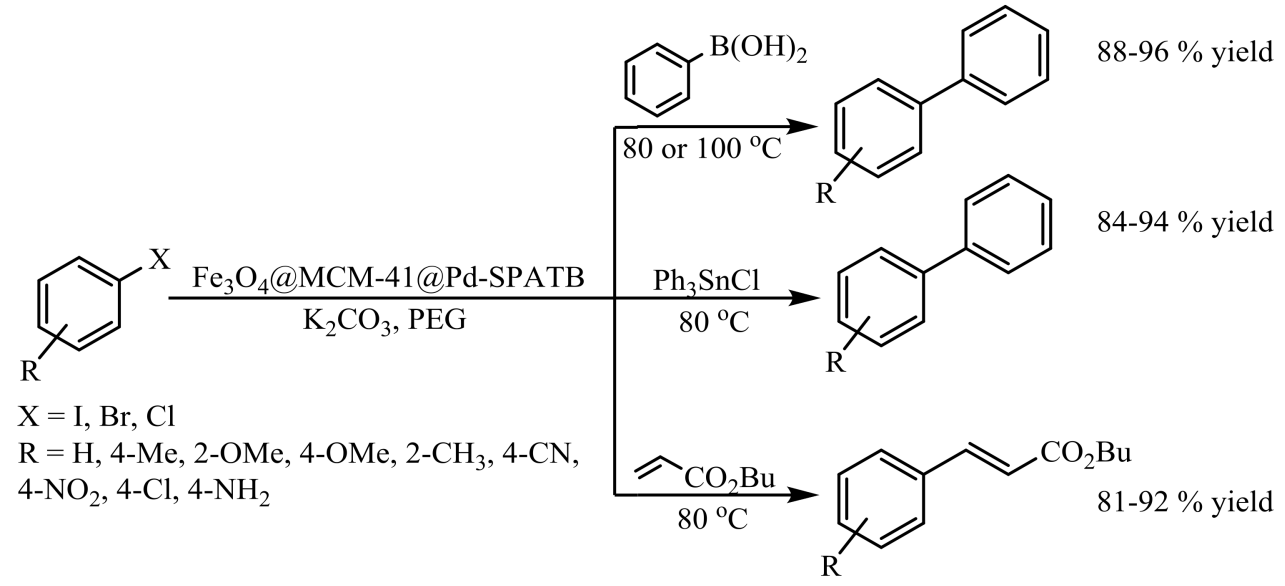

Scheme 88. Catalytic activity of $\mathrm{Fe}_{3} \mathrm{O}_{4} @ M C M-41 @ P d-S P A T B$ in Suzuki-Miyaura, Still, and Heck cross-coupling reactions [68].

\section{Conclusions}

Magnetic nanocatalysts have emerged as valuable catalysts for a number of catalytic transformations. Preparing Pd complexes supported on magnetic nanoparticles introduces new possibilities for catalysis due to their excellent properties such as reusability and thermal stability. We have seen that Pd complexes can interact with some magnetic nanoparticles and are able to catalyze a widespread number of $\mathrm{C}-\mathrm{C}$ and $\mathrm{C}-\mathrm{X}$ coupling reactions that require the presence of transition metals such as palladium. In this review, convenient methods of anchoring or immobilizing $\mathrm{Pd}$ complexes on the magnetic supports, magnetic polymer, and porous nanocomposites are investigated in order to synthesize recoverable magnetic nanocatalysts and achieve their characterization. Directed functionalization of the magnetic nanomaterial surfaces is an effective way for Pd complexes heterogenization for magnetic separation. These nanocatalysts showed excellent catalytic performance in C-X and C-C coupling reactions and can be recycled from the reaction mixture and reused several times without a marked loss of catalytic activity.

Reported methods for the C-X and C-C coupling reactions using magnetic nanocatalysts suffer from drawbacks such as the use of toxic solvents, expensive materials, harsh reaction conditions, low yields, and long reaction times. Therefore, it is desirable to devise simple and efficient methods for the $\mathrm{C}-\mathrm{X}$ and $\mathrm{C}-\mathrm{C}$ coupling reactions using safer and cheaper magnetic nanocatalysts under aqueous reaction conditions, in ethanol or a $\mathrm{H}_{2} \mathrm{O}: \mathrm{EtOH}$ mixture.

Nowadays, researchers are working on finding novel synthetic routes to improve magnetic catalytic systems. Moreover, these magnetic systems can be ideal for the immobilization of other transition metals. The sustainable synthesis of magnetic nanocatalysts using less toxic and more readily available reagents as well as environmentally benign solvents or supports under ambient conditions will also make this field of chemical research more "green." Thus, the chance to prepare new magnetic nanocatalysts with excellent catalytic activity is an issue still open to researchers to improve the coupling reactions in the future.

Funding: This research received no external funding.

Acknowledgments: I gratefully acknowledge the University of Qom and the Iranian Nano Council for the support of this review article. I am also deeply indebted to all the researchers mentioned in the references for their contributions to the development of $\mathrm{C}-\mathrm{C}$ and $\mathrm{C}-\mathrm{X}$ coupling reactions using magnetic nanocatalysts supported palladium complexes.

Conflicts of Interest: The authors declare no conflict of interest. 


\section{References}

1. Yin, L.; Liebscher, J. Carbon-carbon coupling reactions catalyzed by heterogeneous palladium catalysts. Chem. Rev. 2007, 107, 133-173. [CrossRef] [PubMed]

2. Tsuji, J. New perspectives for the 21st century. In Palladium Reagents and Catalysts; John Wiley Sons, Ltd.: Chichester, UK, 2005; Volume 9, p. 670.

3. Nasrollahzadeh, M.; Maham, M.; Tohidi, M.M. Green synthesis of water-dispersable palladium nanoparticles and their catalytic application in the ligand- and copper-free Sonogashira coupling reaction under aerobic conditions. J. Mol. Catal. A Chem. 2014, 391, 83-87. [CrossRef]

4. Fakhri, P.; Nasrollahzadeh, M.; Jaleh, B. Graphene oxide supported Au nanoparticles as an efficient catalyst for reduction of nitro compounds and Suzuki-Miyaura coupling in water. RSC Adv. 2014, 4, 48691-48697. [CrossRef]

5. Nasrollahzadeh, M.; Banaei, A. Hybrid Au/Pd nanoparticles as reusable catalysts for Heck coupling reactions in water under aerobic conditions. Tetrahedron Lett. 2015, 56, 500-503. [CrossRef]

6. Nasrollahzadeh, M.; Sajadi, S.M.; Rostami-Vartooni, A.; Bagherzadeh, M. Green synthesis of Pd/CuO nanoparticles by Theobroma cacao L. seeds extract and their catalytic performance for the reduction of 4-nitrophenol and phosphine-free Heck coupling reaction under aerobic conditions. J. Colloid Interface Sci. 2015, 448, 106-113. [CrossRef] [PubMed]

7. Suzuki, A. Cross-coupling reactions via organoboranes. J. Organomet. Chem. 2002, 653, 83-90. [CrossRef]

8. Nasrollahzadeh, M.; Sajadi, S.M.; Rostami-Vartooni, A.; Khalaj, M. Green synthesis of $\mathrm{Pd}_{/} \mathrm{Fe}_{3} \mathrm{O}_{4}$ nanoparticles using Euphorbia condylocarpa M. bieb root extract and their catalytic applications as magnetically recoverable and stable recyclable catalysts for the phosphine-free Sonogashira and Suzuki coupling reactions. J. Mol. Catal. A Chem. 2015, 396, 31-39. [CrossRef]

9. Nasrollahzadeh, M.; Sajadi, S.M.; Maham, M. Green synthesis of palladium nanoparticles using Hippophae rhamnoides Linn leaf extract and their catalytic activity for the Suzuki-Miyaura coupling in water. J. Mol. Catal. A Chem. 2015, 396, 297-303. [CrossRef]

10. Chatterjee, A.; Ward, T. Recent advances in the palladium catalyzed Suzuki-Miyaura cross-coupling reaction in water. Cat. Lett. 2016, 146, 820-840. [CrossRef]

11. Nasrollahzadeh, M.; Atarod, M.; Alizadeh, M.; Hatamifard, A.; Sajadi, S.M. Recent advances in the application of heterogeneous nanocatalysts for Sonogashira coupling reactions. Curr. Org. Chem. 2017, 21, 708-749. [CrossRef]

12. Nasrollahzadeh, M.; Issaabadi, Z.; Tohidi, M.M.; Sajadi, S.M. Recent progress in application of graphene supported metal nanoparticles in C-C and C-X coupling reactions. Chem. Rec. 2018, 18, 165-229. [CrossRef] [PubMed]

13. Jaleh, B.; Khalilipour, A.; Habibi, S.; Niyaifar, M.; Nasrollahzadeh, M. Synthesis, characterization, magnetic and catalytic properties of graphene oxide $/ \mathrm{Fe}_{3} \mathrm{O}_{4}$. J. Mater. Sci. Mater. Electron. 2017, 28, 4974-4983. [CrossRef]

14. Yao, Y.; Patzig, C.; Hu, Y.; Scott, R.W.J. In Situ X-ray absorption spectroscopic study of Fe@FexOy/Pd and Fe@FexOy/Cu nanoparticle catalysts prepared by galvanic exchange reactions. J. Phys. Chem. C 2015, 119, 21209-21218. [CrossRef]

15. Wang, D.; Astruc, D. Fast-growing field of magnetically recyclable nanocatalysts. Chem. Rev. 2014, 114, 6949-6985. [CrossRef] [PubMed]

16. Sajjadi, M.; Nasrollahzadeh, M.; Sajadi, S.M. Green synthesis of $\mathrm{Ag} / \mathrm{Fe}_{3} \mathrm{O}_{4}$ nanocomposite using Euphorbia peplus L. leaf extract and evaluation of its catalytic activity. J. Colloid Interface Sci. 2017, 497, 1-13. [CrossRef] [PubMed]

17. Sydnes, M.O. The use of palladium on magnetic support as catalyst for Suzuki-Miyaura cross-coupling reactions. Catalysts 2017, 7, 35. [CrossRef]

18. Naghipor, A.; Fakhri, A. Heterogeneous $\mathrm{Fe}_{3} \mathrm{O}_{4} @$ chitosan-Schiff base Pd nanocatalyst: Fabrication, characterization and application as highly efficient and magnetically-recoverable catalyst for Suzuki-Miyaura and Heck-Mizoroki C-C coupling reactions. Catal. Commun. 2016, 73, 39-45. [CrossRef]

19. Rangraz, Y.; Nemati, F.; Elhampour, E. Organoselenium-palladium(II) complex immobilized on functionalized magnetic nanoparticles as a promising retrievable nanocatalyst for the "phosphine-free" Heck-Mizoroki coupling reaction. New J. Chem. 2018, 42, 15361-15371. [CrossRef] 
20. Li, Y.; Zhang, Z.; Fan, T.; Li, X.; Dong, P.; Baines, R.; Shen, J.; Ye, M. Magnetic core-shell to yolk-shell structures in palladium-catalyzed Suzuki-Miyaura reactions: Heterogeneous versus homogeneous nature. ChemPlusChem 2016, 81, 564-573. [CrossRef]

21. Laska, U.; Frost, C.G.; Price, G.J.; Plucinski, P.K. Easy-separable magnetic nanoparticle-supported Pd catalysts: Kinetics, stability and catalyst re-use. J. Catal. 2009, 268, 318-328. [CrossRef]

22. Ay, A.N.; Abramova, N.V.; Konuk, D.; Lependina, O.L.; Sokolov, V.I.; Zümreoglu-Karan, B. Magnetically-recoverable Pd-immobilized layered double hydroxide-iron oxide nanocomposite catalyst for carbon-carbon cross-coupling reactions. Inorg. Chem. Commun. 2013, 27, 64-68. [CrossRef]

23. Schätz, A.; Long, T.R.; Grass, R.N.; Stark, W.J.; Hanson, P.R.; Reiser, O. Immobilization on a nanomagnetic Co/C surface using ROM polymerization: Generation of a hybrid material as support for a recyclable palladium catalyst. Adv. Funct. Mater. 2010, 20, 4323-4328. [CrossRef] [PubMed]

24. Zeltner, M.; Schätz, A.; Hefti, M.L.; Stark, W.J. Magnetothermally responsive C/Co@PNIPAM-nanoparticles enable preparation of self-separating phase-switching palladium catalysts. J. Mater. Chem. 2011, 21, 2991-2996. [CrossRef]

25. Li, W.; Tian, Y.; Zhang, B.; Tian, L.; Li, X.; Zhang, H.; Ali, N.; Zhang, Q. Fabrication of a $\mathrm{Fe}_{3} \mathrm{O}_{4} @ \mathrm{SiO}_{2} @ \mathrm{mSiO}_{2}-\mathrm{HPG}-\mathrm{COOH}-\mathrm{Pd}(0)$ supported catalyst and its performance in catalyzing the Suzuki cross-coupling reaction. New J. Chem. 2015, 39, 2767-2777. [CrossRef]

26. Li, W.; Jia, X.; Zhang, B.; Tian, L.; Li, X.; Zhang, H.; Zhang, Q. Fabrication of PEI grafted $\mathrm{Fe}_{3} \mathrm{O}_{4} @ \mathrm{SiO}_{2} / \mathrm{P}(\mathrm{GMA}-\mathrm{co}-\mathrm{EGDMA})$ nanoparticle anchored palladium nanocatalyst and its application in Sonogashira cross-coupling reactions. New J. Chem. 2015, 39, 2925-2934. [CrossRef]

27. Liu, X.; Zhao, X.; Lu, M. A highly water-dispersible and magnetically separable palladium catalyst based on functionalized poly(ethylene glycol)-supported iminophosphine for Suzuki-Miyaura coupling in water. Appl. Organomet. Chem. 2015, 29, 419-424. [CrossRef]

28. Yuan, D.; Chen, L.; Yuan, L.; Liao, S.; Yang, M.; Zhang, Q. Superparamagnetic polymer composite microspheres supported Schiff base palladium complex: An efficient and reusable catalyst for the Suzuki coupling reactions. Chem. Eng. J. 2016, 287, 241-251. [CrossRef]

29. Tabatabaei Rezaei, S.J.; Shamseddin, A.; Ramazani, A.; Mashhadi Malekzadeh, A.; Azimzadeh Asiabi, P. Palladium nanoparticles immobilized on amphiphilic and hyperbranched polymer-functionalized magnetic nanoparticles: an efficient semi-heterogeneous catalyst for Heck reaction. Appl. Organomet. Chem. 2017, 31, e3707. [CrossRef]

30. Lv, G.; Mai, W.; Jin, R.; Gao, L. Immobilization of dipyridyl complex to magnetic nanoparticle via click chemistry as a recyclable catalyst for Suzuki cross-coupling reactions. Synlett 2008, 2008, 1418-1422. [CrossRef]

31. Phan, N.T.S.; Le, H.V. Superparamagnetic nanoparticles-supported phosphine-free palladium catalyst for the Sonogashira coupling reaction. J. Mol. Catal. A Chem. 2011, 334, 130-138. [CrossRef]

32. Zheng, J.; Lin, S.; Jiang, B.-W.; Marder, T.B.; Yang, Z. The role of magnetic nanoparticles (MNP) as reducing agents in an MNP-supported Pd-catalyst for the reductive homocoupling of aryl halides. Can. J. Chem. 2012, 90, 138-144. [CrossRef]

33. Esmaeilpour, M.; Sardarian, A.R.; Javidi, J. Synthesis and characterization of Schiff base complex of Pd(II) supported on superparamagnetic $\mathrm{Fe}_{3} \mathrm{O}_{4} @ \mathrm{SiO}_{2}$ nanoparticles and its application as an efficient copper- and phosphine ligand-free recyclable catalyst for Sonogashira-Hagihara coupling reactions. J. Organomet. Chem. 2014, 749, 233-240. [CrossRef]

34. Sobhani, S.; Pakdin-Parizi, Z. Palladium-DABCO complex supported on $\gamma-\mathrm{Fe}_{2} \mathrm{O}_{3}$ magnetic nanoparticles: A new catalyst for $\mathrm{C}-\mathrm{C}$ bond formation via Mizoroki-Heck cross-coupling reaction. Appl. Catal. A Gen. 2014, 479, 112-120. [CrossRef]

35. Esmaeilpour, M.; Javidi, J.; Dodeji, F.N.; Abarghoui, M.M. M(II) Schiff base complexes (M = zinc, manganese, cadmium, cobalt, copper, nickel, iron, and palladium) supported on superparamagnetic $\mathrm{Fe}_{3} \mathrm{O}_{4} @ \mathrm{SiO}_{2}$ nanoparticles: Synthesis, characterization and catalytic activity for Sonogashira-Hagihara coupling reactions. Transit. Met. Chem. 2014, 39, 797-809. [CrossRef]

36. Esmaeilpour, M.; Javidi, J. Magnetically-recoverable Schiff base complex of Pd(II) Immobilized on $\mathrm{Fe}_{3} \mathrm{O}_{4} @ \mathrm{SiO}_{2}$ Nanoparticles: an efficient catalyst for Mizoroki-Heck and Suzuki-Miyaura coupling reactions. J. Chin. Chem. Soc. 2015, 62, 614-626. [CrossRef] 
37. Azizi, K.; Ghonchepour, E.; Karimi, M.; Heydari, A. Encapsulation of Pd(II) into superparamagnetic nanoparticles grafted with EDTA and their catalytic activity towards reduction of nitroarenes and Suzuki-Miyaura coupling. Appl. Organomet. Chem. 2015, 29, 187-194. [CrossRef]

38. Cappelletti, A.L.; Uberman, P.M.; Martín, S.E.; Saleta, M.E.; Troiani, H.E.; Sánchez, R.D.; Carbonio, R.E.; Strumia, M.C. Synthesis, characterization, and nanocatalysis application of core-shell superparamagnetic nanoparticles of $\mathrm{Fe}_{3} \mathrm{O}_{4} @$ Pd. Aust. J. Chem. 2015, 68, 1492-1501. [CrossRef]

39. Singh, A.S.; Shelkar, R.S.; Nagarkar, J.M. Palladium(II) on functionalized $\mathrm{NiFe}_{2} \mathrm{O}_{4}$ : An efficient and recyclable phosphine-free heterogeneous catalyst for Suzuki coupling reaction. Catal. Lett. 2015, 145, 723-730. [CrossRef]

40. Movassagh, B.; Takallou, A.; Mobaraki, A. Magnetic nanoparticle-supported Pd(II)-cryptand 22 complex: An efficient and reusable heterogeneous precatalyst in the Suzuki-Miyaura coupling and the formation of aryl-sulfur bonds in honor and memory of late Prof. Mathias Mertes. J. Mol. Catal. A Chem. 2015, 401, 55-65. [CrossRef]

41. Sobhani, S.; Zeraatkar, Z.; Zarifi, F. Pd complex of an NNN pincer ligand supported on $\gamma-\mathrm{Fe}_{2} \mathrm{O}_{3} @ \mathrm{SiO}_{2}$ magnetic nanoparticles: A new catalyst for Heck, Suzuki and Sonogashira coupling reactions. New J. Chem. 2015, 39, 7076-7085. [CrossRef]

42. Karami, K.; Najvani, S.D.; Naeini, N.H.; Hervés, P. Palladium particles from oxime-derived palladacycle supported on $\mathrm{Fe}_{3} \mathrm{O}_{4}$ /oleic acid as a catalyst for the copper-free Sonogashira cross-coupling reaction. Cuihua Xuebao/Chin. J. Catal. 2015, 36, 1047-1053. [CrossRef]

43. Ghorbani-Choghamarani, A.; Norouzi, M. Suzuki, Stille and Heck cross-coupling reactions catalyzed by $\mathrm{Fe}_{3} \mathrm{O}_{4} @ \mathrm{PTA}-\mathrm{Pd}$ as a recyclable and efficient nanocatalyst in green solvents. New J. Chem. 2016, 40, 6299-6307. [CrossRef]

44. Dehghani Firuzabadi, F.; Asadi, Z.; Panahi, F. Immobilized NNN Pd-complex on magnetic nanoparticles: efficient and reusable catalyst for Heck and Sonogashira coupling reactions. RSC Adv. 2016, 6, 101061-101070. [CrossRef]

45. Sobhani, S.; Falatooni, Z.M.; Asadi, S.; Honarmand, M. Palladium-Schiff base complex immobilized covalently on magnetic nanoparticles as an efficient and recyclable catalyst for Heck and Suzuki cross-coupling reactions. Catal. Lett. 2016, 146, 255-268. [CrossRef]

46. Sobhani, S.; Ramezani, Z. Synthesis of arylphosphonates catalyzed by Pd-imino-Py- $\gamma-\mathrm{Fe}_{2} \mathrm{O}_{3}$ as a new magnetically recyclable heterogeneous catalyst in pure water without requiring any additive. RSC Adv. 2016, 6, 29237-29244. [CrossRef]

47. Panahi, F.; Zarnaghash, N.; Khalafi-Nezhad, A. Phosphanamine-functionalized magnetic nanoparticles (PAFMNP): An efficient magnetic recyclable ligand for the Pd-catalyzed Heck reaction of chloroarenes. New J. Chem. 2016, 40, 1250-1255. [CrossRef]

48. Aghayee, M.; Zolfigol, M.A.; Keypour, H.; Yarie, M.; Mohammadi, L. Synthesis and characterization of a novel magnetic nano-palladium Schiff base complex: application in cross-coupling reactions. Appl. Organomet. Chem. 2016, 30, 612-618. [CrossRef]

49. Rezaei, S.; Ghorbani-Choghamarani, A.; Badri, R. Schiff base complex of palladium immobilized on magnetic nanoparticles: An efficient and recyclable nanocatalyst for C-C coupling reactions. Appl. Organomet. Chem. 2016, 30, 985-990. [CrossRef]

50. Ghorbani-Choghamarani, A.; Tahmasbi, B.; Noori, N.; Ghafouri-nejad, R. A new palladium complex supported on magnetic nanoparticles and applied as an catalyst in amination of aryl halides, Heck and Suzuki reactions. J. Iran. Chem. Soc. 2017, 14, 681-693. [CrossRef]

51. Hajipour, A.R.; Tavangar-Rizi, Z. Methionine-functionalized chitosan-Pd(0) complex: A novel magnetically separable catalyst for Heck reaction of aryl iodides and aryl bromides at room temperature in water as only solvent. Appl. Organomet. Chem. 2017, 31, e3638. [CrossRef]

52. Ghorbani-Choghamarani, A.; Tahmasbi, B.; Moradi, Z. S-Benzylisothiourea complex of palladium on magnetic nanoparticles: A highly efficient and reusable nanocatalyst for synthesis of polyhydroquinolines and Suzuki reaction. Appl. Organomet. Chem. 2017, 31, e3665. [CrossRef]

53. Catalyzed, O.A.; Miyaura, S.; Reactions, H.M. Thiophene methanimine-palladium Schiff base complex anchored on magnetic nanoparticles: A novel, highly efficient and recoverable nanocatalyst for cross-coupling reactions in mild and aqueous media. Catal. Lett. 2017, 147, 2640-2655. 
54. Manjunatha, K.; Koley, T.S.; Kandathil, V.; Dateer, R.B.; Balakrishna, G.; Sasidhar, B.S.; Patil, S.A.; Patil, S.A. Magnetic nanoparticle-tethered Schiff base-palladium(II): Highly active and reusable heterogeneous catalyst for Suzuki-Miyaura cross-coupling and reduction of nitroarenes in aqueous medium at room temperature. Appl. Organomet. Chem. 2018, 32, e4266. [CrossRef]

55. Wittmann, S.; Majoral, J.; Grass, R.; Stark, W.; Reiser, O. Carbon coated magnetic nanoparticles as supports in microwave-assisted palladium catalyzed Suzuki-Miyaura couplings. DE GRUYTER 2012, 1, 275-279. [CrossRef]

56. Ghotbinejad, M.; Khosropour, A.R.; Mohammadpoor-Baltork, I.; Moghadam, M.; Tangestaninejad, S.; Mirkhani, V. SPIONs-bis(NHC)-palladium(II): A novel, powerful and efficient catalyst for Mizoroki-Heck and Suzuki-Miyaura C-C coupling reactions. J. Mol. Catal. A Chem. 2014, 385, 78-84. [CrossRef]

57. Wilczewska, A.Z.; Misztalewska, I. Direct synthesis of imidazolinium salt on magnetic nanoparticles and its palladium complex application in the heck reaction. Organometallics 2014, 33, 5203-5208. [CrossRef]

58. Wang, Z.; Yu, Y.; Zhang, Y.X.; Li, S.Z.; Qian, H.; Lin, Z.Y. A magnetically separable palladium catalyst containing a bulky $N$-heterocyclic carbene ligand for the Suzuki-Miyaura reaction. Green Chem. 2015, 17, 413-420. [CrossRef]

59. Martínez-Olid, F.; Andrés, R.; de Jesús, E.; Flores, J.C.; Gómez-Sal, P.; Heuzé, K.; Vellutini, L. Magnetically recoverable catalysts based on mono- or bis-(NHC) complexes of palladium for the Suzuki-Miyaura reaction in aqueous media: Two NHC-Pd linkages are better than one. Dalton Trans. 2016, 45, 11633-11638. [CrossRef] [PubMed]

60. Hajipour, A.R.; Tadayoni, N.S.; Khorsandi, Z. Magnetic iron oxide nanoparticles-N-heterocyclic carbene-palladium(II): A new, efficient and robust recyclable catalyst for Mizoroki-Heck and Suzuki-Miyaura coupling reactions. Appl. Organomet. Chem. 2016, 30, 590-595. [CrossRef]

61. Fareghi-Alamdari, R.; Saeedi, M.S.; Panahi, F. New bis(N-heterocyclic carbene) palladium complex immobilized on magnetic nanoparticles: as a magnetic reusable catalyst in Suzuki-Miyaura cross coupling reaction. Appl. Organomet. Chem. 2017, 31, e3870. [CrossRef]

62. Nayan Sharma, K.; Satrawala, N.; Kumar Joshi, R. Thioether-NHC-ligated Pd ${ }^{\mathrm{II}}$ complex for crafting a filtration-free magnetically retrievable catalyst for Suzuki-Miyaura Coupling in Water. Eur. J. Inorg. Chem. 2018, 2018, 1743-1751. [CrossRef]

63. Biglione, C.; Cappelletti, A.L.; Strumia, M.C.; Martín, S.E.; Uberman, P.M. Magnetic Pd nanocatalyst $\mathrm{Fe}_{3} \mathrm{O}_{4} \mathrm{Pd}$ for C-C bond formation and hydrogenation reactions. J. Nanopart. Res. 2018, 20, 127. [CrossRef]

64. Rafiee, F.; Mehdizadeh, N. Palladium N-heterocyclic carbene complex of Vitamin B1 supported on silica-coated $\mathrm{Fe}_{3} \mathrm{O}_{4}$ nanoparticles: a green and efficient catalyst for C-C coupling. Catal. Lett. 2018, 148, 1-10. [CrossRef]

65. Shylesh, S.; Wang, L.; Thiel, W.R. Palladium(II)-phosphine complexes supported on magnetic nanoparticles: Filtration-free, recyclable catalysts for Suzuki-Miyaura cross-coupling reactions. Adv. Synth. Catal. 2010, 352, 425-432. [CrossRef]

66. Le, X.; Dong, Z.; Jin, Z.; Wang, Q.; Ma, J. Suzuki-Miyaura cross-coupling reactions catalyzed by efficient and recyclable $\mathrm{Fe}_{3} \mathrm{O}_{4} @ \mathrm{SiO}_{2} @ \mathrm{mSiO}_{2}-\mathrm{Pd}(\mathrm{II})$ catalyst. Catal. Commun. 2014, 53, 47-52. [CrossRef]

67. Liu, H.; Wang, P.; Yang, H.; Niu, J.; Ma, J. Palladium supported on hollow magnetic mesoporous spheres: A recoverable catalyst for hydrogenation and Suzuki reaction. New J. Chem. 2015, 39, 4343-4350. [CrossRef]

68. Nikoorazm, M.; Ghorbani, F.; Ghorbani-Choghamarani, A.; Erfani, Z. Pd(0)-S-propyl-2-aminobenzothioate immobilized onto functionalized magnetic nanoporous MCM-41 as efficient and recyclable nanocatalyst for the Suzuki, Stille and Heck cross coupling reactions. Appl. Organomet. Chem. 2018, 32, e4282. [CrossRef]

(C) 2018 by the author. Licensee MDPI, Basel, Switzerland. This article is an open access article distributed under the terms and conditions of the Creative Commons Attribution (CC BY) license (http://creativecommons.org/licenses/by/4.0/). 